MAURICIO HIGA

MÉTODOS PARA QUANTIFICAÇÃO DA ARTÉRIA CARÓTIDA EM IMAGENS DE ULTRASSOM MODO-B E DOPPLER 
MAURICIO HIGA

\title{
MÉTODOS PARA QUANTIFICAÇÃO DA ARTÉRIA CARÓTIDA EM IMAGENS DE ULTRASSOM MODO-B E DOPPLER
}

\author{
Dissertação apresentada à Escola \\ Politécnica da Universidade de São Paulo \\ para obtenção do título de Mestre em \\ Engenharia Elétrica \\ Área de concentração: \\ Sistemas Eletrônicos - PTC \\ Engenharia Biomédica \\ Orientador: \\ Prof. Dr. Marco Antonio Gutierrez
}

São Paulo 
Este exemplar foi revisado e alterado em relação à versão original, sob responsabilidade única do autor e com a anuência de seu orientador.

São Paulo, 22 de dezembro de 2009.

Assinatura do autor

Assinatura do orientador

\section{FICHA CATALOGRÁFICA}

Higa, Mauricio

Métodos para quantificação da artéria carótida em imagens de ultrassom modo-B e Doppler / M. Higa. - ed.rev. - São Paulo, 2009.

$79 \mathrm{p.}$

Dissertação (Mestrado) - Escola Politécnica da Universidade de São Paulo. Departamento de Engenharia de Telecomunicações e Controle.

1. Processamento de imagens 2. Ultrassonografia 3. Diag nóstico por imagem 4. Fluxo sanguíneo I. Universidade de São Paulo. Escola Politécnica. Departamento de Engenharia de Telecomunicações e Controle II. t. 
Aos meus familiares, tanto os que comigo caminham até chegarmos ao nosso destino eterno, quanto os que já vivem junto a Deus, porque sempre contribuíram direta ou indiretamente para a minha formação humana ao longo desses anos. 


\section{AGRADECIMENTOS}

Aos meus pais, Nelson e Eunice; à minha irmã, Rosana e ao meu irmão, Armando e sua esposa, Ângela, pelo contínuo apoio, união e momentos de lazer.

A São Josemaría Escrivá e aos amigos do Centro Cultural Vila Nova, que me ensinaram e ajudaram a santificar as muitíssimas horas de estudo.

Ao Professor e Doutor Marco Antonio Gutierrez, que me orientou na medida exata das minhas capacidades, além de buscar os recursos financeiros para a continuidade deste trabalho.

Aos funcionários, professores e estudantes que conheci no Instituto do Coração e na Escola Politécnica durante esta caminhada, pelo apoio operacional, pelas ideias e discussões técnicas e pelos momentos de descontração.

À Fundação de Apoio à Universidade de São Paulo (FUSP) e à Coordenação de Aperfeiçoamento de Pessoal de Nível Superior (CAPES) pelo suporte financeiro.

Muito obrigado! 


\section{RESUMO}

No campo da medicina diagnóstica através de imagens, o baixo custo e a característica não-invasiva da ultrassonografia modo-B favoreceram as pesquisas que analisam a relação entre a espessura íntima-média (EIM) da artéria carótida e o desenvolvimento de doenças cardiovasculares. Outra técnica de ultrassonografia, baseada no efeito Doppler, também tem sido extensivamente empregada em ambientes clínicos para a medição da velocidade e do fluxo de sangue das artérias periféricas, oferecendo uma abordagem distinta para estudar as doenças cardiovasculares. Neste trabalho, métodos computacionais foram implementados e analisados para extrair informações quantitativas de artérias a partir de imagens 2D. Os ensaios com imagens em modo-B contemplaram a combinação de técnicas de filtragem e algoritmos de contornos ativos para a detecção das interfaces das paredes arteriais e medições da EIM e do diâmetro da luz (DL). Um modelo matemático e 7 imagens reais da artéria carótida comum foram utilizados neste estudo que, dentre as diversas combinações de filtros e algoritmos, apresentou resultados quantitativos similares no cálculo do DL. Para a EIM, porém, a reduzida dimensão da camada íntima-média proporcionou variações indesejadas dos cálculos. Para medir a velocidade do sangue utilizando o modo Doppler, um método semiautomático foi incorporado a um aplicativo computacional para a detecção da envoltória do espectro do gráfico de velocidades. Uma análise comparativa entre sistemas de ultrassonografia comerciais operados por especialistas e este aplicativo incluiu a velocidade de pico sistólico e a integral de velocidade e tempo (VTI) das artérias carótida comum e braquial e de exames ecocardiográficos. A análise de Bland-Altman e o coeficiente de correlação validaram esta metodologia que, complementada pela interface gráfica amigável do aplicativo, pode auxiliar os clínicos em seus estudos de larga escala, baseados nas imagens Doppler ultrassonográficas, com as seguintes vantagens: redução do tempo operacional e de resultados subjetivos e aumento do grau de reprodutibilidade dos resultados.

Palavras-chave: Ultrassonografia modo-B. Ultrassonografia Doppler. Quantificação da artéria carótida. Contornos ativos. Modelo matemático da artéria. Gráfico de velocidade do sangue. Fluxo de sangue. Integral de velocidade e tempo. 


\section{ABSTRACT}

In the field of image-based diagnostic medicine, low cost and noninvasive B-mode ultrasound technique have supported the researches which investigates the relation between the carotid intima-media thickness (IMT) and the development of cardiovascular diseases. Other ultrasound technique, that offers a different approach to study these diseases, is based on Doppler effect and has also been extensively used in clinical sites to measure blood velocity and flow in peripheral arteries. In this work, computational methods were implemented and analyzed to extract quantitative data from $2 \mathrm{D}$ images of arteries. Tests with B-mode images covered the combination of filtering techniques and active contour algorithms, in order to detect the arterial wall interfaces and to measure IMT and lumen diameter (LD). One mathematical model and seven real images of the common carotid artery were used in this study which, among several filters and algorithms combinations, showed similar quantitative results for DL measurements. However, for IMT, the small thickness of intima-media layer led to undesirable variation results. To measure blood velocity by using Doppler mode, a semi-automatic methodology was implemented in a computational tool to detect the spectrum envelope of the velocity graphic. A comparative analysis between commercial ultrasound systems operated by specialists and this tool included systolic peak velocities and velocity-time integral (VTI) of the common carotid and brachial arteries and of echocardiographic exams. Bland-Altman's analysis and the correlation coefficient validated this methodology which, besides the user friendly graphical interface of the tool, may help the clinicians for their large-scale studies based on Doppler ultrasound images, with the following advantages: to save operational time, to lower subjective results, and to support measurement reproducibility.

Keywords: B-mode ultrasound. Doppler ultrasound. Carotid artery quantification. Active contour. Mathematical model of the artery. Blood velocity. Blood flow. Velocitytime integral. 


\section{LISTA DE ILUSTRAÇÕES}

Figura 3.1 - Definições da resolução axial e da resolução lateral.

Figura 3.2 - Vista lateral identificando as artérias carótidas comum (ACC), interna $(\mathrm{ACl})$ e externa $(\mathrm{ACE})$

Figura 3.3 - Vista frontal identificando a artéria carótida comum (ACC) 21

Figura 3.4 - Imagem de ultrassonografia da artéria carótida comum com a identificação das regiões proximal e distal e das camadas arteriais .... 22

Figura 3.5 - Correspondência entre a representação anatômica e a do eco .... 23

Figura 3.6 - Tela típica de um sistema de ultrassonografia que mostra um gráfico da velocidade de sangue vascular em função do tempo 25

Figura 3.7 - Aplicação de um filtro gaussiano à imagem original corrompida com ruído aditivo de distribuição gaussiana

Figura 4.1 - Modelo simplificado de uma estrutura arterial 34

Figura 4.2 - Diagrama em blocos das etapas iniciais para a sintetização de uma imagem através de um hipotético sistema de ultrassonografia 37

Figura 4.3 - Imagem sintética de ultrassonografia da artéria carótida . 38

Figura 4.4 - Diagrama em blocos da implementação no ITK da Transformada de Hilbert e da extração da envoltória da imagem 39

Figura 4.5 - Aplicação de um filtro gaussiano à imagem original corrompida com ruído aditivo e derivada de primeira ordem na direção axial

Figura 4.6 - Etapas de calibração e seleção da ROI

Figura 4.7 - Detecção do eixo "X", da envoltória e dos picos. 49

Figura 4.8 - Contagem de componentes conexos na imagem binária para evitar a falsa detecção da envoltória 50

Figura 5.1 - Imagens do phantom nas saídas dos filtros; derivada de 1a․ ordem na direção axial; e inicialização dos contornos ativos 54

Figura 5.2 - Posição final dos contornos ativos sobre o phantom.. 55

Figura 5.3 - Imagens reais da artéria carótida comum nas saídas dos filtros; derivada de $1^{\text {a }}$. ordem na direção axial; e inicialização dos contornos ativos 59

Figura 5.4 - Posição final dos contornos ativos sobre uma imagem real da artéria carótida comum 


\section{LISTA DE GRÁFICOS}

Gráfico 5.1 - Erros percentuais do DL e da EIM referentes ao phantom

Gráfico 5.2 - Coeficientes de correlação de Pearson do DL e da EIM para cada combinação de filtro e algoritmo de contornos ativos, tendo como referência as medidas obtidas por um aplicativo computacional. 60

Gráfico 5.3 - Análises de Bland-Altman e Regressão Linear da velocidade de pico sistólico medida pelo sistema de ultrassonografia e pela

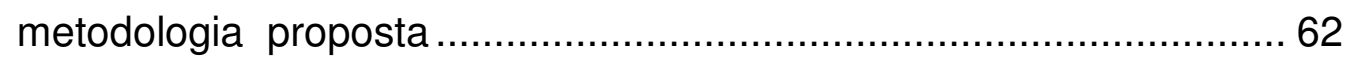

Gráfico 5.4 - Análises de Bland-Altman e Regressão Linear da VTI medida pelo sistema de ultrassonografia e pela metodologia proposta. 63 


\section{LISTA DE TABELAS}

Tabela 5.1 - Nomenclatura dos filtros e dos algoritmos de contornos ativos 53

Tabela 5.2 - Valores dos principais parâmetros dos filtros e dos algoritmos de contornos ativos

Tabela 5.3 - Comparação entre os valores conhecidos do phantom e os cálculos do DL e da EIM para 9 combinações de filtros e algoritmos de contornos ativos 56

Tabela 5.4 - Resumo dos cálculos estatísticos da velocidade de pico sistólico. 62

Tabela 5.5 - Resumo dos cálculos estatísticos da VTI 63 


\section{LISTA DE ABREVIATURAS E SIGLAS}

2D

ACC

ACE

$\mathrm{ACl}$

AVC

BIF

C1

$\mathrm{C} 2$

C3

DL

EIM

F1

F2

F3

FFT

FWHM

HC FMUSP

IFFT

InCor

ITK

MeVisLab

MFC

$\mathrm{NIH} / \mathrm{NLM}$

ROI

SInfo

SRAD

VTI
Bidimensional

Artéria carótida comum

Artéria carótida externa

Artéria carótida interna

Acidente vascular cerebral

Bifurcação

Algoritmo de contornos ativos de Kass, Witkin e Terzopoulos

Algoritmo de contornos ativos de Williams e Shah

Algoritmo de contornos ativos de Lobregt e Viergever

Diâmetro da luz

Espessura íntima-média

Filtro gaussiano

Filtro de difusão anisotrópica

Filtro SRAD

Transformada Rápida de Fourier (Fast Fourier Transform)

Full width at half-maximum

Hospital das Clínicas da Faculdade de Medicina da Universidade de São Paulo

Transformada Rápida Inversa de Fourier (Inverse FFT)

Instituto do Coração

Insight Segmentation and Registration Toolkit

Medical Image Processing and Visualization

Microsoft Foundation Classes

National Institutes of Health / National Library of Medicine

Região de interesse (Region of interest)

Serviço de Informática do Instituto do Coração

Filtro de difusão anisotrópica para a redução de speckle (Speckle Reducing Anisotropic Diffusion)

Integral de velocidade e tempo (Velocity-time integral) 


\section{SUMÁRIO}

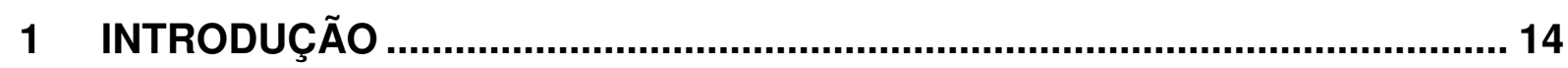

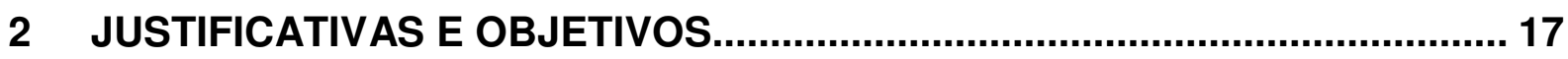

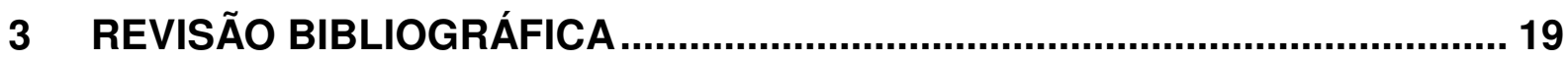

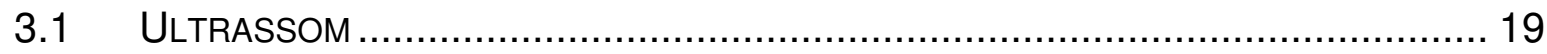

3.2 A IMAGEM DE ULTRASSONOGRAFIA DA ARTÉRIA CARÓTIDA .............................. 20

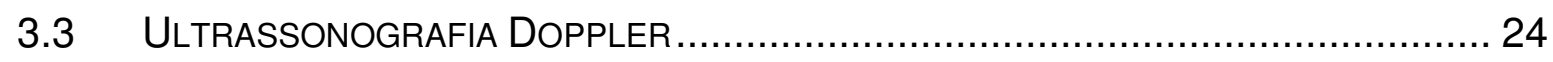

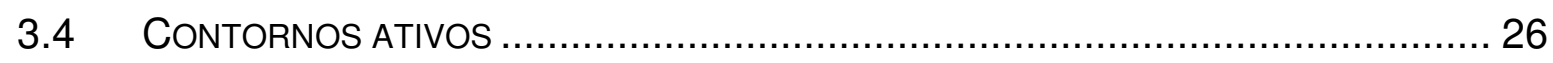

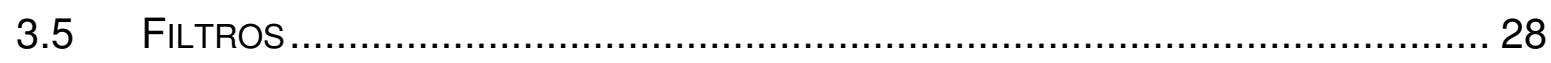

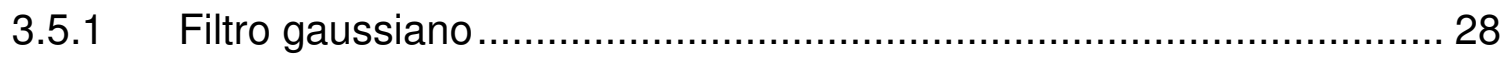

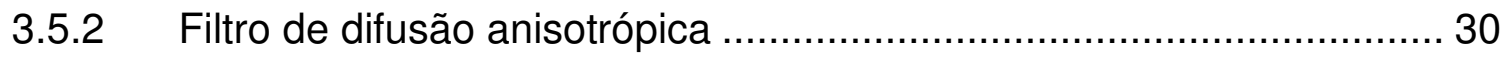

3.5.3 Filtro de difusão anisotrópica para a redução de speckle (SRAD) ...... 31

4 METODOLOGIA

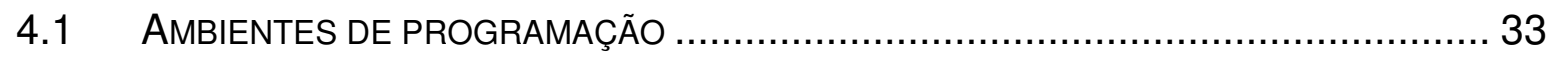

4.2 PHANTOM MATEMÁTICO DA IMAGEM EM MODO-B …...................................... 34

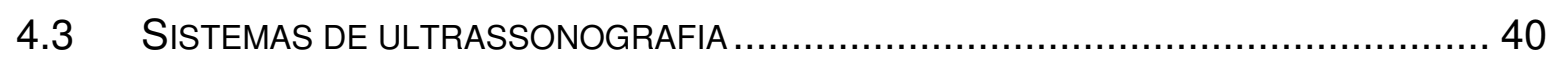

4.4 ASPECTOS DA IMPLEMENTAÇÃO DOS FILTROS ............................................ 40

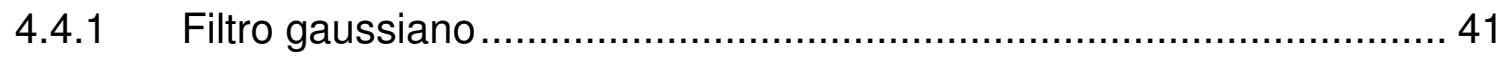

4.4.2 Filtro de difusão anisotrópica ............................................... 42

4.4.3 Filtro de difusão anisotrópica para a redução de speckle (SRAD) ...... 42

4.5 ASPECTOS DA IMPLEMENTAÇÃO DOS ALGORITMOS DE CONTORNOS ATIVOS ......... 43

4.5.1 Algoritmo de Kass, Witkin e Terzopoulos ........................................ 43

4.5.2 Algoritmo de Williams e Shah ....................................................... 44

4.5.3 Algoritmo de Lobregt e Viergever.................................................. 45

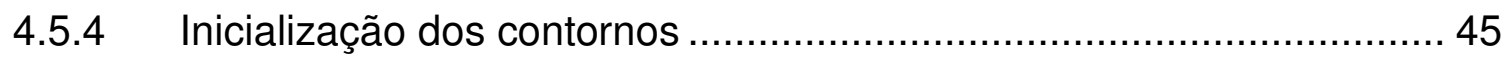

4.6 QUANTIFICAÇÃO SEMIAUTOMÁTICA DA VELOCIDADE DO SANGUE......................... 46

$5 \quad$ RESULTADOS E DISCUSSÃO ................................................................ 52

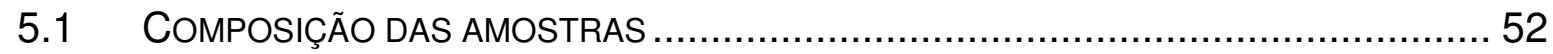

5.2 ENSAIOS COM PHANTOM MATEMÁTICO DA IMAGEM EM MODO-B ........................ 53 
5.3 ENSAIOS COM IMAGENS REAIS DA ARTÉRIA CARÓTIDA EM MODO-B

5.4 MEDIÇÃO dA VELOCIDADE E dO FLUXO SANGUíNEOS UTILIZANDO A TÉCNICA DOPPLER

6 CONCLUSÃO 65

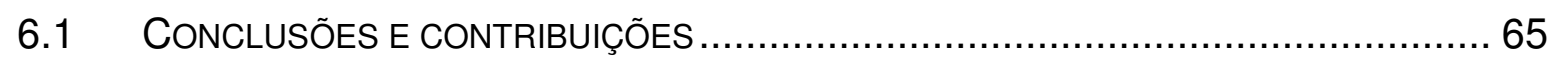

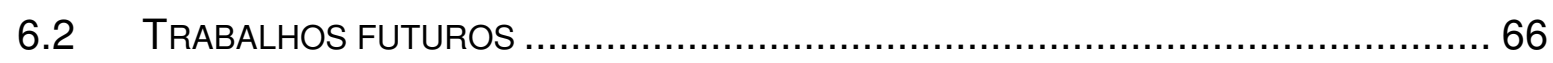

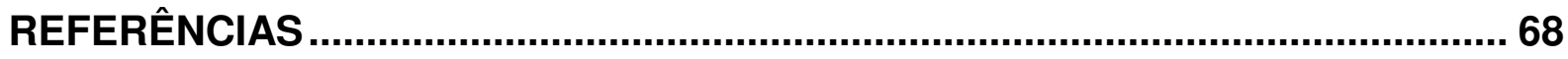

APÊNDICE - TRABALHOS PUBLICADOS ...................................................... 73

A Computational Tool for Quantitative Assessment of Peripheral

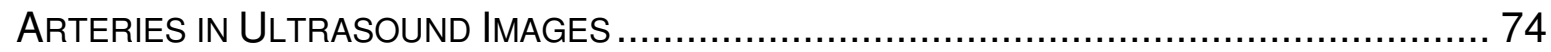

Comparison of Three Different Derivative Approaches Aiming at

ESTIMATION OF IMAGE MOVEMENT. 78 


\section{INTRODUÇÃO}

$\mathrm{Na}$ sociedade contemporânea a televisão, o computador e, mais recentemente, o telefone celular seriam, talvez, os objetos mais lembrados pela população em geral se o tema de referência fosse "processamento de imagens". Certamente, a popularização destes objetos de consumo está estreitamente relacionada com o sentido da visão, explorado através das imagens que, por sua vez, demandam todo um trabalho de processamento até se alcançar o resultado desejado.

Obviamente, o campo de aplicação do processamento de imagens não se restringe aos objetos de consumo de massa exemplificados acima. A gama de aplicação é enorme e tem motivado a pesquisa e a publicação especializada de inúmeros livros, revistas e artigos, além de congressos científicos que abordam este tema, seja com dedicação integral, ou parcial, através de painéis específicos de processamento de imagens inseridos em um contexto mais amplo.

Um exemplo menos generalizado, mas ainda assim bastante amplo, é o processamento de imagens médicas. Este ramo se consolidou como uma importante ferramenta para a medicina no planejamento de terapias e de cirurgias, na navegação intraoperatória e no diagnóstico do paciente, através da visualização, da quantificação e da inspeção da anatomia e fisiologia a partir de imagens provenientes da tomografia computadorizada, da ressonância magnética e da ultrassonografia, entre outras técnicas de formação de imagens.

Migrando para um campo mais específico, dentro das aplicações das imagens médicas, nas últimas duas décadas diversos estudos (AMATO et al., 2007; BOTS et al., 1997; BOTS et al., 2007; LORENZ et. al., 2007; O'LEARY et al., 1999; SALONEN; SALONEN, 1993) procuraram investigar a correlação entre a espessura íntima-média (EIM) da artéria carótida humana e o desenvolvimento de doenças cardiovasculares que podem resultar em eventos críticos como o infarto do miocárdio ou o acidente vascular cerebral (AVC). Tais estudos foram beneficiados e intensificados, em parte, pela exploração da ultrassonografia modo-B, com suas vantagens em relação a outras técnicas, especialmente o baixo custo de aquisição de imagens e a característica não-invasiva. $O$ uso da ultrassonografia modo-B 
possibilita a obtenção, entre outras, da imagem da carótida de onde se podem detectar as interfaces das paredes arteriais para o cálculo do diâmetro da luz (DL) e da EIM.

No estudo de Roterdã, que tomou como base um conjunto de dados de acompanhamento de pacientes ao longo de, aproximadamente, três anos no início da década de 1990, Bots et al. (1997) analisaram a relação entre a EIM da artéria carótida comum e a incidência de infarto do miocárdio e AVC em homens e mulheres com idade igual ou superior a 55 anos, totalizando 7983 casos. De acordo com os resultados obtidos até então, considerava-se uma questão discutível se o aumento da EIM da artéria carótida comum era, de fato, consequência da aterosclerose local. De qualquer modo, notava-se que este aumento poderia ser, pelo menos, um indicador da aterosclerose em uma região indeterminada do sistema arterial e concluiu-se que havia uma relação entre o aumento da EIM com futuros eventos cárdio e cerebrovasculares (BOTS et al., 1997).

Em uma revisão mais recente, Bots et al. (2007) fizeram um levantamento de uma série de outros estudos para reavaliar a relação entre a EIM da carótida e a aterosclerose coronária. Dado que o desenvolvimento e a extensão da aterosclerose não ocorrem uniformemente ao longo das várias artérias, os autores justificaram que os fatores limitantes desta relação estavam mais propensos à variabilidade de como a aterosclerose se desenvolve em cada uma das artérias, que propriamente às limitações na medição da EIM da carótida.

Embora não haja um consenso dentro desta revisão de estudos, vários trabalhos apontaram a idade, o sexo do indivíduo, o hábito de fumar e a pressão arterial, entre outros, como fatores determinantes para a alteração da EIM da artéria carótida ao longo do tempo. Quanto à relação entre a EIM da carótida e os futuros eventos cardiovasculares, os estudos indicam que a exposição a elevados fatores de risco reflete-se, a longo prazo, no valor da EIM. Porém, dados adicionais ainda são requeridos para se estabelecer corretamente esta relação (BOTS et al., 2007).

Além do modo-B, as mesmas vantagens de baixo custo e a característica não-invasiva também são aproveitadas no emprego do ultrassom ao se explorar a técnica Doppler. Baseada na diferença entre as frequências de um sinal transmitido e de um sinal recebido quando há um movimento relativo entre a fonte e o receptor destes sinais, esta técnica tem sido extensivamente empregada em ambientes 
clínicos para a medição da velocidade e do fluxo de sangue vascular, entre outras aplicações (GERHARD-HERMAN et al., 2006; NICHOLS; O'ROURKE, 1990).

A informação de velocidade está contida em uma imagem gerada pela técnica Doppler, que apresenta um gráfico de velocidade do sangue em função do tempo. Este gráfico não é composto por uma linha simples e bem definida, mas por um sinal espectral correspondente às diferentes velocidades das células que constituem o fluxo sanguíneo a cada unidade de tempo.

Há um vasto campo a ser explorado sobre a relação entre a forma espectral durante o ciclo cardíaco, o perfil de velocidade no interior de um vaso sanguíneo e a ocorrência de doenças cardiovasculares. Qualitativamente, por exemplo, na presença de placa aterosclerótica que perturbe o padrão de fluxo do sangue de uma artéria normal, haverá uma maior dispersão das velocidades com o consequente espalhamento do espectro (HOSKINS, 1990; YAO et al., 2004); ou então, quantitativamente, quando uma estenose corresponde à redução de 50\% ou mais do diâmetro arterial, o incremento da velocidade do pico sistólico é superior a 100\% em relação ao segmento arterial proximal e há, também neste caso, maior espalhamento espectral devido à turbulência na região imediatamente após a estenose e o surgimento de componentes de baixa velocidade (YAO et al., 2004).

Outros exemplos que requerem o conhecimento da velocidade e fluxo sanguíneos são os estudos baseados na disfunção endotelial na insuficiência cardíaca (CARVALHO et al., 2006; CORRETTI, 2002) e aqueles que visam monitorar os efeitos da administração de determinados medicamentos no sistema circulatório (LAGE et al., 2002). 


\section{JUSTIFICATIVAS E OBJETIVOS}

Para a medição do DL e da EIM é necessário identificar determinadas interfaces (descritas na seção 3.2) das paredes arteriais. A delineação manual destas interfaces requer a dedicação de um especialista e esta atividade, além de consumir tempo excessivo, incorre em resultados sujeitos a variações que dependem da sua experiência e da sua avaliação subjetiva. Consequentemente, as medições manuais apresentam uma considerável variação de resultados inter e intraobservadores (WENDELHAG et al., 1997). Adicionalmente, esta tarefa costuma ser complicada e dificultada pela presença de artefatos nas imagens de ultrassonografia, tais como speckle, ruídos intrínsecos à metodologia e áreas de sombra acústica.

Em decorrência desta dificuldade, diversos trabalhos e pesquisas introduziram procedimentos de análise automática ou semiautomática para a detecção das interfaces, tendo em vista a redução do tempo de obtenção dos resultados e das suas variabilidades inter e intraobservadores.

A extração de dados quantitativos de velocidade do sangue a partir das imagens ultrassonográficas é normalmente realizada durante os exames clínicos com o próprio sistema de ultrassonografia utilizado para a aquisição das imagens (ATL, 1996; SIEMENS, 2002). Estes sistemas dispõem de um trackball com o qual um operador pode desenhar a envoltória do espectro do gráfico de velocidade e assinalar as amplitudes de interesse, calculando-se, deste modo, as velocidades de pico e a integral da velocidade multiplicada pelo tempo (VTI - velocity-time integral), entre outras grandezas. Em contrapartida, estes sistemas comerciais de ultrassonografia apresentam pouca flexibilidade quando se deseja realizar estudos em larga escala, com uma série de pacientes, para correlacionar estas medidas com alguma possível doença, visto que eles são dedicados principalmente à execução da rotina de exames para prover informações instantâneas, individualmente.

Este trabalho tem por objetivo implementar e analisar metodologias computacionais para extrair informações quantitativas de vasos arteriais, mais especificamente da artéria carótida humana, a partir de imagens bidimensionais (2D) obtidas em ultrassonografia modo-B e Doppler. 
Os ensaios com imagens em modo-B contemplam a combinação de técnicas de filtragem das imagens e algoritmos de contornos ativos propostos por outros pesquisadores (KASS; WITKIN; TERZOPOULOS, 1988; WILLIAMS; SHAH, 1992; LOBREGT; VIERGEVER, 1995) para a detecção das interfaces das paredes arteriais, a fim de avaliar a melhor solução quanto à precisão das medições.

Para a extração da velocidade utilizando o modo Doppler, propõe-se uma metodologia semiautomática para a detecção da envoltória do espectro do gráfico de velocidade e o cálculo de velocidades (média geral e média dos picos), fluxos (idem) e VTI. Esta metodologia, que independe do sistema de ultrassonografia utilizado para a aquisição das imagens, foi incorporada a um sistema previamente desenvolvido por Pilon (2002) e Gutierrez et al. (2002). Espera-se que, através de protocolos clínicos que incluam centenas de pacientes, o novo recurso possa auxiliar na investigação das relações que envolvam a velocidade das células sanguíneas e a ocorrência de doenças cardiovasculares, bem como em outros estudos, como os exemplos citados no capítulo anterior.

Além de todo o conhecimento adquirido ao longo do projeto, o aplicativo computacional e os algoritmos, inclusive, poderão ser disponibilizados para uso no Instituto do Coração do Hospital das Clínicas da Faculdade de Medicina da Universidade de São Paulo (InCor-HC FMUSP), visto que o trabalho foi plenamente desenvolvido no Serviço de Informática (SInfo) desta instituição. 


\section{REVISÃO BIBLIOGRÁFICA}

\subsection{Ultrassom}

O ultrassom é uma onda mecânica cuja frequência é superior a $20 \mathrm{kHz}$, a máxima frequência da audição humana. Para a aplicação a que se refere este trabalho, isto é, para a aquisição de imagens 2D de artérias periféricas como a carótida, a frequência tipicamente utilizada no equipamento de ultrassonografia varia em torno de $7 \mathrm{MHz}$, estabelecendo um compromisso entre a minimização da perda de penetração do sinal (quanto menor a frequência, menor a perda) e a melhor resolução espacial (quanto maior a frequência, melhor a resolução).

Nos tecidos biológicos moles, em geral, a velocidade de propagação do ultrassom é, aproximadamente, $1540 \mathrm{~m} / \mathrm{s}$. Como a frequência $(f)$, a velocidade $(c)$ e o comprimento de onda $(\lambda)$ se relacionam pela equação (3.1), o comprimento de onda nesta aplicação varia em torno de 0,2 $\mathrm{mm}$.

$$
c=\lambda f
$$

$\mathrm{Na}$ prática, muitas variáveis interferem na resolução das imagens de ultrassonografia e não há uma definição absoluta para o seu cálculo. Costuma-se, entretanto, distinguir dois tipos de resolução quando o sistema de ultrassonografia utiliza a técnica do pulso-eco (BAMBER; TRISTAM; WEBB, 1993; SHUNG; SMITH; TSUI, 1992) (Figura 3.1):

- resolução axial: dada pelo produto da velocidade de propagação com a metade da duração da envoltória do pulso em um determinado nível abaixo do pico;

- resolução lateral: dada pela largura total do feixe em um determinado nível abaixo do pico.

Pode-se adotar, por exemplo, os níveis de $3 \mathrm{~dB}, 6 \mathrm{~dB}$ ou $10 \mathrm{~dB}$ abaixo do pico; ou, o que é mais comum, a metade do nível de pico para se medir a largura total. Este último método para o cálculo da resolução é conhecido como FWHM (full width at half-maximum) (BAMBER; TRISTAM; WEBB, 1993). 

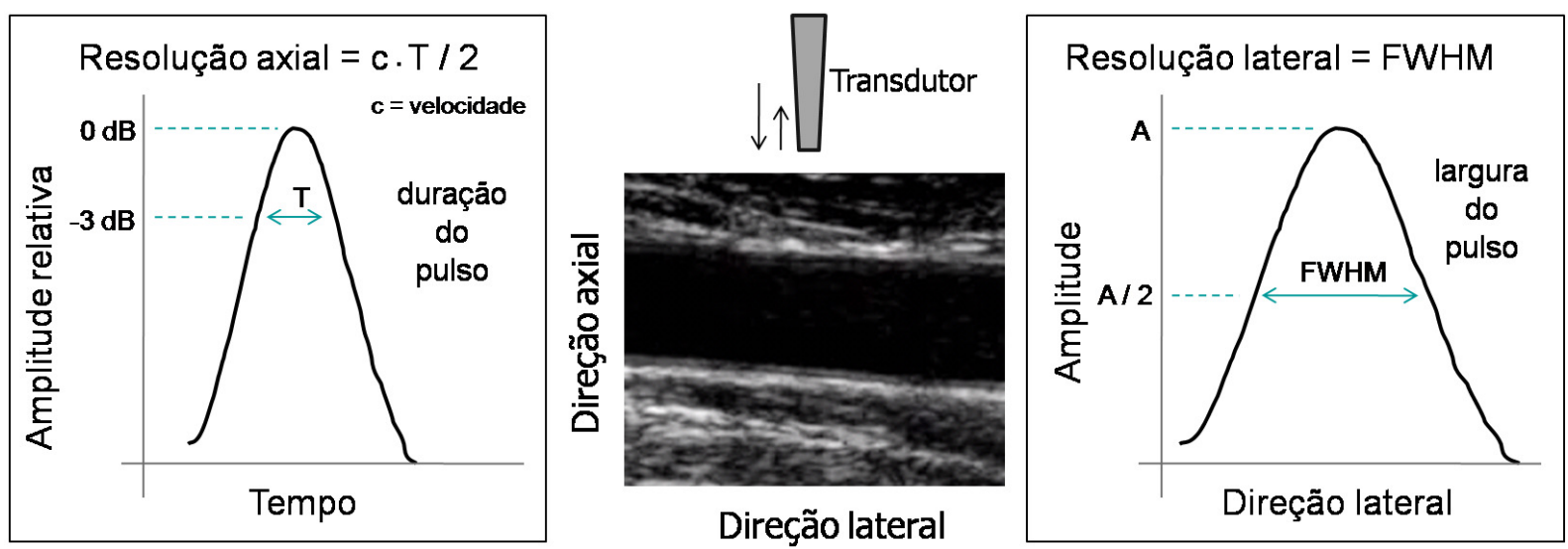

Figura 3.1 - Definições da resolução axial em função da duração do pulso; e da resolução lateral como a largura total do pulso na metade do nível de pico (FWHM - full width at half-maximum).

Na técnica do pulso-eco, pulsos elétricos de curta duração alimentam o transdutor que os convertem nas ondas de ultrassom que se propagam pelos tecidos. Parte do sinal é refletida quando encontra uma interface entre dois meios com impedâncias acústicas distintas e retorna ao transdutor que, desta vez, converte o sinal mecânico em elétrico, a partir do qual se efetua o processamento digital. Com a informação da velocidade de propagação e dos intervalos de tempo transcorridos entre a transmissão de uma série de pulsos e a recepção dos respectivos ecos, o sistema de ultrassonografia calcula as distâncias de cada interface. Isto possibilita um mapeamento da intensidade de sinal recebido de cada eco para gerar uma imagem com variações no brilho como a da Figura 3.1. Este método utilizado para representar a região desejada é conhecido como modo-B do ultrassom.

\subsection{A imagem de ultrassonografia da artéria carótida}

As artérias carótidas são responsáveis pela condução do sangue arterial desde o coração até a região encefálica. De cada lado (direito e esquerdo) da região cervical há uma artéria carótida comum (ACC). Seguindo no sentido da região encefálica, há uma bifurcação (BIF) em duas artérias denominadas artéria carótida interna $(\mathrm{ACl})$ e artéria carótida externa (ACE) (Figuras 3.2 e 3.3). 


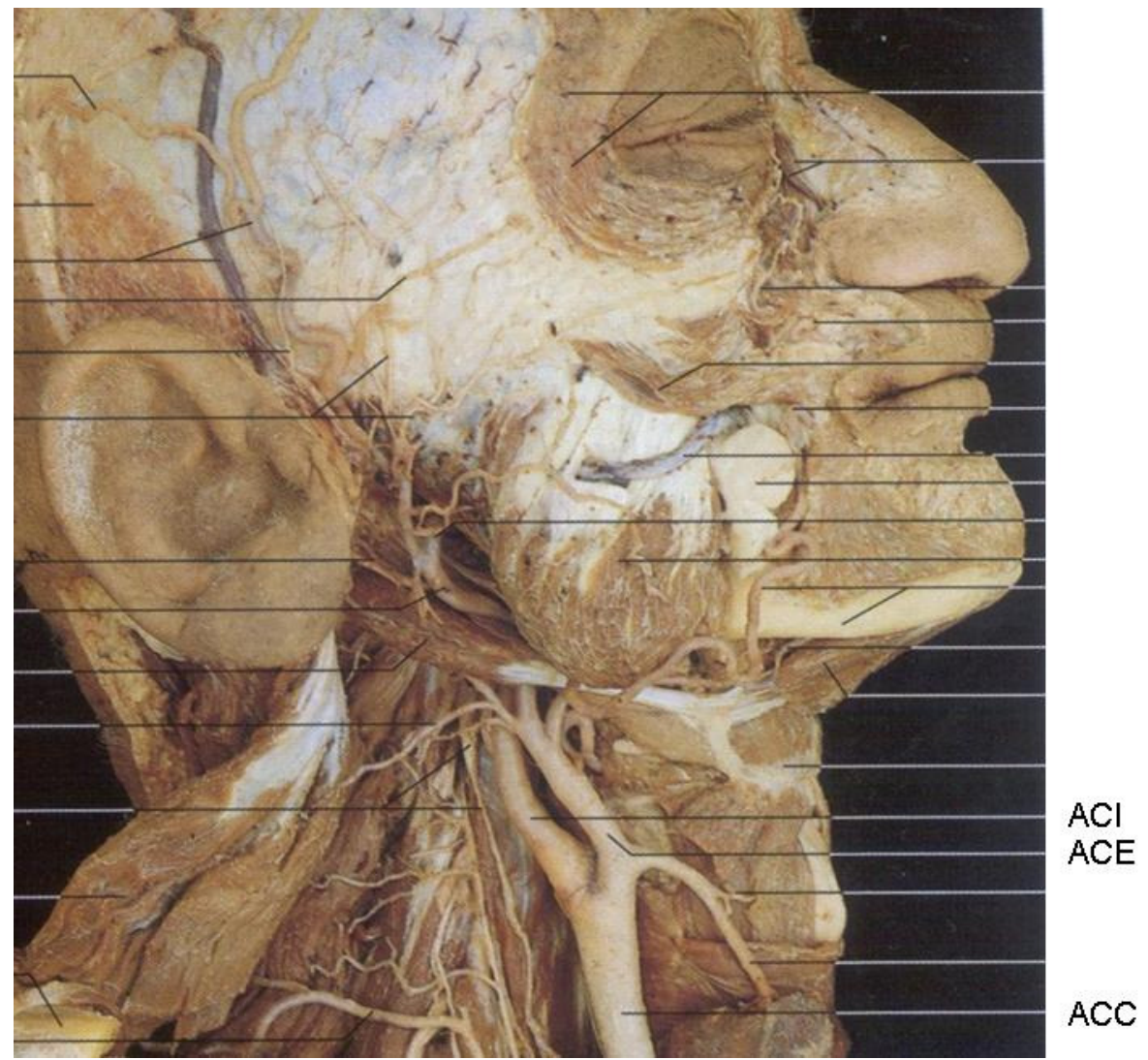

Figura 3.2 - Vista lateral identificando as artérias carótidas comum (ACC), interna (ACl) e externa (ACE) (ROHEN; YOKOCHI; LÜTJEN-DRECOLL, 2007).

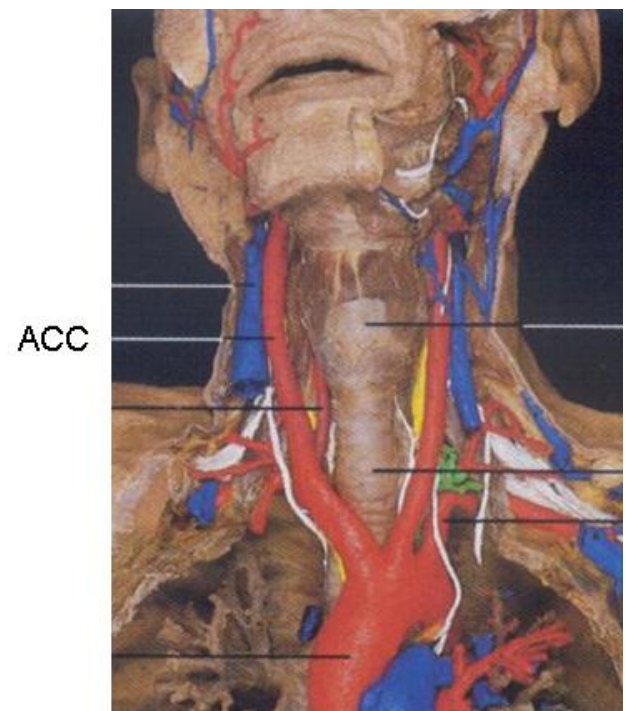

Figura 3.3 - Vista frontal identificando a artéria carótida comum (ACC) (ROHEN; YOKOCHI; LÜTJENDRECOLL, 2007).

Nas imagens 2D de ultrassonografia da artéria carótida comum, quando apresentada em um corte longitudinal (Figura 3.4), define-se como a região proximal aquela composta pela parede arterial mais próxima do transdutor e, naturalmente, como a região distal aquela composta pela parede mais distante. 
As paredes estão separadas entre si por uma larga faixa escura que corresponde à luz arterial, por onde flui o sangue. Em ambas, dependendo da qualidade da imagem, é possível identificar três camadas: a íntima, a média e a adventícia (Figura 3.4).

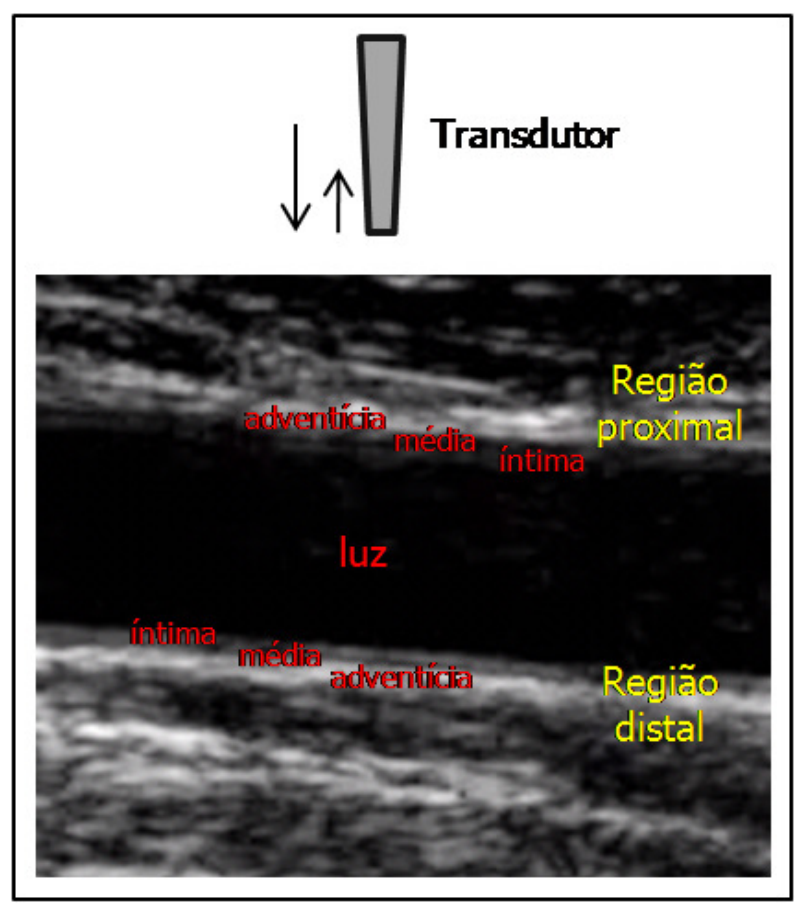

Figura 3.4 - Imagem de ultrassonografia da artéria carótida comum com a identificação das regiões proximal e distal e das camadas arteriais.

Apesar da simetria na disposição das camadas das paredes proximal e distal vistas no corte longitudinal, os padrões das imagens de cada parede são distintos devido à diferença da sequência em que o sinal do ultrassom incidente percorre as interfaces; por exemplo: na parede proximal, uma parte do sinal incidente atravessa e outra parte sofre reflexão, primeiramente, na interface adventícia-média e, posteriormente, na íntima-luz, enquanto que na parede distal, sucede-se a ordem inversa. Pignoli et al. (1986) notaram que, nestas imagens, a maioria das paredes distais das artérias investigadas durante as suas experiências, apresentava um padrão com duas faixas paralelas de maior brilho (ecogênicas) intercaladas por uma estreita faixa de menor brilho (hipoecogênica). No mesmo estudo comprovaram que a primeira faixa ecogênica (no sentido do sinal do ultrassom incidente) da parede distal era gerada pela íntima, enquanto que a segunda faixa ecogênica, mais espessa, era gerada pela adventícia. Finalmente, verificaram também que a distância entre a primeira borda desta primeira faixa ecogênica (interface luz-íntima) 
e a primeira borda da segunda faixa ecogênica (interface média-adventícia) estava bem correlacionada com a EIM da parede distal obtida por patologia macroscópica (coeficiente de correlação entre 0,87 e 0,93 em artérias aórticas).

Em contrapartida, não se consegue obter medidas confiáveis da EIM da parede proximal porque nesta, como ilustrado na Figura 3.5, o eco (e a espessura resultante) formado na camada adventícia sobrepõe-se ao eco formado na interface adventícia-média (indicado pela seta no interior da elipse). Este problema não pode ser contornado pela identificação, na imagem, da borda mais distante gerada pelo eco na adventícia (linha 1 na Figura 3.5), porque ela está sempre localizada abaixo da transição adventícia-média, o que levaria a uma subestimação da EIM da parede proximal. Além disso, esta localização é dependente de outros fatores como o ajuste de ganho no equipamento de ultrassonografia ou a composição do tecido da adventícia (WIKSTRAND, 2007).

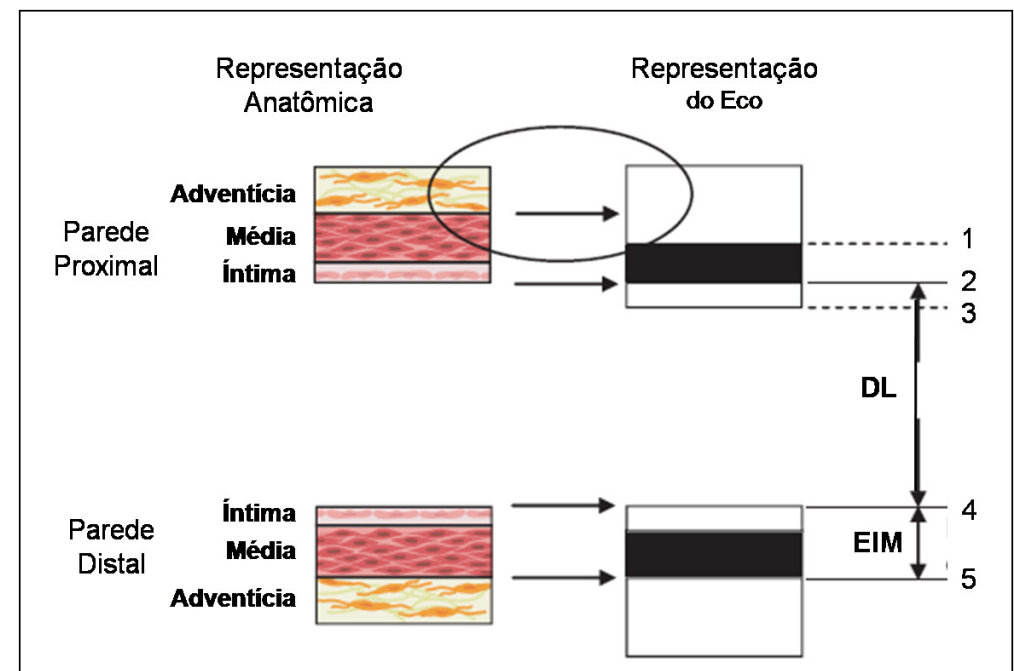

Figura 3.5 - Correspondência entre a representação anatômica e a do eco. Na parede proximal identifica-se: 1) borda distal gerada pelo eco na adventícia, 2) primeira borda da segunda zona de eco gerada na interface íntima-luz, 3) borda distal gerada na interface íntima-luz. Na parede distal: 4) primeira borda gerada na interface luz-íntima, 5) primeira borda da segunda zona de eco gerada na interface média-adventícia. (adaptado de Wikstrand (2007)).

Ainda na parede proximal, a interface íntima-luz costuma estar bem definida pela primeira borda da segunda zona de eco (linha 2 na Figura 3.5) porque, ao contrário da adventícia, a camada média é uma estrutura que gera pouco eco e, portanto, não há sobreposição ao sinal proveniente da interface íntima-luz. Embora a detecção desta interface não seja suficiente para a obtenção da EIM da parede proximal _ devido à ausência da informação confiável da interface adventícia-média _, ela é necessária para o cálculo do DL (WIKSTRAND, 2007). 
O DL é medido entre a interface íntima-luz da parede proximal (linha 2 na Figura 3.5) e a interface luz-íntima da parede distal (linha 4 na Figura 3.5). Esta corresponde à primeira borda do eco gerado na parede distal.

$\mathrm{Na}$ parede distal, a EIM é medida entre a interface luz-íntima (linha 4 na Figura 3.5) e a interface média-adventícia, a primeira borda da segunda linha de maior brilho (linha 5 na Figura 3.5) (BOTS et al., 1997; WIKSTRAND, 2007). Como na parede proximal, a camada média da parede distal gera pouco eco, não interferindo na formação da imagem na interface média-adventícia.

A EIM da carótida (esquerda ou direita) pode ser medida na ACC, na BIF ou na $\mathrm{ACl}$. Considerando um determinado comprimento (por exemplo, $10 \mathrm{~mm}$ da parede distal da ACC), a partir das medidas pode-se calcular a espessura média ou máxima da parede em questão, ou combiná-las para extrair uma única estimativa (por exemplo, a média das máximas espessuras); não há um consenso, porém, sobre qual o parâmetro mais apropriado para a avaliação da aterosclerose, para a avaliação do risco vascular ou para a avaliação da alteração temporal da EIM (BOTS et al., 2007).

\subsection{Ultrassonografia Doppler}

A técnica de ultrassonografia Doppler baseia-se na diferença entre as frequências de um sinal transmitido e de um sinal recebido quando há um movimento relativo entre a fonte e o receptor destes sinais.

No exame clínico de ultrassom, o efeito Doppler pode ser observado em duas etapas: na primeira, a fonte de sinal (transdutor) está parada em relação ao meio de propagação e os receptores (células vermelhas do sangue), que refletem e espalham o sinal, estão em movimento; na segunda etapa, considerando o sinal refletido, as fontes (células vermelhas do sangue) estão em movimento e o receptor (pode ser o mesmo ou outro transdutor) é estacionário em relação ao meio (ROUTH, 1996; LYNCH et al., 2004).

Assumindo inicialmente que um sinal mecânico de frequência $f_{0}$, gerado por um transdutor, se propaga pelo tecido biológico em uma direção tal que o seu vetor 
forme um ângulo $\theta$ com o vetor de velocidade $v$ de uma célula vermelha do sangue. Admitindo também que a velocidade de propagação no tecido mole ( $c \cong 1540 \mathrm{~m} / \mathrm{s}$ ) é muito superior à velocidade da célula ( $v$, da ordem de grandeza de $1 \mathrm{~m} / \mathrm{s}$ ). Pelo efeito Doppler o sinal refletido por esta célula e que retorna ao transdutor é composto por outra frequência $f$ e a diferença entre as frequências possibilita o cálculo da velocidade da célula, segundo a expressão (BAMBER; TRISTAM; WEBB, 1993; ROUTH, 1996; YAO et al., 2004):

$$
v=\frac{c\left(f-f_{0}\right)}{2 f_{0} \cos \theta}
$$

Pode-se extrapolar o conceito acima para um conjunto de células que constituem o fluxo sanguíneo e que espalham e refletem o sinal de ultrassom em frequências distintas devido às suas velocidades distintas, seja na magnitude ou no ângulo da direção de deslocamento de cada célula. Assim, tem-se que um gráfico de velocidade em função do tempo, com a amplitude de sinal em cada frequência representada pelo nível da escala de cinza (FISH, 1990), não é composto por uma linha simples e bem definida, mas por um espectro de frequências correspondentes às diferentes velocidades das células a cada unidade de tempo (Figura 3.6).

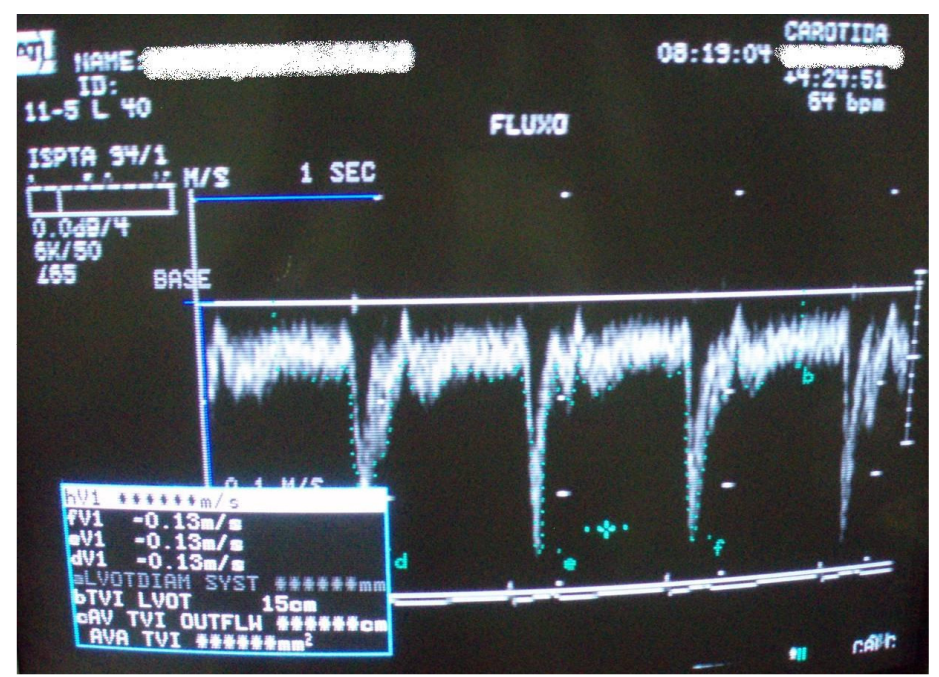

Figura 3.6 - Tela típica de um sistema de ultrassonografia que mostra um gráfico da velocidade de sangue vascular em função do tempo e as correspondentes medições de amplitude e integral. 


\subsection{Contornos ativos}

Dentro da área de conhecimento de processamento de imagens, a etapa de identificação das interfaces da artéria carótida está associada à segmentação, isto é, à identificação de estruturas de interesse, seguindo um determinado critério, que possibilita a análise e a interpretação da imagem através das diferentes partes que a constituem.

Uma das técnicas de segmentação, bastante apropriada para a presente aplicação e extensivamente discutida na literatura atual, utiliza os modelos de contornos ativos, ou snakes, como também são conhecidos, originalmente propostos por Kass, Witkin e Terzopoulos (1988) e refinados por outros _ cite-se, por exemplo: Amini, Weymouth e Jain (1990); Cohen, Cohen e Ayache (1992); Zahalka e Fenster (2001) e Liang, Mclnerney e Terzopoulos (2006).

Geometricamente, trata-se de uma curva paramétrica que, estando sobreposta a uma imagem, passa dinamicamente por uma série de deformações provocadas por forças internas e externas. As forças internas, que dependem dos parâmetros da própria curva, tendem a manter as suas condições de suavidade e continuidade e as forças externas, que dependem das características da imagem, procuram atrair a curva para, por exemplo, a região com maior brilho da imagem. Como consequência, a abordagem automática, ou semiautomática (quando há necessidade de alguma intervenção do operador), proporciona maior acurácia, consistência e reprodutibilidade dos resultados (McINERNEY; TERZOPOULOS, 1996).

A imagem 2D é representada por $I(x, y)$, onde $(x, y) \in \mathfrak{R}^{2}$ e o contorno paramétrico é representado por:

$$
v(s)=(x(s), y(s))^{T}
$$

onde $x$ e $y$ são coordenadas em função de $s$; e $s \in[0,1]$ é o domínio paramétrico. A forma do contorno sujeita a uma imagem $I(x, y)$ é obtida pela expressão:

$$
\varepsilon(v)=\eta(v)+\rho(v)
$$


que pode ser vista como uma representação da energia do contorno cuja forma final, depois de passar por uma sequência de deformações, corresponde à situação mínima de energia (McINERNEY; TERZOPOULOS, 1996).

O primeiro termo:

$$
\eta(v)=\frac{1}{2} \int_{0}^{1} w_{1}(s)\left|\frac{\partial v}{\partial s}\right|^{2}+w_{2}(s)\left|\frac{\partial^{2} v}{\partial s^{2}}\right|^{2} d s
$$

refere-se à energia interna e é composta por duas funções $w_{1}(s)$ e $w_{2}(s)$ nãonegativas que, respectivamente, ponderam: a) o efeito de encurtar o contorno (ou não permitir que ele seja esticado demasiadamente), dado pela sua derivada de primeira ordem; b) o efeito de suavizar o contorno pela redução das suas curvaturas locais, dado pela derivada de segunda ordem. Isto permite um controle mais preciso do contorno, adaptando a expressão de energia conforme o objetivo desejado. $\mathrm{Na}$ prática, é comum assumir $w_{1}(s)=w_{1}$ e $w_{2}(s)=w_{2}$, ou seja, pesos constantes em todo o contorno paramétrico para simplificar o algoritmo.

O segundo termo:

$$
\rho(v)=\int_{0}^{1} P(v(s)) d s
$$

refere-se à energia externa e faz com que a deformação do contorno dependa também dos dados da imagem. A função de energia potencial $P(v(s))$ é escolhida tal que ela assuma valores menores nas bordas da estrutura ou em outras características desejadas. Uma alternativa simplificada para que o potencial de menor energia esteja mais próximo das bordas a serem detectadas é adotar:

$$
P(v(s))=-w_{e}\left|\nabla\left[G_{\sigma}(x, y) * I(x, y)\right]\right|
$$

onde $w_{e}$ é não-negativo e cumpre um papel equivalente aos fatores de ponderação da energia interna e $\nabla$ é o operador gradiente aplicado sobre a convolução (designada pelo sinal $*$ ) da imagem $I(x, y)$ em tons de cinza com uma máscara gaussiana $G_{\sigma}(x, y)$ de desvio-padrão $\sigma$. Este último controla a extensão espacial do efeito de borrar a imagem, ajustando, assim, o alcance de atuação da energia externa para atrair o contorno até a região de menor energia. Há que se considerar, 
porém, que o aumento de $\sigma$ tende a deslocar as bordas das suas posições originais.

Um tratamento dinâmico pode ser dado ao processo de deformação dos contornos ao se acrescentar a variável tempo $t$ no contorno paramétrico, representando-o, portanto, como:

$$
v(s, t)=(x(s, t), y(s, t))^{T}
$$

Assim, a evolução temporal do contorno é verificada pela expressão:

$$
\gamma \frac{\partial v}{\partial t}=\frac{\partial}{\partial s}\left(w_{1} \frac{\partial v}{\partial s}\right)-\frac{\partial^{2}}{\partial s^{2}}\left(w_{2} \frac{\partial^{2} v}{\partial s^{2}}\right)-\nabla P(v)
$$

que foi deduzida a partir da solução que minimiza a energia em (3.4) para satisfazer a equação de Euler-Lagrange (XU et al., 2000; XU; PRINCE, 1998). O termo à esquerda, que contém a derivada parcial em relação ao tempo, torna-se nulo quando o contorno $v(s, t)$ atinge uma condição estável. $\bigcirc$ coeficiente $\gamma$ foi introduzido para manter a correspondência das unidades dimensionais entre os termos da esquerda e da direita da equação.

Para a inicialização dos contornos ativos exploram-se, previamente, algumas características conhecidas da estrutura que se deseja segmentar, como sua localização aproximada, tamanho, orientação e forma. As características intrínsecas dos contornos ativos, que preservam a sua continuidade e suavidade, os tornam mais robustos contra o ruído, na falta de clareza na imagem e na presença de outras irregularidades nas bordas do objeto a serem detectadas.

\subsection{Filtros}

\subsubsection{Filtro gaussiano}

Uma família da solução para a equação de difusão de calor dada por:

$$
\frac{\partial I}{\partial t}=\operatorname{div}(\nabla I)
$$

com a condição inicial: 


$$
I(t=0)=I_{0}
$$

pode ser gerada pela convolução deste sinal inicial com uma máscara gaussiana $\left(G_{\sigma}\right)$ de desvio-padrão $\sigma$ e variância $t=\sigma^{2}$ (KOENDERINK, 1984; PERONA; MALIK, 1990). Considerando que $I(x, y ; t)$ representa uma imagem 2D com coordenadas $(x, y)$ e com um parâmetro $t$ denominado de parâmetro de escala, então:

$$
I(x, y ; t)=I_{0}(x, y) * G(x, y ; t)
$$

onde:

$$
G(x, y ; t)=\frac{1}{2 \pi t} e^{-\frac{\left(x^{2}+y^{2}\right)}{2 t}}
$$

corresponde a uma família da solução em que, à medida que $t$ aumenta, a representação da imagem fica mais grosseira (mais borrada) e os detalhes vão se perdendo neste processo.

No exemplo da Figura 3.7 a imagem $I_{0}(x, y)$ está corrompida com ruído aditivo de distribuição gaussiana para melhor ilustrar o efeito do filtro gaussiano com $t=2, t=4$ ou $t=9$.
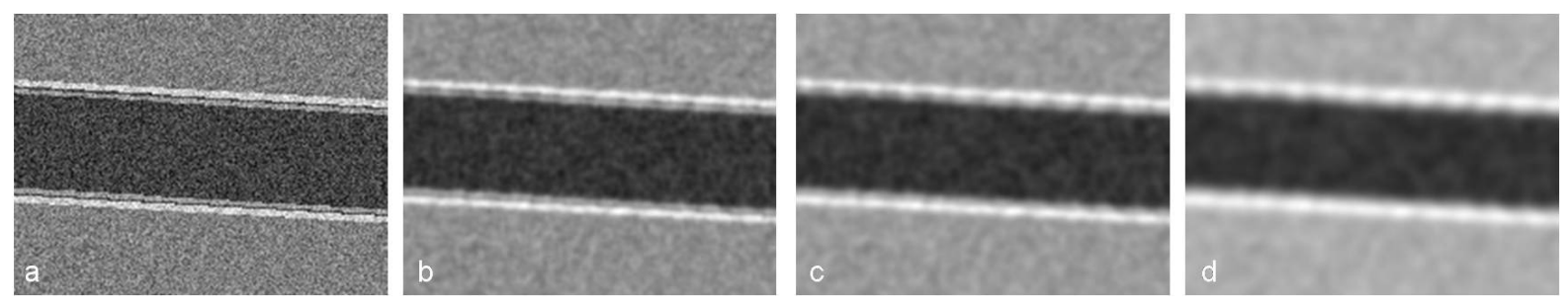

Figura 3.7 - Aplicação de um filtro gaussiano à imagem original (a) $I_{0}(x, y)$ corrompida com ruído aditivo de distribuição gaussiana para obter (b) $I_{0}(x, y) * G(x, y ; t=2)$; (c) $I_{0}(x, y) * G(x, y ; t=4)$ e (d) $I_{0}(x, y) * G(x, y ; t=9)$.

A máscara gaussiana se comporta, pois, como um filtro passa-baixas que, ao atenuar ruídos de alta frequência, pode também alterar significativamente determinadas características da imagem como, por exemplo, as interfaces das paredes arteriais. 


\subsubsection{Filtro de difusão anisotrópica}

Uma alternativa para este problema foi proposto por Perona e Malik (1990) com o filtro de difusão anisotrópica. Esta abordagem, diferentemente da difusão isotrópica, como ocorre na convolução da imagem com uma máscara gaussiana com variância constante em todas as direções, oferece a vantagem de minimizar os efeitos colaterais do deslocamento e suavização das bordas. Para tanto, introduz-se um coeficiente de difusão $c(|\nabla I(x, y)|)$ na equação de difusão de calor (3.10) que, na forma geral, pode ser reescrita como:

$$
\frac{\partial I}{\partial t}=\operatorname{div}[c(|\nabla I|) \cdot \nabla I]
$$

Este coeficiente, como indicado acima, é uma função do gradiente da imagem (ou de outra grandeza que caracterize as bordas) e o seu comportamento é tal que inibe o efeito da difusão nas proximidades das bordas, preservando-as, pois leva em consideração os valores mais elevados da magnitude do gradiente nestes locais. Quando o coeficiente de difusão é convenientemente escolhido, além da propriedade de realçar as bordas, a difusão anisotrópica satisfaz também o critério da causalidade, garantindo que novas características (bordas, neste caso) não sejam geradas ao se passar das escalas mais finas para as mais grossas no contexto do espaço de escala (PERONA; MALIK, 1990).

Duas propostas apresentadas por Perona e Malik (1990) que satisfazem estes critérios são:

$$
\begin{aligned}
& c(|\nabla I|)=e^{-\left(\frac{|\nabla I|}{k}\right)^{2}} \\
& c(|\nabla I|)=\frac{1}{1+\left(\frac{|\nabla I|}{k}\right)^{2}}
\end{aligned}
$$

onde $k$ estabelece a condutância do processo de difusão. Para $k>|\nabla I|, \quad 0$ coeficiente aproxima-se de 1 e a difusão tende a ser isotrópica como em (3.10); por outro lado, valores menores de $k$ favorecem a minimização do coeficiente, especialmente quando $|\nabla I|$ for alta, tendendo a inibir a difusão. 


\subsubsection{Filtro de difusão anisotrópica para a redução de speckle (SRAD)}

Outra alternativa de filtro analisada neste projeto explora, simultaneamente, o modelo da difusão anisotrópica e a técnica de filtros adaptativos para a redução de ruído speckle, um tipo de ruído multiplicativo presente nas imagens de ultrassonografia. A difusão anisotrópica para a redução do speckle (SRAD - Speckle Reducing Anisotropic Diffusion) foi proposta por Yu e Acton (2002) ao estabelecer uma relação entre os filtros adaptativos Lee (LEE, 1980) e Frost (FROST et al., 1982) e o filtro de difusão anisotrópica por meio de uma equação diferencial parcial. Desta relação, o coeficiente de difusão $c(x, y)$, proveniente da formulação da difusão anisotrópica, passa a depender de um coeficiente de variação proveniente da formulação dos filtros adaptativos, mas agora qualificado como instantâneo $q(x, y ; t)$ para refletir a evolução temporal da equação de difusão. $O$ coeficiente de variação instantâneo é dado por (YU; ACTON, 2002):

$$
q(x, y ; t)=\sqrt{\frac{\frac{1}{2}\left(\frac{|\nabla I|}{I}\right)^{2}-\frac{1}{16}\left(\frac{\nabla^{2} I}{I}\right)^{2}}{\left[1+\frac{1}{4}\left(\frac{\nabla^{2} I}{I}\right)\right]^{2}}}
$$

e representa uma estatística local da imagem, assumindo valores altos nas bordas ou em regiões de alto contraste, enquanto que nas regiões homogêneas seu valor é baixo.

De forma análoga ao parâmetro $k$ do coeficiente de difusão em (3.15) e (3.16), uma função de escala do speckle estimada como:

$$
q_{0}(t)=\frac{\sqrt{\operatorname{var}[z(t)]}}{\overline{z(t)}}
$$

é utilizada para controlar a intensidade da suavização. $\operatorname{var}[z(t)]$ e $\overline{z(t)}$ são, respectivamente, a variância e a média da intensidade sobre uma área homogênea no instante $t$. 
Assim, o coeficiente de difusão, como função do coeficiente de variação pode ser formulado como:

$$
c(q)=\exp \left\{-\left[q^{2}-q_{0}^{2}\right] /\left[q_{0}^{2}\left(1+q_{0}^{2}\right)\right]\right\}
$$

ou

$$
c(q)=\frac{1}{1+\left[q^{2}-q_{0}^{2}\right] /\left[q_{0}^{2}\left(1+q_{0}^{2}\right)\right]}
$$

que foram adaptados de (3.15) e (3.16), respectivamente, da difusão anisotrópica.

De acordo com as expressões acima, a difusão se comporta isotropicamente à medida que o coeficiente de variação instantâneo $q(x, y ; t)$ se aproxima da função de escala do speckle $q_{0}(t)$, ou seja, nas regiões homogêneas da imagem. Portanto, o filtro SRAD utiliza um coeficiente de variação que se adapta à região da imagem para suavizá-la na presença de ruído speckle e preservar ou, até mesmo, realçar as bordas. 


\section{METODOLOGIA}

\subsection{Ambientes de programação}

Para o tratamento das imagens de ultrassonografia modo- $B$, incluindo os algoritmos de segmentação das paredes arteriais e a confecção do modelo matemático (vide seção 4.2), este trabalho contou com o auxílio de uma poderosa ferramenta de programação orientada a objetos: o Insight Segmentation and Registration Toolkit (ITK) (IBÁÑEZ; SCHROEDER, 2005) concebido pelo US National Library of Medicine do National Institutes of Health (NIH / NLM) e que está em contínuo desenvolvimento por inúmeros colaboradores em todo o mundo, em função da sua ampla aceitação e das vantagens de se utilizar um software de código aberto.

O conjunto de classes do ITK está implementado na linguagem de programação $\mathrm{C}++$ e contempla uma série de módulos para leitura, gravação, filtragem e segmentação de imagens, entre outros, com a possibilidade de criação de novos módulos, inclusive. Outras características importantes são a sua portabilidade entre as plataformas Windows, Linux e Unix e a disponibilidade de interfaces para viabilizar a programação em outras linguagens, tais como Tcl, Python e Java. As classes do ITK foram adicionadas a um ambiente de programação disponibilizado gratuitamente: o Microsoft Visual C++ 2008 Express Edition (versão 9.0), que atendeu às necessidades deste trabalho.

Para a extração de informações das imagens de ultrassonografia Doppler, utilizou-se como base um sistema previamente desenvolvido (GUTIERREZ et al., 2002; PILON, 2002), especializado para os cálculos da espessura da parede e do diâmetro arteriais a partir de imagens de ultrassonografia modo-B. O ambiente de programação utilizado, neste caso, foi a versão comercial do Microsoft Visual Studio (versão 6.0, 1998), também na linguagem de programação $\mathrm{C}++$ e complementado pela biblioteca de classes MFC (Microsoft Foundation Classes), pois o aplicativo deveria dispor de interfaces gráficas apropriadas para a interação com o usuário. 
Sobre esta base, um novo módulo foi acrescentado ao aplicativo para os cálculos de velocidade e fluxo de sangue.

\subsection{Phantom matemático da imagem em modo-B}

A adoção de um modelo matemático gerado computacionalmente tem, por objetivo, confirmar se os algoritmos implementados estão sendo executados satisfatoriamente porque, neste caso, os resultados esperados são bem determinados e conhecidos a priori.

No presente trabalho que utiliza a técnica de segmentação aplicada às paredes da artéria carótida para a detecção das interfaces e para os cálculos da EIM e do DL, um modelo matemático da imagem de ultrassonografia modo-B que simula a presença de ruído speckle, descrito a seguir, foi criado a partir de algumas classes do ITK, com ligeira diferença em relação à imagem sintetizada por Yu e Acton (2002).

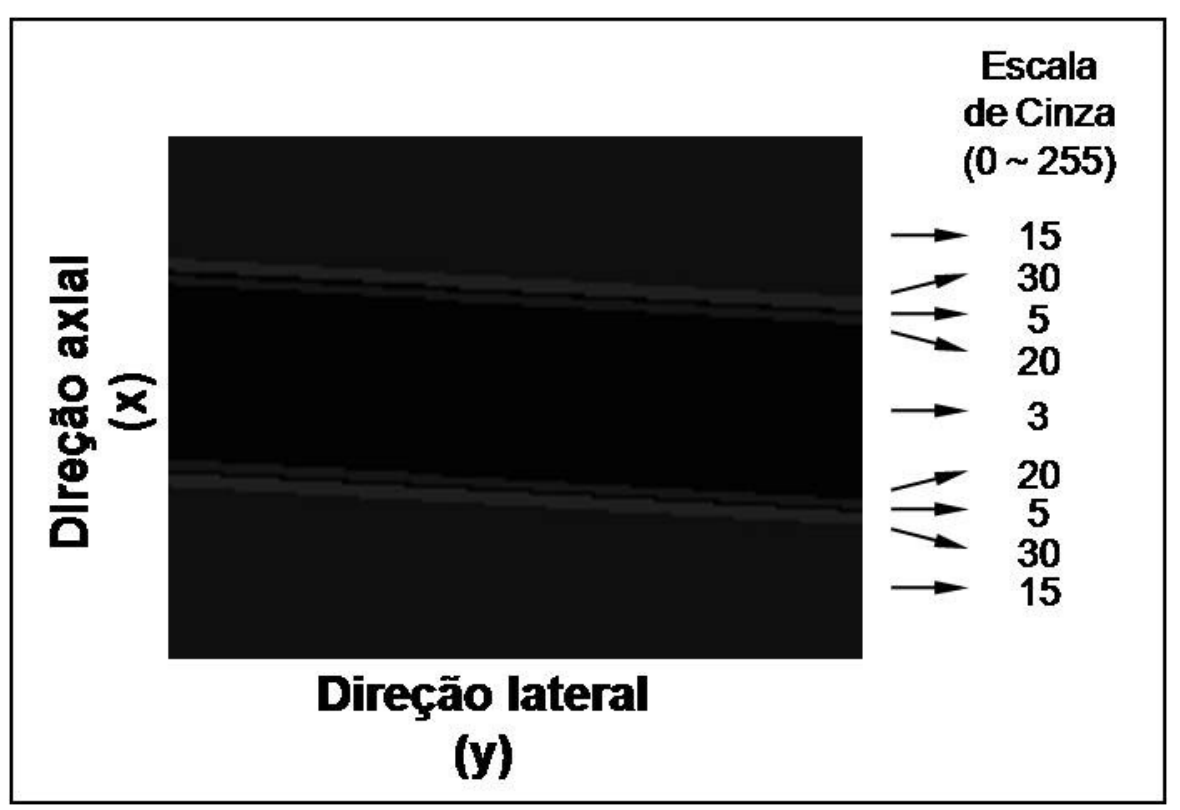

Figura 4.1 - Modelo simplificado de uma estrutura arterial. 
Partindo de um modelo simplificado de uma estrutura arterial (Figura 4.1) ${ }^{1}$ representado por $t(x, y)$, de tamanho 576 x 456 pixels e com a proporção adotada de 9 pixels / $1 \mathrm{~mm}$, um ruído multiplicativo com distribuição gaussiana $G_{\sigma}(x, y)$ de média nula e desvio-padrão $\sigma=1,0$ foi aplicado em toda a imagem para simular variações de impedância acústica devido à heterogeneidade dos tecidos arteriais. Notar que o eixo $x$ está na posição vertical para representar a direção axial, enquanto que $y$ representa a direção lateral, na posição horizontal.

Assim, o novo modelo, que passa a considerar o efeito de espalhamento do sinal nos tecidos foi calculado como:

$$
T(x, y)=t(x, y) \cdot G_{\sigma}(x, y)
$$

A resposta impulsiva de um hipotético sistema de aquisição de imagens por ultrassonografia, representado por $h(x, y)$, foi tratada separadamente como $h_{1}(x)$ e $h_{2}(y)$, onde $h_{1}(x)$ é uma função senoidal com ponderação gaussiana (função de Gabor) dada por:

$$
h_{1}(x)=\operatorname{sen}\left(k_{0} x\right) \cdot \exp \left(\frac{-x^{2}}{2 \sigma_{x}^{2}}\right)
$$

com

$$
k_{0}=\frac{2 \pi f_{0}}{c}
$$

onde $C=1540 \mathrm{~m} / \mathrm{s}$ é a velocidade do som no tecido, $f_{0}=7 \mathrm{MHz}$ é a frequência central do transdutor e $\sigma_{x}=0,33 \mathrm{~mm}$ é a largura de pulso da onda de ultrassom transmitida.

O segundo termo $h_{2}(y)$ é a resposta espacial referente à direção lateral dada por:

$$
h_{2}(y)=\exp \left(\frac{-y^{2}}{2 \sigma_{y}^{2}}\right)
$$

\footnotetext{
${ }^{1}$ Como mencionado, o tamanho da imagem original é $576 \times 456$ pixels; porém, para uma melhor visualização dos detalhes, esta imagem e as seguintes estão apresentadas como um recorte de tamanho $200 \times 150$ pixels.
} 
onde $\sigma_{y}=0,06 \mathrm{~mm}$ é a largura do feixe de transmissão do ultrassom.

Portanto, uma imagem sintética com ruído do tipo multiplicativo na saída do hipotético sistema de aquisição de imagens foi obtida pela expressão:

$$
V(x, y)=h(x, y) * T(x, y)
$$

com

$$
h(x, y)=h_{1}(x) \cdot h_{2}(y)
$$

e * denota a operação de convolução, tendo $h_{1}(x)$ a dimensão de $15 \times 1$ pixels e $h_{2}(y)$ a dimensão de $1 \times 15$ pixels.

As três etapas acima, desde o modelo simplificado da estrutura arterial até a saída representada pelas expressões 4.5 e 4.6, estão ilustradas no diagrama em blocos da Figura 4.2.

Como não foi encontrado na biblioteca de classes do ITK um gerador de sinal com distribuição gaussiana, esta função foi obtida a partir de duas funções densidade de probabilidade uniforme entre 0 e 1 (referentes às variáveis aleatórias " $a$ " e " $b$ " na Figura 4.2), sendo que uma delas foi utilizada para gerar outra função com distribuição Rayleigh (SCHWARTZ; SHAW, 1975 apud AL-BAYATI; ALJUDI, 1991).

Dado que $V(x, y)$ é um sinal de banda passante, sua representação em quadratura é (YU; ACTON, 2002):

$$
V_{a}(x, y)=V(x, y)+j \hat{V}(x, y)
$$

onde $\hat{V}(x, y)$ é a Transformada de Hilbert de $V(x, y)$ em relação a $x$.

A metodologia utilizada para o cálculo da Transformada de Hilbert exigiu 0 cálculo da Transformada Rápida de Fourier (FFT - Fast Fourier Transform) que, por sua vez, requereu, preliminarmente, que a imagem com ruído multiplicativo fosse redimensionada para um tamanho (largura e altura) igual a uma potência de dois. A opção foi redimensioná-la para 512 x 512 pixels, através de um simples recorte, sem alterar a área de maior interesse. 
Entretanto, a FFT disponível no ITK apresentava, na saída, o complexo conjugado da transformada, o que exigiu a decomposição nas partes real e imaginária para a obtenção da saída complexa desejada.

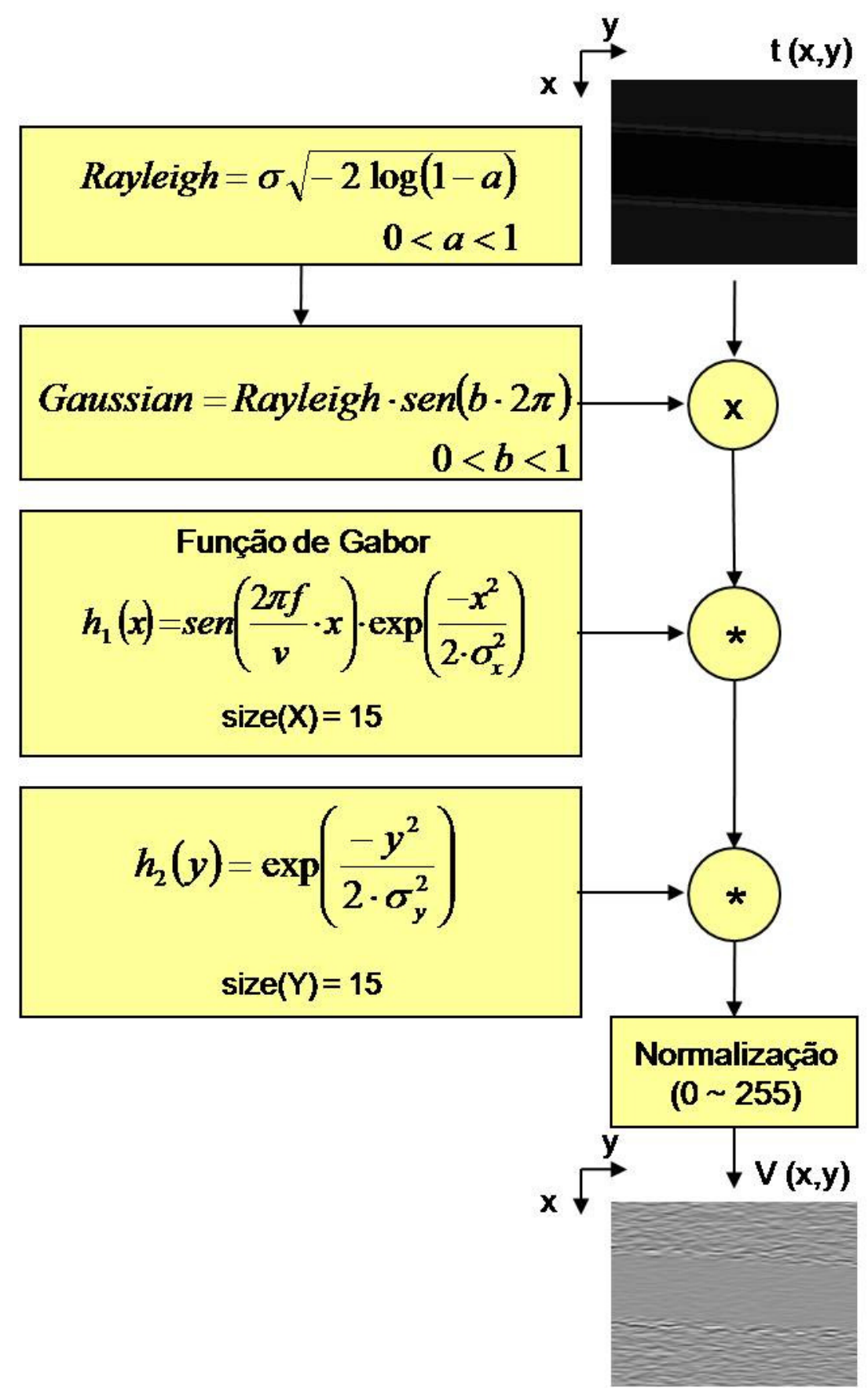

Figura 4.2 - Diagrama em blocos das três etapas iniciais para a sintetização de uma imagem através de um hipotético sistema de aquisição por ultrassonografia. O sinal * denota a operação de convolução. 
Os passos seguintes no domínio da frequência foram as supressões do nível DC $(f=0)$ e da componente Nyquist $(f=256)$, além da aplicação da função $-j \cdot \operatorname{sgn}(f)$ (LATHI, 1989), onde:

$$
\operatorname{sgn}(f)=\left\{\begin{array}{cc}
1 & \text { se } f>0 \\
0 & \text { se } f=0 \\
-1 & \text { se } f<0
\end{array}\right.
$$

Novamente, houve a necessidade da decomposição nas partes real e imaginária para o cálculo do complexo conjugado antes da Transformada Rápida Inversa de Fourier (IFFT - Inverse FFT), cuja saída correspondia à Transformada de Hilbert desejada.

A envoltória do sinal foi extraída pelo cálculo da magnitude:

$$
A(x, y)=\left|V_{a}(x, y)\right|
$$

que corresponde à imagem sintética utilizada nos ensaios deste trabalho (Figura 4.3).

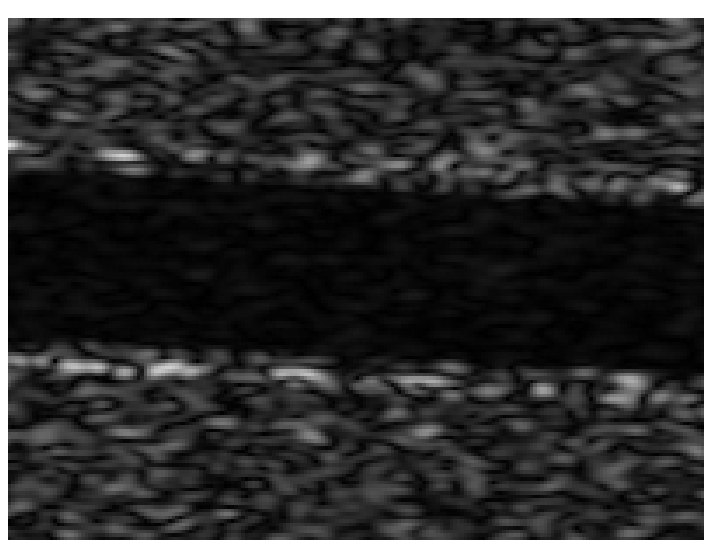

Figura 4.3 - Imagem sintética de ultrassonografia da artéria carótida.

Convém observar que a etapa final para a extração da envoltória exigiu também as supressões do nível DC e da componente Nyquist diretamente da FFT da imagem de entrada com ruído multiplicativo.

O processamento descrito acima que incluiu a Transformada de Hilbert e a extração da envoltória da imagem está ilustrado no diagrama em blocos da Figura 4.4 . 


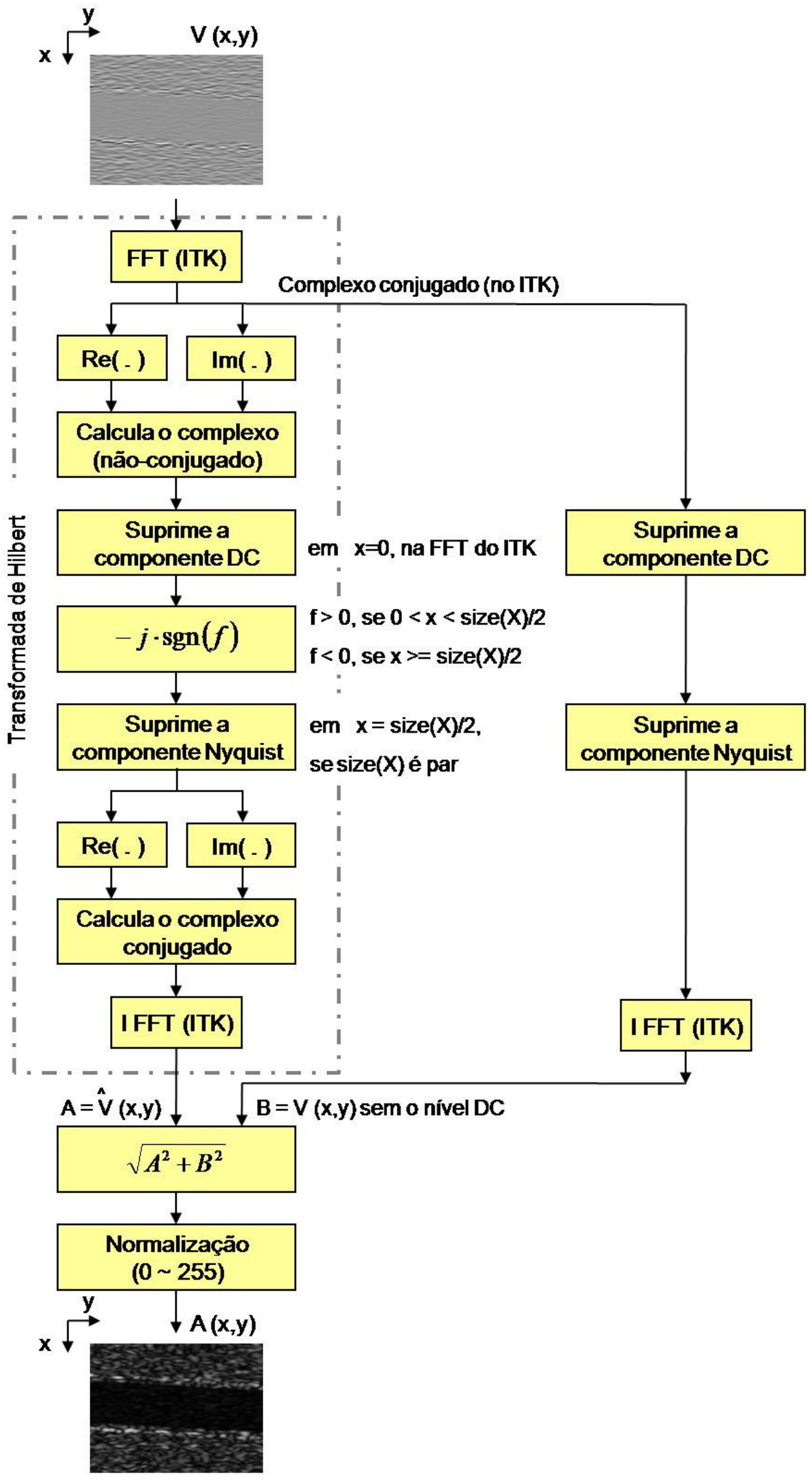

Figura 4.4 - Diagrama em blocos da implementação no ITK da Transformada de Hilbert e da extração da envoltória da imagem. 


\subsection{Sistemas de ultrassonografia}

Imagens reais de ultrassonografia modo-B da artéria carótida foram adquiridas com um sistema de grande porte disponível no InCor, o Apogee 800 Plus (ATL, Bothell, WA, USA) equipado com um transdutor linear 11-5L40 (5 a $11 \mathrm{MHz})$ (ATL, 1996).

Quanto às imagens que contêm os espectros representados pelas curvas de velocidade em função do tempo, estas foram adquiridas das artérias carótida e braquial e dos exames ecocardiográficos pela técnica de ultrassonografia Doppler utilizando o mesmo sistema acima e outros três modelos de sistemas pertencentes ao InCor, a saber: o sistema portátil Cypress $^{\mathrm{TM}}$ (ACUSON, Mountain View, CA, USA), equipado com um transdutor 7L3 (5,22 MHz) (SIEMENS, 2002); o HDI 5000 (Philips/ATL, Bothell, WA, USA) com transdutor P4-2 (2 a $4 \mathrm{MHz}$ ) ou P5-3 (3 a 5 $\mathrm{MHz}$ ); e o Sonos 5500 (HP/Philips, Bothell, WA, USA) com transdutor S3 (1 a 3 $\mathrm{MHz}$ ) ou S4 (2 a $4 \mathrm{MHz}$ ).

\subsection{Aspectos da implementação dos filtros}

Para a segmentação das paredes arteriais, uma etapa preliminar à aplicação da técnica de contornos ativos é o processamento, através de filtros, da imagem proveniente do equipamento de ultrassonografia modo-B. Os ensaios deste trabalho utilizaram, com o propósito de comparação de desempenho, três tipos de filtros que visavam atenuar os ruídos intrínsecos das imagens de ultrassonografia e que, com o cálculo da derivada de primeira ordem na direção axial na etapa seguinte, buscavam enfatizar as bordas das paredes arteriais, favorecendo, pois, a detecção das mesmas.

A aplicação da derivada de primeira ordem na direção axial foi motivada pela observação da Figura 3.5 onde, pela representação do eco, as três interfaces desejadas (íntima-luz da parede proximal e luz-íntima e média-adventícia da parede distal) apresentam características semelhantes de transição de uma faixa 
hipoecogênica para outra ecogênica. No ITK esta operação foi realizada através da convolução da imagem filtrada com a seguinte máscara:

$$
D_{y}=\left[\begin{array}{c}
-1 / 2 \\
0 \\
1 / 2
\end{array}\right]
$$

\subsubsection{Filtro gaussiano}

O primeiro filtro (doravante denominado F1), mais básico, compreende a aplicação de uma máscara gaussiana através da sua convolução com a imagem, como descrito na revisão bibliográfica, seguida pelo cálculo da derivada de primeira ordem na direção axial. A Figura 4.5 reapresenta o exemplo da Figura 3.7 e acrescenta, na linha inferior, as imagens das derivadas correspondentes para ilustrar a filtragem do ruído e a enfatização das bordas neste processo.
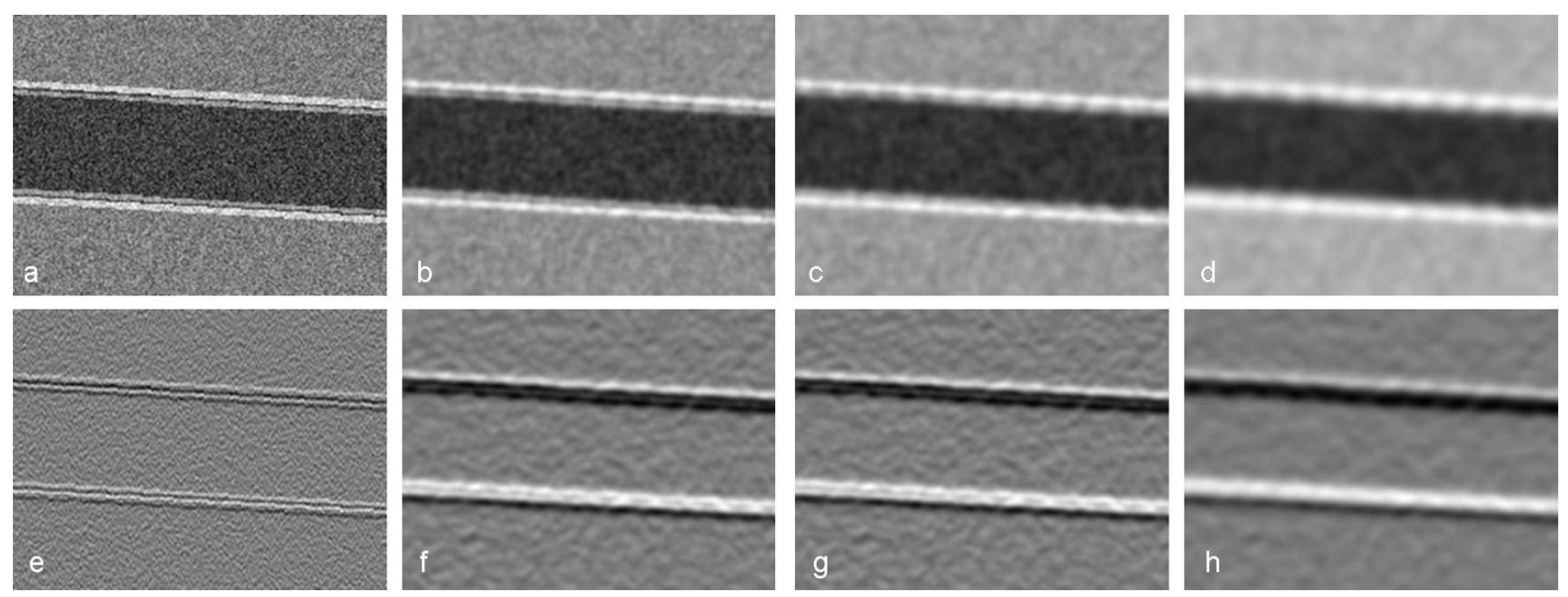

Figura 4.5 - Aplicação de um filtro gaussiano à imagem original (a) $I_{0}(x, y)$ corrompida com ruído aditivo de distribuição gaussiana para obter (b) $I_{0}(x, y) * G(x, y ; t=2)$; (c) $I_{0}(x, y) * G(x, y ; t=4)$ $\mathrm{e}(\mathrm{d}) I_{0}(x, y) * G(x, y ; t=9)$. Na linha inferior, $(\mathrm{e}),(\mathrm{f}),(\mathrm{g}) \mathrm{e}(\mathrm{h})$ correspondem à derivada de primeira ordem na direção axial de (a), (b), (c) e (d), respectivamente. 


\subsubsection{Filtro de difusão anisotrópica}

O segundo filtro (F2) utiliza o conceito da difusão anisotrópica, conforme foi introduzido na revisão bibliográfica.

A biblioteca de classes do ITK dispõe de um filtro de difusão anisotrópica com o mesmo coeficiente apresentado em (3.15), cuja implementação numérica é similar à descrita no artigo de Perona e Malik (1990), mas com uma técnica mais robusta para a estimativa da magnitude do gradiente (IBÁÑEZ; SCHROEDER, 2005). Além do parâmetro $k$ das equações (3.15) e (3.16) que controla a condutância do processo de difusão, há também outro parâmetro $t$ que representa 0 incremento temporal e desempenha uma função análoga ao $\sigma$, a largura efetiva do filtro gaussiano. Uma solução para a equação diferencial e parcial não-linear (3.14), isto é, uma imagem de saída deste filtro, é obtida por um processo iterativo e, portanto, requer-se o ajuste de mais um parâmetro: o número de iterações.

$\mathrm{Na}$ saída do filtro de difusão anisotrópica espera-se uma imagem suavizada nas regiões homogêneas, mas com as características preservadas nas interfaces entre regiões distintas. Como no primeiro filtro, o cálculo da derivada de primeira ordem no estágio seguinte, auxiliou no processo de detecção das bordas.

\subsubsection{Filtro de difusão anisotrópica para a redução de speckle (SRAD)}

O princípio da difusão anisotrópica também é aplicado no terceiro filtro (F3) utilizado nos ensaios. Porém, este explora simultaneamente o modelo anterior e a técnica de filtros adaptativos para a redução de ruído speckle, denominando-o SRAD, conforme descrito com mais detalhes na revisão bibliográfica. Como nos demais filtros implementados, o cálculo da derivada de primeira ordem na direção axial da imagem na saída do SRAD, consolida a etapa de enfatização das bordas.

Como a biblioteca de classes do ITK não dispõe do filtro SRAD, a sua implementação seguiu, passo-a-passo, o desenvolvimento matemático indicado no artigo de Yu e Acton (2002), aproveitando algumas classes mais simples do ITK. 


\subsection{Aspectos da implementação dos algoritmos de contornos ativos}

A detecção das paredes arteriais de interesse pôde ser realizada a partir de um dos três filtros disponíveis (F1, F2 ou F3), seguido pela aplicação dos contornos ativos que, neste projeto, foram desenvolvidos segundo os modelos de:

C1) Kass, Witkin e Terzopoulos (1988);

C2) Williams e Shah (1992);

C3) Lobregt e Viergever (1995).

Assim como o filtro SRAD, todos os três algoritmos foram implementados a partir de algumas classes mais simples do ITK e os coeficientes de ponderação das energias interna e externa foram mantidos constantes em relação à posição de cada ponto do contorno ativo (coordenadas $x$ e y da imagem).

\subsubsection{Algoritmo de Kass, Witkin e Terzopoulos}

O algoritmo C1 utilizou o método numérico de aproximação das derivadas parciais pelo cálculo das diferenças finitas, tratando separadamente as direções $\mathrm{X}$ e Y. As equações de Euler-Lagrange (XU et al., 2000; XU; PRINCE, 1998) foram, então, escritas na forma matricial para formar uma matriz de banda pentadiagonal cujos elementos foram calculados a partir dos coeficientes de ponderação. Sua inversa foi calculada eficientemente pela decomposição LU (lower · upper) para encontrar a solução que minimizasse a energia total do contorno a cada iteração (KASS; WITKIN; TERZOPOULOS, 1988).

Os coeficientes de ponderação: $\alpha=0,1 ; \beta=0,1$ e fator externo $=1,5$ referentes à energia interna de continuidade, à energia interna de curvatura e à energia externa, respectivamente, foram obtidos heuristicamente após uma série de simulações. O parâmetro que, no tratamento dinâmico, representa o intervalo de tempo entre cada iteração foi definido como unitário.

Dado que na aplicação deste trabalho o contorno é aberto, as derivadas parciais não foram calculadas nos extremos e impôs-se que nos dois primeiros e nos dois últimos pontos do contorno houvesse somente a atuação da força externa. A propósito, neste algoritmo, enquanto o conceito de energia foi aplicado ao contorno 
(energia interna), o conceito de força foi aplicado à imagem (força externa), embora as duas abordagens sejam equivalentes.

Como neste algoritmo há um tratamento separado da decomposição da força externa nas direções $X$ e $Y$, o cálculo desta força levou em consideração tanto a derivada de primeira ordem na direção axial quanto a derivada de primeira ordem na direção lateral.

\subsubsection{Algoritmo de Williams e Shah}

No algoritmo C2, a cada iteração, houve um cálculo preliminar da distância média entre os pontos do contorno que foi, em seguida, utilizada para o cálculo da energia interna de continuidade com o objetivo de manter os pontos igualmente espaçados, evitando uma alta concentração (distância entre pontos abaixo da média) ou uma grande dispersão (distância entre pontos acima da média) indesejada dos mesmos.

A energia de curvatura foi determinada pela derivada de segunda ordem do contorno e a energia externa foi extraída da derivada de primeira ordem na direção axial da imagem.

Como no algoritmo $\mathrm{C} 1$, os coeficientes de ponderação foram estabelecidos heuristicamente com os valores: $\alpha=1,5$ para a energia interna de continuidade, $\beta=$ 2,2 para a energia interna de contorno e $\gamma=0,5$ para a energia externa.

Para cada ponto do contorno foram calculadas as energias totais de cada vizinho (pixels da imagem vizinhos ao ponto do contorno), considerando uma matriz de vizinhos de tamanho 3 × 3 pixels. Cada ponto foi, então, movido (ou mantido na mesma posição) para o de menor energia dentro desta matriz. Nos dois extremos do contorno aberto as energias internas foram desconsideradas porque as curvaturas não estão definidas nestes locais; portanto, apenas as energias externas atuaram no deslocamento destes pontos. 


\subsubsection{Algoritmo de Lobregt e Viergever}

$\mathrm{Na}$ proposta de Lobregt e Viergever (1995) a abordagem é ligeiramente diferente das anteriores, uma vez que o modelo do contorno apresenta uma estrutura discreta formada por vértices que são interligados por segmentos de retas. Outra pequena diferença é a utilização do conceito de forças internas e externas que atuam sobre os vértices, ao invés das energias. Das forças, calcula-se a aceleração e desta, a velocidade do vértice. Portanto, na implementação numérica de C3 estas grandezas atuaram no deslocamento de cada vértice e atualizaram sua posição a cada iteração. Quando necessário, para manter uma resolução pré-estabelecida do contorno, igual a 10 pixels, vértices foram removidos ou inseridos automaticamente, procurando conservá-los a uma distância regular entre si.

Para os cálculos da curvatura, forças, aceleração, velocidade e posição, os vetores foram projetados nas direções $\mathrm{X}$ e $\mathrm{Y}$ e processados separadamente. Como no algoritmo $\mathrm{C} 1$, esta separação também necessitou da derivada de primeira ordem na direção lateral, além da derivada de primeira ordem na direção axial. Nos dois extremos do contorno aberto impôs-se a condição de forças internas nulas, de modo que os seus deslocamentos ficaram sujeitos apenas às forças externas.

Os coeficientes de ponderação da força interna $\left(w_{\text {in }}=1,0\right)$ e da força externa $\left(w_{\mathrm{ex}}=0,5\right)$ foram obtidos heuristicamente. Como em $\mathrm{C} 1$, definiu-se como unitário o parâmetro que, no tratamento dinâmico, representa o intervalo de tempo entre cada iteração.

Para melhorar a convergência para um estado de equilíbrio, uma nova força, a de amortecimento, proporcional e de sentido oposto à velocidade, foi adicionada com o respectivo coeficiente de ponderação $\left(w_{\text {damp }}=-1,2\right)$ obtido empiricamente.

\subsubsection{Inicialização dos contornos}

A inicialização dos contornos foi tratada da mesma forma para os três algoritmos. Considerando os eixos $X$ (abscissa) e $Y$ (ordenada) da imagem 2D longitudinal da artéria em questão, para cada imagem foi estabelecido um valor inicial yo como uma semente para o posicionamento de um segmento de reta na 
direção $X$, próximo ao centro da luz arterial. Outros dois valores, $x_{\min }$ e $x_{\max }$, também definidos para cada imagem, delimitavam horizontalmente a extensão do segmento.

Deste modo explorou-se o conhecimento, a priori, de que a borda da parede proximal que precisava ser detectada estava localizada acima deste segmento inicial, enquanto que as bordas desejadas da parede distal estavam localizadas abaixo deste segmento.

A partir do segmento, foram criados dois contornos constituídos por pontos equidistantes em 5 pixels na direção horizontal, ao longo da luz. Cada ponto do primeiro contorno era deslocado para cima, independentemente dos demais, até se aproximar suficientemente da interface íntima-luz da parede proximal de acordo com um limiar pré-estabelecido de intensidade da derivada de primeira ordem na direção axial da imagem filtrada por F1, F2 ou F3; de modo análogo, cada ponto do segundo contorno era deslocado para baixo, independentemente dos demais pontos, até se aproximar da interface luz-íntima da parede distal, nas mesmas condições de limiar. A partir do segundo contorno já inicializado, criou-se um terceiro a uma distância, determinada empiricamente, de 5 pixels abaixo do segundo, com o objetivo de detectar a interface média-adventícia, aproveitando também o conhecimento prévio de que esta interface localiza-se, aproximadamente, nesta distância abaixo da luzíntima.

Após a etapa de inicialização destes três contornos executou-se 0 tratamento dinâmico de deformação automática dos mesmos, separadamente, para melhor aproximação das bordas desejadas, segundo os algoritmos C1, C2 ou C3 implementados. Nesta etapa, as forças ou energias externas atuantes foram extraídas da derivada de primeira ordem da imagem original, ou seja, sem a utilização dos filtros, visto que os pontos dos contornos já estavam suficientemente próximos das interfaces de interesse.

\subsection{Quantificação semiautomática da velocidade do sangue}

A metodologia para a quantificação semiautomática da velocidade do sangue em imagens de ultrassonografia Doppler está exposta nos subitens 
seguintes que incluem as etapas de preparação, processamento de imagem e cálculos envolvidos neste processo:

- abertura da imagem de entrada previamente convertida para tons de cinza (escala de 0 a 255);

- calibração dos eixos de velocidade ("Y") e tempo ("X") para extrair as escalas da imagem em pixel/(m/s) e pixel/s, respectivamente: com o auxílio do mouse e tendo, como referência, as marcas de escala presentes no gráfico, o usuário desenha uma linha vertical e uma horizontal e, através de caixas de diálogo, atribui os tamanhos das linhas (pixels) nas grandezas correspondentes (m/s ou s). A Figura 4.6 ilustra a etapa de calibração do eixo "Y";

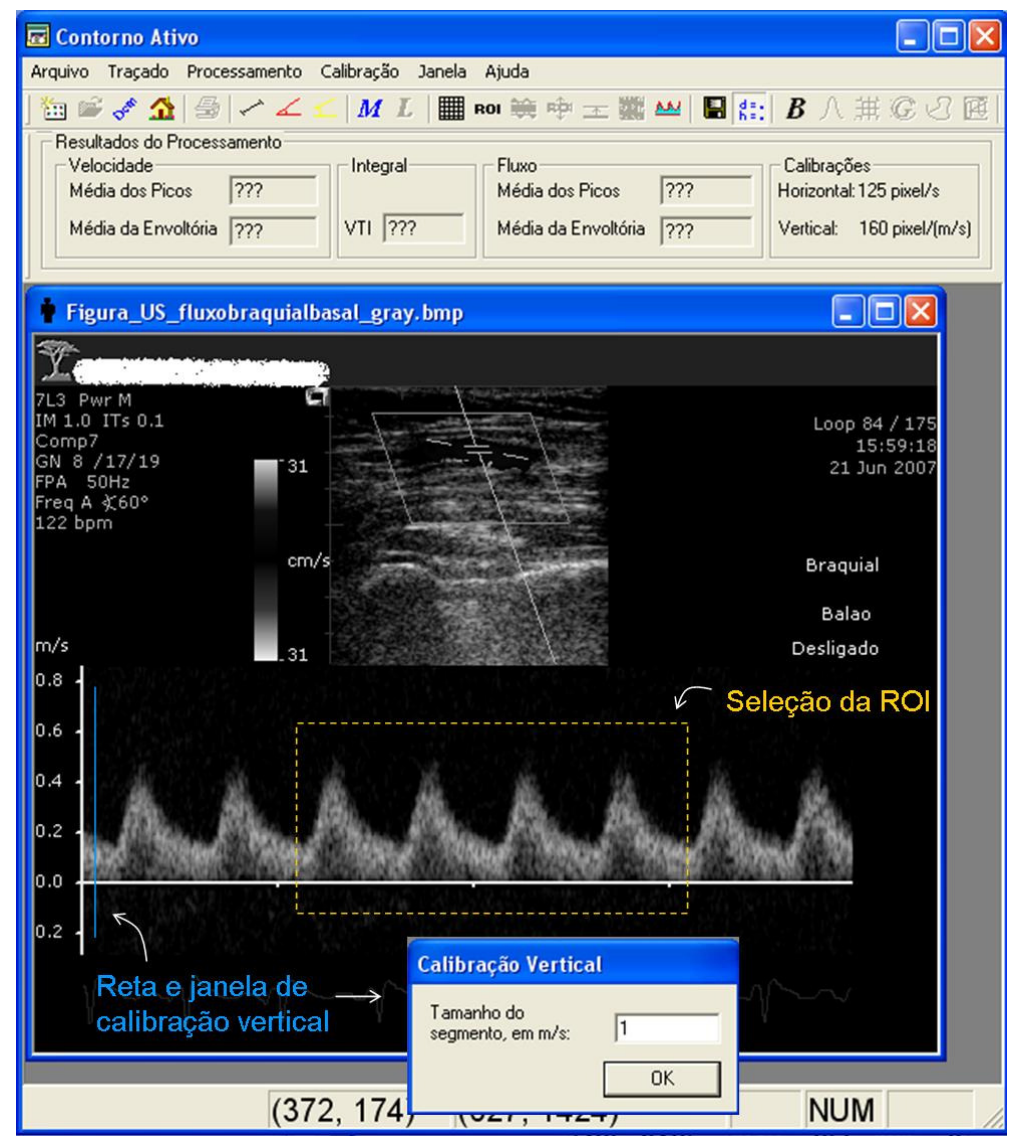

Figura 4.6 - Etapas de calibração e seleção da ROI.

- seleção de uma região de interesse (ROI - region of interest) retangular definida pelo usuário, também através do mouse, que contenha a envoltória e o eixo " $X$ " a serem detectados (Figura 4.6);

- aplicação de um filtro gaussiano com $\sigma$ (desvio-padrão) $=1$ pixel definido empiricamente para a redução de ruídos de alta frequência; 
- detecção do eixo "X" da variável de tempo: sabendo-se que este eixo é inserido na imagem, na direção horizontal, pelo próprio sistema de ultrassonografia e que, geralmente, é composto por pixels com pouca variação de intensidade entre eles, definem-se as funções:

$$
\begin{gathered}
g(i, j)=\left\{\begin{array}{rr}
\frac{1}{|I(i, j)-I(i+1, j)|+1}, & I(i, j)>z \\
0 \quad, \quad I(i, j) \leq z
\end{array}\right. \\
f(j)=\sum_{i=0}^{m-2} g(i, j), \quad j \in\left[y_{\text {min }}, y_{\text {max }}\right]
\end{gathered}
$$

onde:

$I(i, j)$ é a intensidade (nível de cinza) da imagem nas coordenadas $i$ e $j$;

$m$ é a largura (em pixels) da imagem;

$y_{\min }$ e $y_{\max }$ são, respectivamente, as ordenadas das linhas superior e inferior que delimitam a ROI definida pelo usuário;

e $z=40$ é um limiar pré-estabelecido empiricamente para desconsiderar a imagem de fundo do gráfico que, em geral, assume tonalidades mais escuras.

A ordenada "y" do eixo " $X$ " é, então, calculada pela expressão:

$$
y=\left\{j \in\left[y_{\min }, y_{\max }\right] \quad \text { । } f(y)=\max f(j)\right\}
$$

Em suma, quanto menor a variação de intensidade de pixel ao longo de uma linha pertencente à ROI, maior será a soma cumulativa nesta linha dada por $f(j)$. O valor $j$ que maximiza esta função é atribuído à ordenada "y" esperada do eixo "X". Este eixo será a referência, equivalente a $0 \mathrm{~m} / \mathrm{s}$, para o cálculo da velocidade (positiva ou negativa) após a detecção do contorno (superior ou inferior) da amplitude de velocidade (Figura 4.7);

- binarização com um limiar de nível de cinza (entre 0 e 255): o pixel assume o valor 255 ("ON") quando sua intensidade estiver acima do limiar ou o valor 0 ("OFF"), caso contrário. O valor padrão do limiar é 40 , mas pode ser configurado pelo usuário para melhor ajuste da envoltória;

- aplicação de um filtro de mediana na imagem binarizada usando um elemento estruturante de tamanho $3 \times 3$ pixels para a suavização das bordas e supressão de espúrios; 

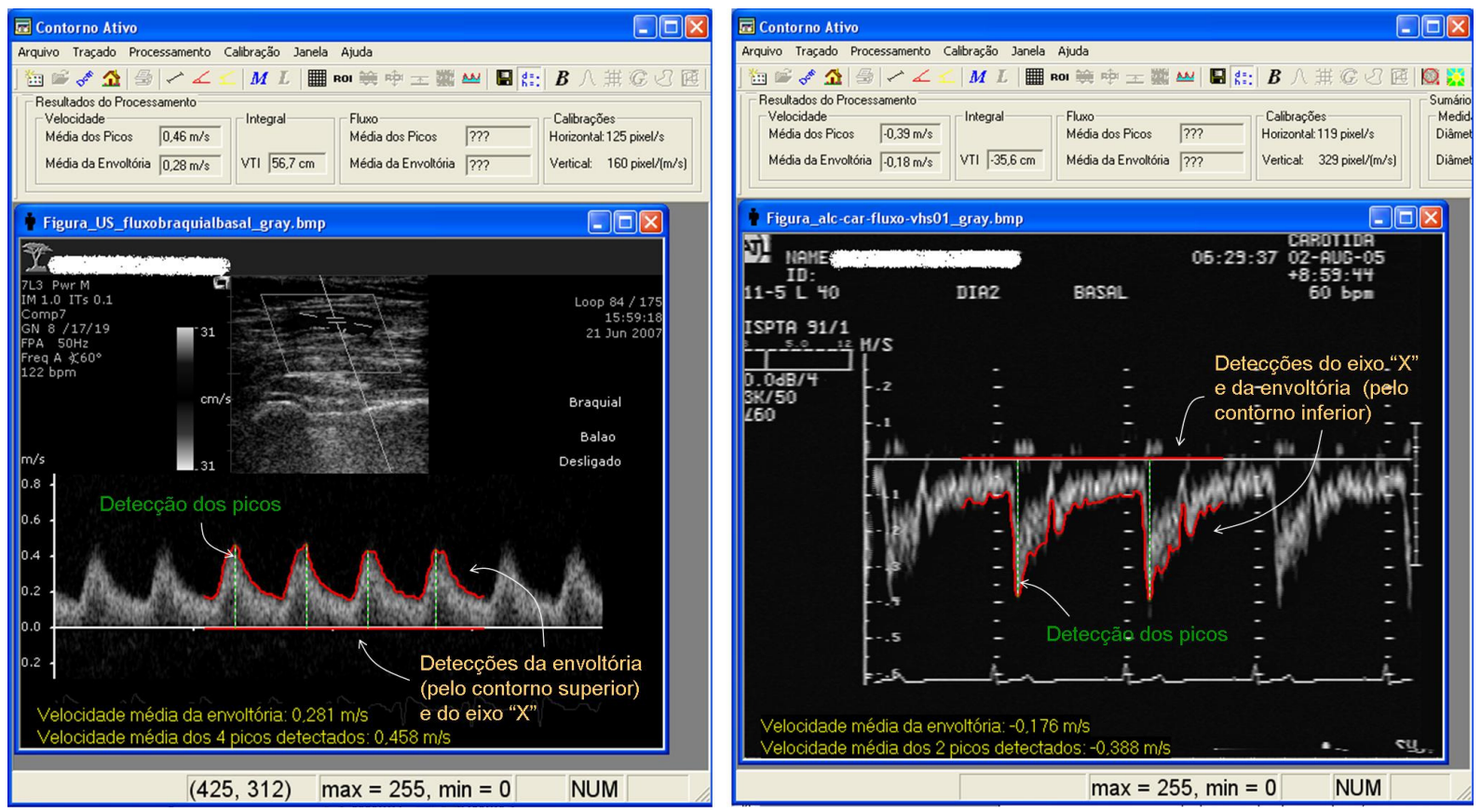

Figura 4.7 - Detecção do eixo "X", da envoltória (pelo contorno superior ou inferior) e dos picos.

- detecção da envoltória da amplitude de velocidade: uma curva composta por pontos espaçados entre si por um pixel na direção horizontal é inicializada na mesma posição da linha superior do ROI retangular. Em seguida, cada ponto desta curva é movido verticalmente, de cima para baixo, até encontrar um pixel ON da imagem binarizada. Como resultado, esta curva se ajusta automaticamente ao contorno superior do gráfico de velocidade. De modo semelhante, outra curva é inicializada na mesma posição da linha inferior do ROI e se move de baixo para cima até se ajustar ao contorno inferior do mesmo gráfico. Porém, como em cada gráfico de velocidade normalmente é desejável apenas o contorno superior (velocidade positiva) ou o inferior (velocidade negativa), um dos contornos detectados pelo processo acima é descartado. $O$ critério adotado assume que, em geral, o contorno desejado apresenta maior variação na amplitude, enquanto que o outro comumente coincide com o próprio eixo "X" (nos casos em que todo o espectro está somente acima ou somente abaixo deste eixo), apresentando, pois, nesta situação, uma amplitude constante. Portanto, a soma cumulativa dos módulos das diferenças de amplitude entre os pontos vizinhos ao longo do contorno (superior ou inferior) indica que aquele cuja soma é maior é o desejado, enquanto o outro é descartado (Figura 4.7).

Entretanto, um dos sistemas utilizados para a aquisição das imagens de velocidade, o ATL Apogee, insere marcas de escala no interior do gráfico que se 
confundem com o espectro de velocidade pela semelhança da tonalidade e, portanto, devem ser tratadas como ruído neste processo. Para evitar detecções indesejáveis dos pixels ON destas marcas, introduziu-se uma etapa intermediária que utiliza a contagem de componentes conexos da imagem binária no esquema de 4-conectividade (vizinhos acima, abaixo, à esquerda e à direita) (GONZALEZ; WOODS, 2002). Assim, o deslocamento dos pontos das curvas superior e inferior até a envoltória desejada continua até que duas condições sejam satisfeitas: 0 pixel da imagem seja $\mathrm{ON}$ e a quantidade de componentes conexos com classificação ON seja maior ou igual a 110 pixels (valor determinado empiricamente). Portanto, pixels $\mathrm{ON}$ agrupados em pequena quantidade, como as marcas de escala, por exemplo, são desprezados na detecção da envoltória (Figura 4.8);

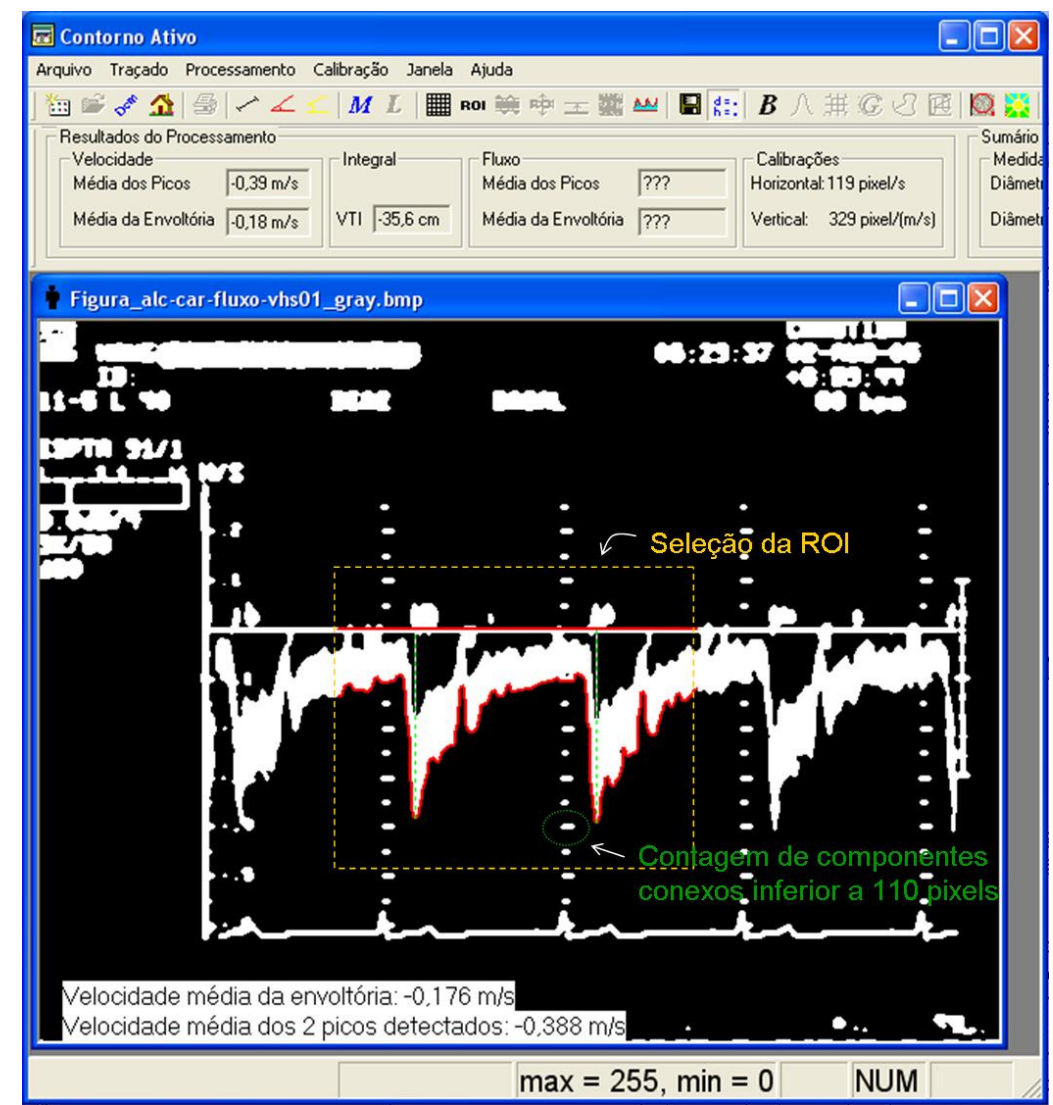

Figura 4.8 - Contagem de componentes conexos na imagem binária para evitar a falsa detecção da envoltória.

- detecção dos picos positivos ou negativos (Figura 4.7) com opção de escolha, através de uma caixa de diálogo, da distância mínima entre eles (valor padrão de 30 pixels) para evitar a detecção de picos intermediários indesejados; 
- cálculo da velocidade média dos picos detectados, da velocidade média da envoltória e da VTI, conforme as expressões:

$$
\begin{aligned}
& \text { Velocidade média dos picos }[\mathrm{m} / \mathrm{s}]=\frac{1}{P \cdot Y C a l} \sum_{p=1}^{P} A_{p} \\
& \text { Velocidade média da envoltória }[\mathrm{m} / \mathrm{s}]=\frac{1}{N \cdot Y C a l} \sum_{n=1}^{N} A_{n} \\
& \qquad \mathrm{VTI}[\mathrm{cm}]=\frac{100}{X C a l \cdot Y C a l} \sum_{n=1}^{N} A_{n}
\end{aligned}
$$

onde:

$A$ é a amplitude, em pixels, de cada ponto da envoltória;

$P$ é o total de picos detectados;

$N$ é o total de pontos da envoltória;

$Y C a l$ é a escala de calibração vertical, em pixels/(m/s);

$X C a l$ é a escala de calibração horizontal, em pixels/s;

- estimativa do fluxo médio dos picos e do fluxo médio da envoltória:

Desde que haja disponibilidade de imagens arteriais em modo-B com o cálculo do DL máximo e mínimo, assume-se que a seção transversal é circular e as estimativas são calculadas pelas expressões:

$$
\begin{aligned}
& \text { Fluxo médio dos picos }[\mathrm{l} / \mathrm{min}]=0,06 \cdot \bar{V}_{P} \cdot \frac{\pi D_{\max }^{2}}{4} \\
& \text { Fluxo médio da envoltória }[\mathrm{l} / \mathrm{min}]=0,06 \cdot \bar{V}_{N} \cdot \frac{\pi\left(D_{\max }+D_{\min }\right)^{2}}{16}
\end{aligned}
$$

onde:

$\bar{V}_{P}$ é a velocidade média dos picos, em $\mathrm{m} / \mathrm{s}$, calculada no subitem anterior;

$\bar{V}_{N}$ é a velocidade média da envoltória, em $\mathrm{m} / \mathrm{s}$, calculada no subitem anterior; $D_{\max }$ e $D_{\min }$ são as médias dos diâmetros da luz máximo e mínimo, em mm, respectivamente, obtidas durante uma etapa preliminar de processamento de imagens arteriais (GUTIERREZ, et al., 2002; PILON, 2002). 


\section{RESULTADOS E DISCUSSÃO}

\subsection{Composição das amostras}

Para uma avaliação comparativa preliminar entre filtros e algoritmos de contornos ativos para a detecção das paredes arteriais, uma imagem foi sintetizada conforme exposto na seção 4.2.

Quanto às imagens em modo-B reais, 7 amostras de pacientes distintos da artéria carótida comum foram adquiridas com o sistema de ultrassonografia Apogee 800 Plus por uma especialista que, em seguida, utilizou a ferramenta computacional (GUTIERREZ et al., 2002; PILON, 2002) especializada para os cálculos da espessura da parede e do diâmetro arteriais para extrair os valores de referência.

Para a validação da metodologia de detecção da envoltória e quantificação da velocidade e VTI, de cada gráfico do espectro foram medidas de 1 a 4 velocidades de pico sistólico e até duas VTIs ao longo dos ciclos cardíacos. As imagens estavam distribuídas em: 30 da artéria carótida comum (subtotal: 39 amostras de velocidade de pico / 31 amostras de VTI), 23 da artéria braquial na condição basal (subtotal: 35 / 24), 10 da artéria braquial na situação de hiperemia reativa após um procedimento de oclusão (subtotal: $15 / 15)$ e 11 de ecocardiografia (subtotal: 13 / 5). Os totais das amostras foram, pois, 102 de velocidade de pico e 75 de VTI.

Outras medições como o fluxo e a velocidade média não foram avaliadas diretamente neste trabalho. Porém, suas análises estão contempladas indiretamente pelas suas relações com a metodologia de detecção da envoltória e com o cálculo da velocidade de pico.

As imagens Doppler das artérias carótida e braquial foram adquiridas com 0 Apogee 800 Plus e com o Cypress $^{\mathrm{TM}}$ e as medições através destes sistemas foram realizadas por uma única operadora treinada. As de ecocardiografia foram adquiridas com o HDI 5000 e com o Sonos 5500; elas estavam disponíveis na base de dados de produção do InCor e as medições foram realizadas por clínicos distintos, não identificados. As mesmas amostras foram, então, processadas de 
forma independente pelo novo módulo computacional com os parâmetros mantidos constantes para todas as imagens.

\subsection{Ensaios com phantom matemático da imagem em modo-B}

Os ensaios com o phantom matemático que representa a imagem de ultrassonografia modo-B da artéria carótida (Figura 4.3) foram realizados alternadamente com os testes que utilizaram imagens reais para possibilitar uma imediata realimentação no processo de ajuste dos diversos parâmetros configuráveis dos filtros e dos algoritmos de contornos ativos.

Tabela 5.1 - Nomenclatura dos filtros e dos algoritmos de contornos ativos.

\begin{tabular}{ll}
\hline & \multicolumn{1}{c}{ Filtro } \\
\hline F1 & Gaussiano \\
F2 & Difusẫo Anisotrópica \\
F3 & SRAD \\
\hline
\end{tabular}

\begin{tabular}{cl}
\hline \multicolumn{2}{l}{ Algoritmo de Contornos Ativos } \\
\hline $\mathrm{C} 1$ & KassMitkin/Terzopoulos \\
$\mathrm{C} 2$ & Williams/Shah \\
$\mathrm{C} 3$ & Lobregt/iergever \\
\hline
\end{tabular}

Tabela 5.2 - Valores dos principais parâmetros dos filtros e dos algoritmos de contornos ativos.

\begin{tabular}{|c|c|c|}
\hline \multicolumn{3}{|c|}{ Parâmetros dos Filtros } \\
\hline F1 & variância $\left(\sigma^{2}\right)$ & 1,8 \\
\hline \multirow{3}{*}{$\mathrm{F} 2$} & condutância (k) & 1,0 \\
\hline & taxa de difusão $(\Delta t)$ & 0,05 \\
\hline & $\mathrm{n}$ ㅇ de iterações & 20 \\
\hline \multirow{2}{*}{ F3 } & taxa de difusão $(\Delta t)$ & 0,05 \\
\hline & $\mathrm{n}$ ㅇ de iterações & 25 \\
\hline
\end{tabular}

\begin{tabular}{llc}
\hline \multicolumn{2}{c}{ Parâmetros dos Algoritmos de Contornos Ativos } \\
\hline \multirow{2}{*}{ C1 } & fator de continuidade $(\alpha)$ & 0,1 \\
& fator de suavização $(\beta)$ & 0,1 \\
& fator externo $(\gamma)$ & 1,5 \\
& & \\
& fator de continuidade $(\alpha)$ & 1,5 \\
C2 & fator de suavização $(\beta)$ & 2,2 \\
& fator externo $(\gamma)$ & 0,5 \\
& janela de vizinhos & $3 \times 3$ pixels \\
& & 1,0 \\
& fator interno $\left(w_{\text {in }}\right)$ & 0,5 \\
C3 & fator externo $\left(w_{\text {ex }}\right)$ & $-1,2$ \\
& fator de amortecimento $\left(w_{\text {damp }}\right)$ &
\end{tabular}


A Tabela 5.1 repete a nomenclatura dos filtros e algoritmos de contornos ativos adotada no capítulo anterior, enquanto que a Tabela 5.2 apresenta os valores dos principais parâmetros utilizados.

O ajuste dos parâmetros dos filtros constituiu uma tarefa crítica, dada a sua importância na etapa de inicialização dos contornos ativos, conforme descrito em 4.5.4. Um adequado balanceamento precisava ser encontrado para que a necessária atenuação do ruído não deformasse excessivamente as interfaces de interesse, especialmente a média-adventícia da parede distal, haja visto que a camada conjunta íntima-média é bastante delgada e uma pequena alteração poderia implicar em uma distorção considerável na medição da EIM.

A Figura 5.1 apresenta os resultados visuais obtidos com o modelo matemático durante a etapa de inicialização ao se empregar cada um dos filtros, antes da aplicação dos algoritmos de contornos ativos.

F1: Gaussiano

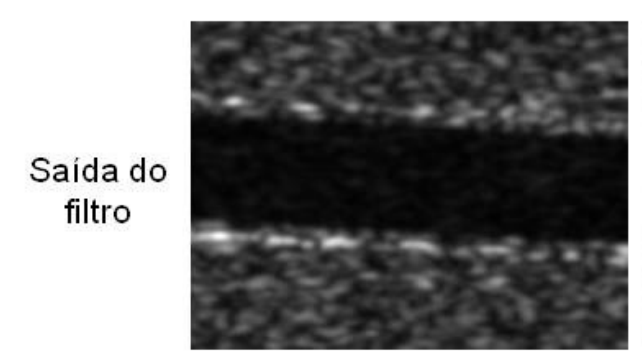

Derivada na direção axial (vertical)

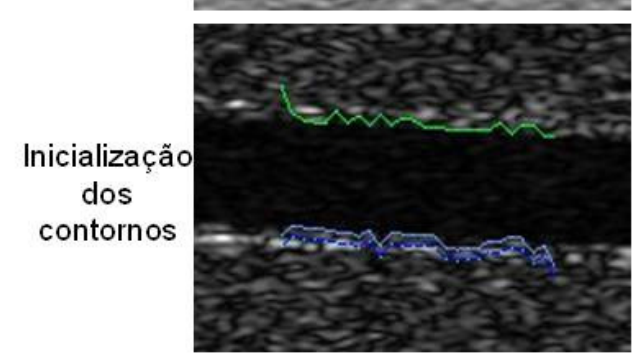

F2: Difusão Anisotrópica
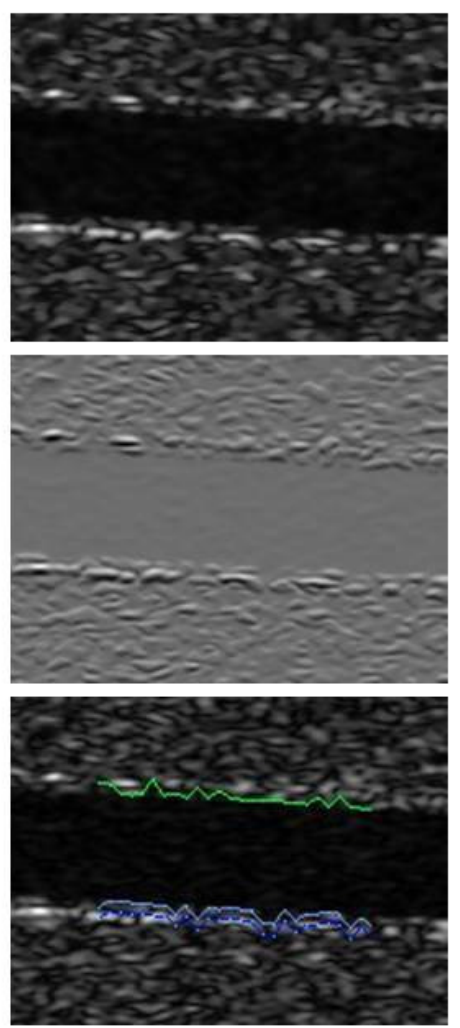

F3: SRAD
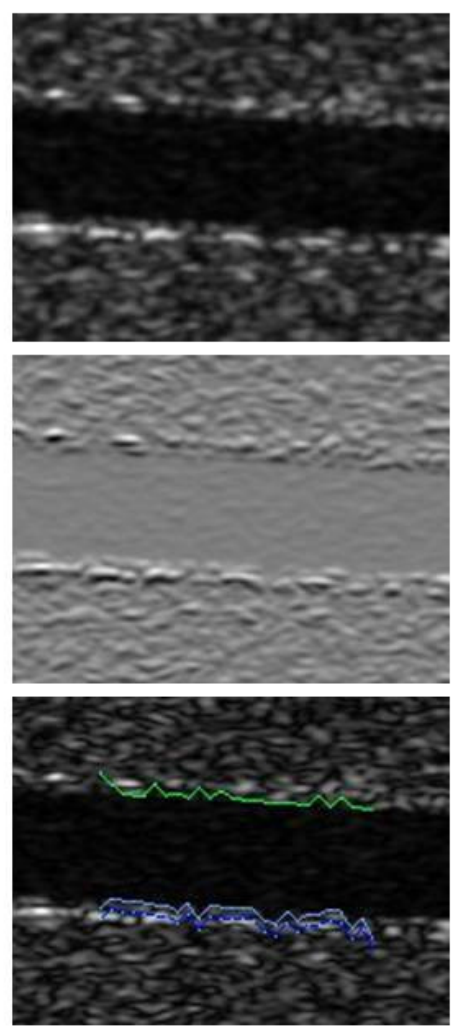

Figura 5.1 - Imagens do phantom nas saídas dos filtros (linha superior) indicados em cada coluna como F1, F2 ou F3; derivada de 1ㄹ. ordem na direção axial das correspondentes imagens filtradas (linha intermediária); e inicialização dos contornos ativos desenhados sobre a imagem original do phantom (linha inferior). Os parâmetros dos filtros estão indicados na Tabela 5.2. 
$\mathrm{Na}$ linha superior estão as imagens referentes às saídas dos filtros. Salientando que os parâmetros foram ajustados para se alcançar os melhores resultados finais, inclusive com as imagens reais, nota-se que $F 2$ foi o filtro que melhor preservou as bordas. As vantagens inerentes a F3 para a redução de speckle, através de uma maior quantidade de iterações do filtro SRAD, não puderam ser melhor aproveitadas devido ao efeito colateral de perda da qualidade da imagem na estreita camada conjunta íntima-média da parede distal.

Na linha intermediária estão as derivadas de primeira ordem na direção axial (vertical) das imagens filtradas com o objetivo de realçar, pelos tons mais claros, a transição das regiões mais escuras para as mais claras no sentido de cima para baixo da imagem, conforme requerido para a detecção das interfaces de interesse. Tais imagens atuaram como a energia ou força externa durante as iterações dos contornos ativos. Estas derivadas também mostram que F2 atenuou melhor o ruído no interior da luz arterial, sem suavizar as bordas demasiadamente.

Os contornos iniciais, vistos na linha inferior da Figura 5.1, estão desenhados sobre a imagem sintética original. Pela comparação visual dos resultados entre os três filtros, F1 e F3 apresentaram uma pequena desvantagem em relação a F2, pois o primeiro ponto do contorno da interface íntima-luz penetrou na parede proximal por causa de uma suavização excessiva da interface.

As inicializações foram suficientes para que, na sequência, os algoritmos de contornos ativos executassem, automaticamente, os ajustes finos para a segmentação das paredes arteriais. A Figura 5.2 mostra três exemplos dos contornos finais, onde foram aplicados os algoritmos C1, C2 ou C3, após a inicialização realizada com o filtro F1.

C1: Kass/Witkin/Terzopoulos

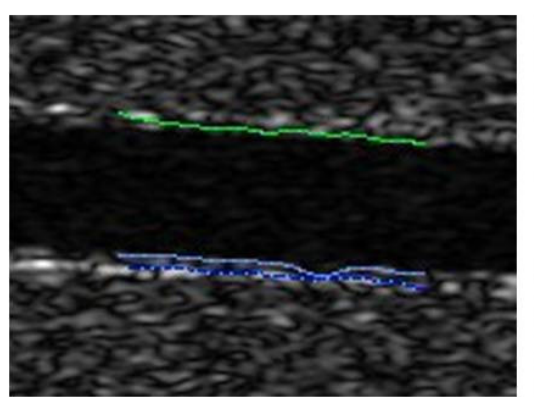

C2: Williams/Shah

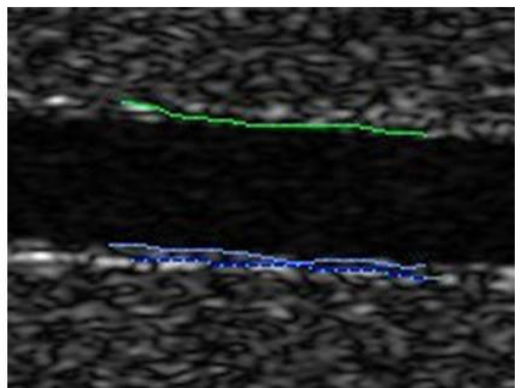

C3: Lobregt/Viergever

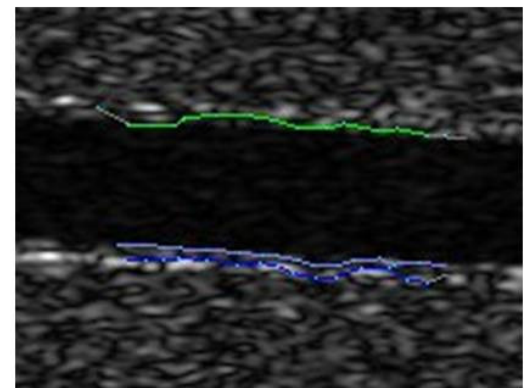

Figura 5.2 - Posição final dos contornos ativos sobre o phantom, com a aplicação dos algoritmos C1, C2 ou C3, após a inicialização realizada com o filtro F1. 
Os resultados numéricos das nove combinações de filtros e algoritmos aplicados sobre o phantom matemático estão apresentados na Tabela 5.3. Ela contém os cálculos da média $(\bar{x})$ e do desvio-padrão $(s d)$ das 121 amostras do DL e da EIM obtidas na posição final dos contornos ativos, segundo as expressões:

$$
\begin{array}{r}
\bar{x}=\frac{\sum_{n=1}^{N} x_{n}}{N} \\
s d=\sqrt{\frac{\sum_{n=1}^{N}\left(x_{n}-\bar{x}\right)^{2}}{N-1}}
\end{array}
$$

onde $x_{n}$ é o DL ou a EIM de cada amostra $n$ e $N$ é o total de amostras (DL ou EIM), sendo que para compor o conjunto de amostras das distâncias entre dois contornos ativos, foram considerados os pontos (vértices) dos contornos ativos e suas interpolações (pixel a pixel).

Os valores médios do DL e da EIM foram comparados com o valor conhecido $(X)$ do phantom para estimar 0 erro percentual $\varepsilon \%$, conforme a expressão (5.3), e os resultados estão apresentados nas correspondentes colunas de erro da Tabela 5.3 e ilustrados no Gráfico 5.1.

$$
\varepsilon \%=\frac{\bar{x}-X}{X} \cdot 100
$$

Tabela 5.3 - Comparação entre os valores conhecidos do phantom e os cálculos do DL e da EIM para 9 combinações de filtros e algoritmos de contornos ativos, com 121 amostras em cada caso. $\mathrm{Na}$

\begin{tabular}{|c|c|c|c|c|c|c|}
\hline \multirow{3}{*}{$\begin{array}{c}\text { Filtro I } \\
\text { Algoritmo }\end{array}$} & \multicolumn{3}{|c|}{ Diâmetro da Luz (DL) } & \multicolumn{3}{|c|}{ Espessura Íntima-Média (EIM) } \\
\hline & \multicolumn{2}{|c|}{ valor conhecido $(\mathrm{mm})$ : } & \multirow{2}{*}{$\begin{array}{c}5,78 \\
\varepsilon(\%)\end{array}$} & \multicolumn{2}{|c|}{ valor conhecido (mm): } & \multirow{2}{*}{$\begin{array}{c}0,44 \\
\varepsilon(\%)\end{array}$} \\
\hline & $\begin{array}{c}\bar{x} \\
(\mathrm{~mm})\end{array}$ & $\begin{array}{c}\text { sd } \\
(\mathrm{mm})\end{array}$ & & $\begin{array}{c}\bar{x} \\
(\mathrm{~mm})\end{array}$ & $\begin{array}{c}\text { sd } \\
(\mathrm{mm})\end{array}$ & \\
\hline $\mathrm{F} 1 \mathrm{C} 1$ & 5,86 & 0,16 & 1,38 & 0,49 & 0,11 & 11,36 \\
\hline $\mathrm{F} 2 \mathrm{C} 1$ & 5,82 & 0,16 & 0,69 & 0,48 & 0,11 & 9,09 \\
\hline $\mathrm{F} 3 \mathrm{C} 1$ & 5,77 & 0,08 & $-0,17$ & 0,50 & 0,10 & 13,64 \\
\hline $\mathrm{F} 1 \mathrm{C} 2$ & 5,89 & 0,16 & 1,90 & 0,42 & 0,13 & $-4,55$ \\
\hline $\mathrm{F} 2 \mathrm{C} 2$ & 5,88 & 0,12 & 1,73 & 0,44 & 0,13 & 0,00 \\
\hline $\mathrm{F} 3 \mathrm{C} 2$ & 5,83 & 0,16 & 0,87 & 0,41 & 0,18 & $-6,82$ \\
\hline $\mathrm{F} 1 \mathrm{C3}$ & 5,76 & 0,28 & $-0,35$ & 0,50 & 0,13 & 13,64 \\
\hline $\mathrm{F} 2 \mathrm{C} 3$ & 5,76 & 0,24 & $-0,35$ & 0,54 & 0,14 & 22,73 \\
\hline $\mathrm{F} 3 \mathrm{C} 3$ & 5,68 & 0,30 & $-1,73$ & 0,49 & 0,22 & 11,36 \\
\hline Aplicativo & 6,11 & $\mathrm{NC}$ & 5,71 & 0,43 & $\mathrm{NC}$ & $-2,27$ \\
\hline
\end{tabular}
última linha foram acrescentados, como referência, os resultados obtidos com um aplicativo computacional. 
A sintetização do phantom matemático foi baseada nas dimensões de uma imagem real da artéria carótida comum. Assim, para fazer uma analogia com dados reais, os valores, originalmente medidos em pixels, foram convertidos para milímetros na razão de $1 \mathrm{~mm} / 9$ pixels.

$\mathrm{Na}$ última linha da Tabela 5.3 foram acrescentados, para efeito comparativo, os resultados das medições realizadas com um aplicativo computacional especializado para o cálculo do DL e da EIM (GUTIERREZ et al., 2002; PILON, 2002).

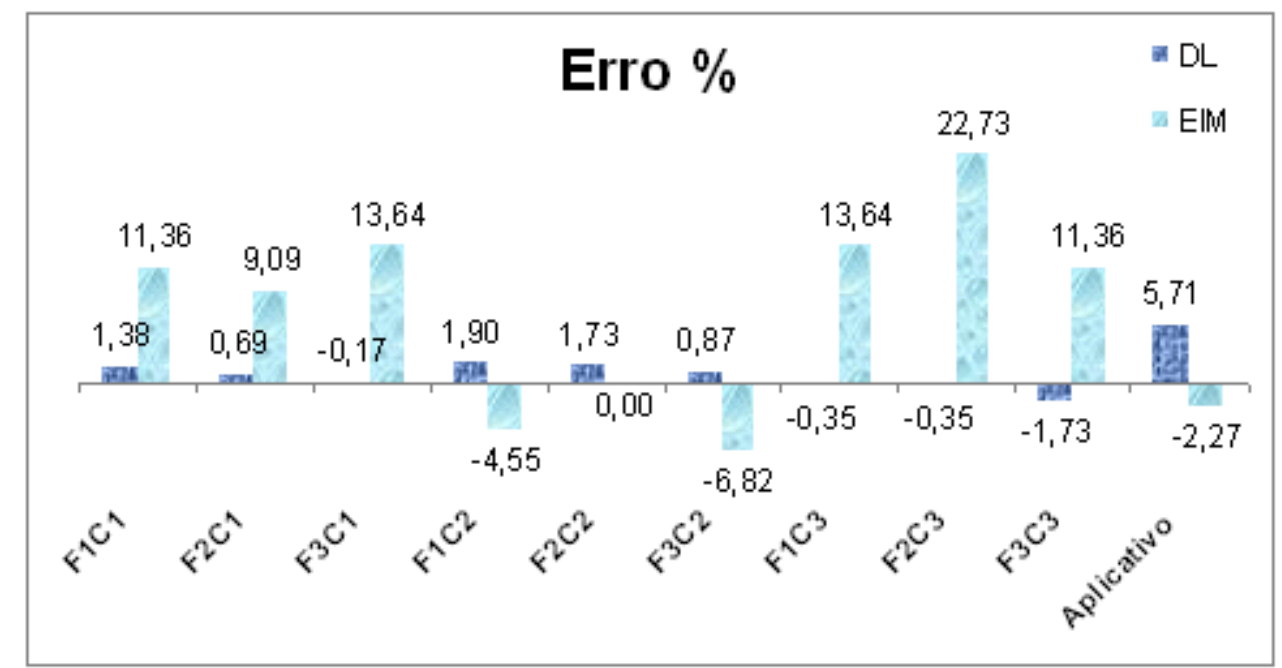

Gráfico 5.1 - Erros percentuais do DL e da EIM referentes aos valores do phantom, conforme a Tabela 5.3.

$\mathrm{Na}$ análise preliminar referente à etapa de inicialização dos contornos ativos, os resultados visuais indicavam que F2 apresentava um equilíbrio ligeiramente melhor entre a suavização da imagem e a preservação ou, até mesmo, a enfatização das bordas. Pelos dados quantitativos, porém, não é possível afirmar que a escolha de um dos filtros tenha proporcionado melhores resultados que os demais. Isso pode significar que os contornos ativos, por si mesmos, tendem a compensar as pequenas diferenças entre os filtros. Com efeito, os erros percentuais do $\mathrm{DL}$ foram muito baixos, semelhantes entre si para cada algoritmo e, além disso, consideravelmente menores que aquele obtido através do aplicativo.

Os erros percentuais da EIM devem ser tratados à parte devido a sua reduzida dimensão que faz com que a diferença de um único pixel represente $25 \%$ de erro para o phantom utilizado. Isso justifica também o alto desvio-padrão em 
relação à média para cada combinação. Apesar da elevada magnitude do erro em vários casos, há alguma semelhança entre si para cada algoritmo, como ocorreu nos cálculos do DL, o que também pode indicar que pequenas diferenças entre os filtros foram compensadas pela atuação dos contornos ativos.

Entre as nove combinações de filtros e algoritmos de contornos ativos, F3C1 (filtro SRAD e algoritmo de Kass, Witkin e Terzopoulos) proporcionou o melhor resultado para $0 \mathrm{DL}$, com a menor magnitude de erro, inclusive em relação ao aplicativo, e com o menor desvio-padrão. Para a EIM a melhor combinação foi F2C2 (filtro de difusão anisotrópica e algoritmo de Williams e Shah), onde o erro nulo é justificado pelo arredondamento após o cálculo da média das amostras.

\subsection{Ensaios com imagens reais da artéria carótida em modo-B}

Conservando-se a mesma nomenclatura da Tabela 5.1 e os mesmos parâmetros da Tabela 5.2 utilizados nos ensaios com o phantom, alguns resultados visuais obtidos durante a etapa de inicialização dos contornos com imagens reais da artéria carótida comum ${ }^{2}$ são apresentados na Figura 5.3, em caráter ilustrativo.

De forma geral, pode-se repetir os mesmos comentários expostos na apresentação da Figura 5.1 para a imagem sintética e, aqui, nota-se novamente que, neste exemplo com imagem real, F2 apresentou um melhor comportamento que os demais filtros ao reduzir o ruído e enfatizar as bordas. No entanto, para a inicialização dos contornos mostrada na linha inferior da Figura 5.3, as diferenças entre os filtros não tiveram impacto relevante, pois os contornos ficaram muito parecidos entre si nas três situações.

Como era desejado, a etapa de inicialização atendeu o propósito de aproximar os contornos suficientemente das interfaces das paredes arteriais, de tal forma que o processo de iteração dos algoritmos de contornos ativos pudesse atingir uma situação de estabilidade final. Três exemplos com imagens reais são mostrados na Figura 5.4 após a inicialização com o filtro F1 e a aplicação dos algoritmos C1, C2 ou C3.

\footnotetext{
${ }^{2} \mathrm{O}$ tamanho da imagem real original é $640 \times 480$ pixels. Os recortes que apresentam detalhes da imagem têm dimensão de $200 \times 150$ pixels.
} 
F1: Gaussiano

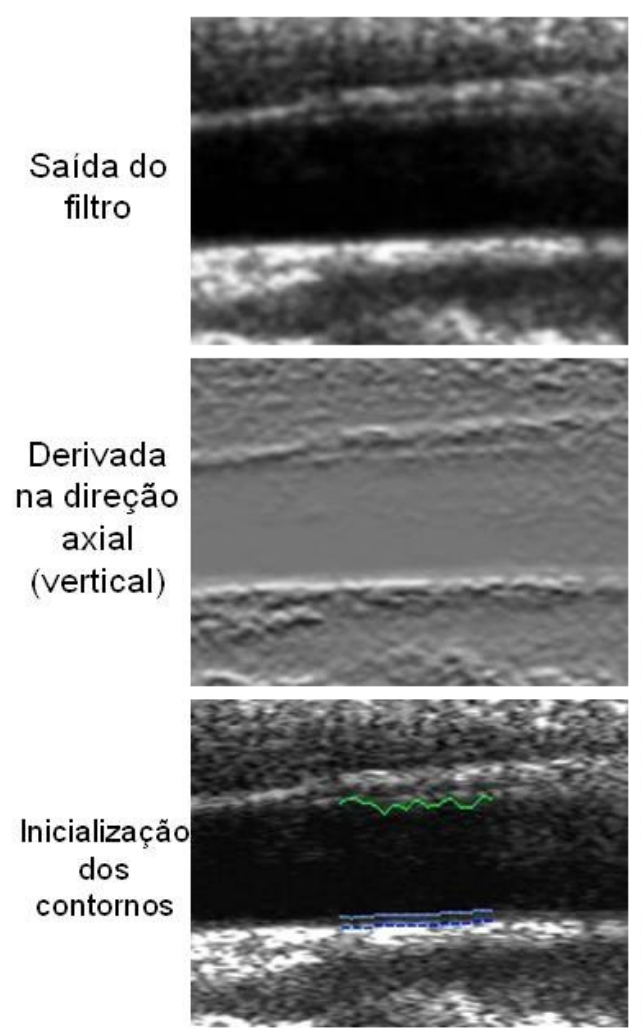

F2: Difusão Anisotrópica
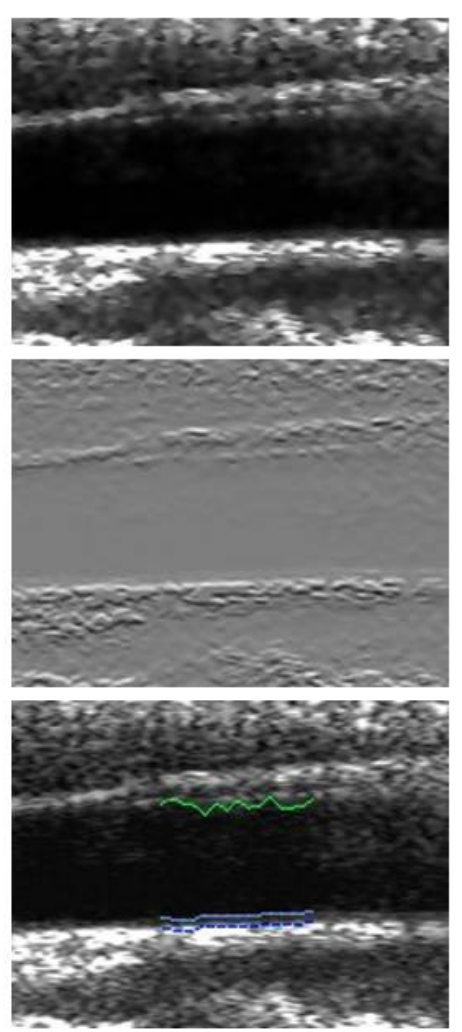

F3: SRAD
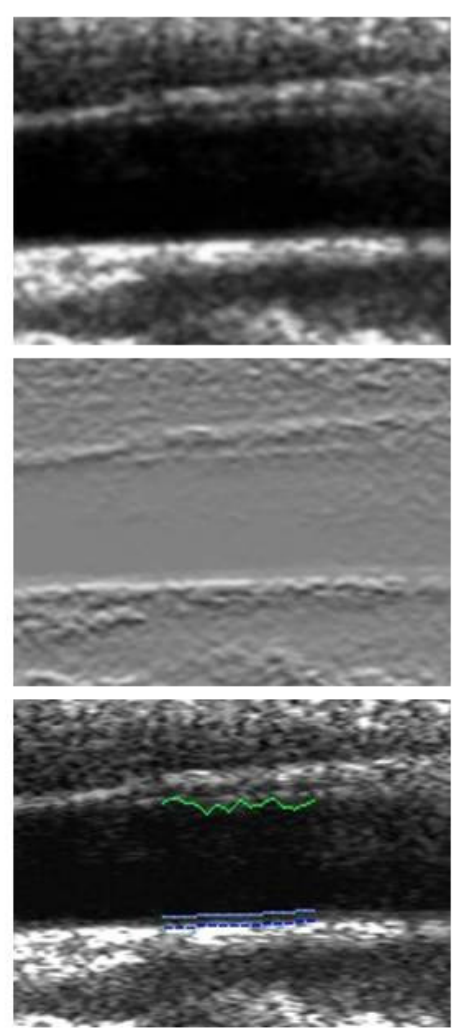

Figura 5.3 - Imagens reais da artéria carótida comum nas saídas dos filtros (linha superior) indicados em cada coluna como F1, F2 ou F3; derivada de 1'a ordem na direção axial das correspondentes imagens filtradas (linha intermediária); e inicialização dos contornos ativos desenhados sobre a imagem original (linha inferior). Os parâmetros dos filtros estão indicados na Tabela 5.2.

Naturalmente, há pequenas diferenças nos resultados finais, mas, em uma análise subjetiva, percebe-se que as três interfaces foram corretamente detectadas pelos três algoritmos.

\section{C1: Kass/Witkin/Terzopoulos}

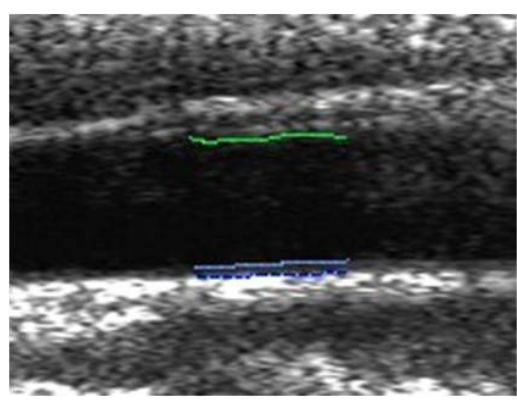

C2: Williams/Shah

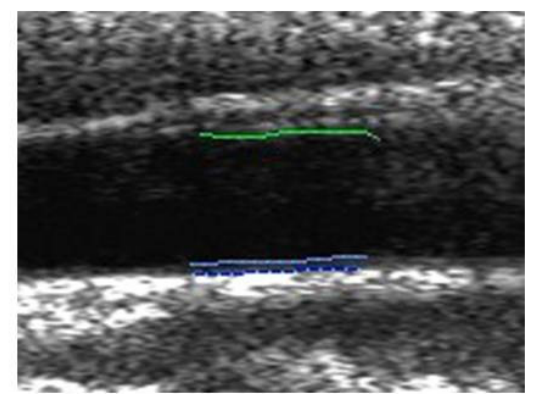

C3: Lobregt/Viergever

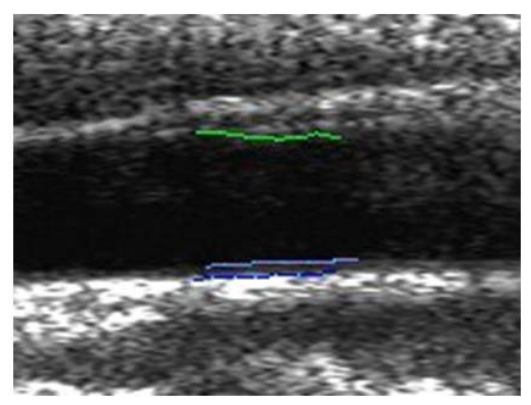

Figura 5.4 - Posição final dos contornos ativos sobre uma imagem real da artéria carótida comum, com a aplicação dos algoritmos C1, C2 e C3, após a inicialização realizada com o filtro F1. 
Para uma análise quantitativa recorreu-se novamente ao aplicativo computacional para o cálculo do DL e da EIM, utilizando estas medidas como referência para calcular o coeficiente de correlação de Pearson (COSTA NETO, 1977) (Gráfico 5.2) para cada combinação de filtros e algoritmos. Em cada caso, foram consideradas 7 amostras de pacientes distintos para o levantamento do gráfico.

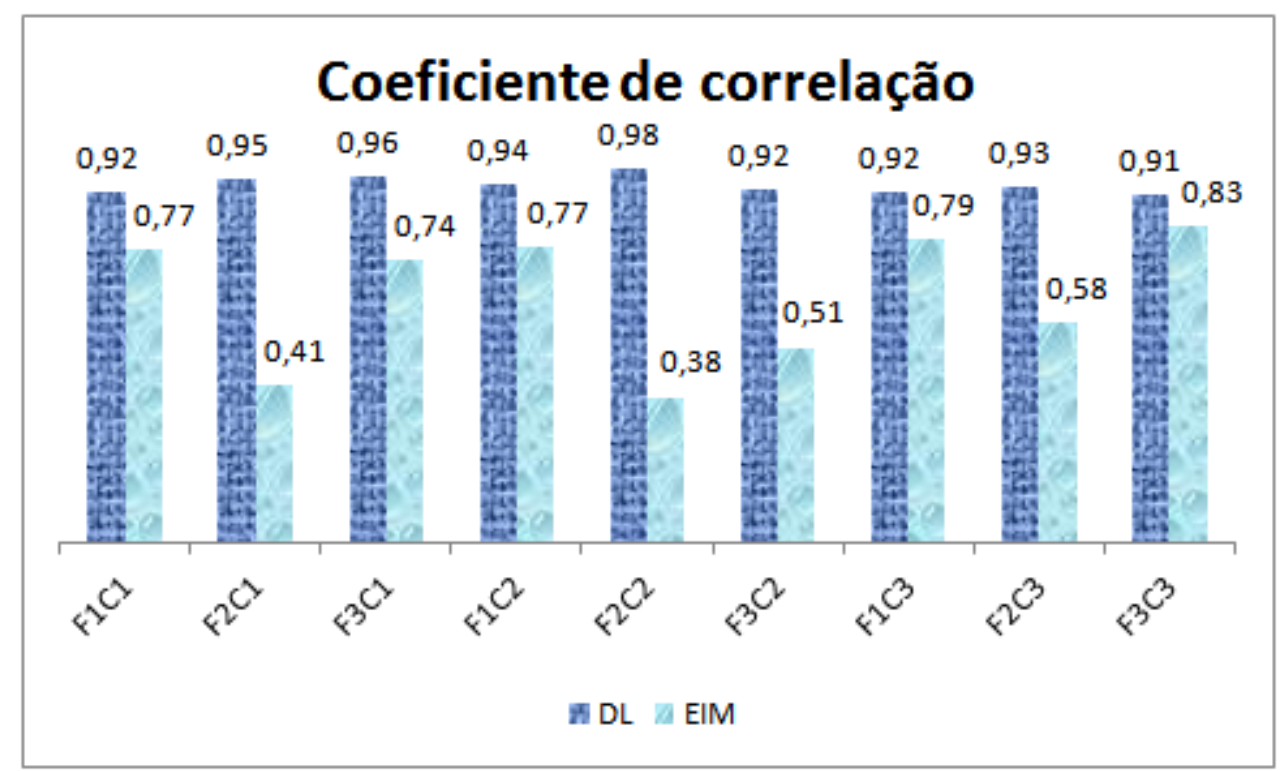

Gráfico 5.2 - Coeficientes de correlação de Pearson do DL e da EIM baseados em 7 amostras para cada combinação de filtro (F1, F2 ou F3) e algoritmo de contornos ativos (C1, C2 ou C3), tendo como referência as medidas obtidas por um aplicativo computacional.

Para o DL os resultados numéricos representados pelos coeficientes de correlação foram bastante semelhantes, indicando que, praticamente, não há distinção entre as nove combinações de filtros e algoritmos, como já tinha sido visualizado nas Figuras 5.3 e 5.4. A razão é que os parâmetros de F1, F2 e F3 (Tabela 5.2) foram cuidadosamente ajustados de modo que suavizassem o mínimo possível a imagem de entrada para não afetar excessivamente a fina camada íntima-média da parede distal; consequentemente, nesta situação de pouca suavização, os três filtros ainda mantêm comportamentos semelhantes.

Paralelamente, a similaridade dos resultados evidencia também que os coeficientes de ponderação das energias ou forças internas e externas dos três algoritmos de contornos ativos foram ajustados adequadamente para atingirem 0 mesmo fim. 
Além disso, todos os valores ficaram acima de 0,90, ou seja, há uma alta correlação para o cálculo do DL entre quaisquer combinações e 0 aplicativo computacional. Estes números também confirmam os ótimos resultados alcançados com o phantom, quando o maior erro encontrado foi 1,90\% (vide seção 5.2).

Para a EIM, porém, os coeficientes de correlação não foram satisfatórios. $O$ maior valor alcançado foi 0,83 ao se combinar o filtro F3 e o algoritmo C3. Como exposto anteriormente, convém ressaltar que a camada conjunta íntima-média é muito delgada e que uma pequena diferença na detecção das interfaces pode levar a uma distorção considerável no resultado da EIM, o que justifica os valores relativamente baixos e não uniformes da correlação.

\subsection{Medição da velocidade e do fluxo sanguíneos utilizando a técnica Doppler}

Conforme o procedimento utilizado, as velocidades de pico medidas na artéria carótida foram negativas, com um valor médio das amostras de -0,59 m/s. Na artéria braquial, tanto na condição basal como na resposta de hiperemia reativa, as velocidades de pico foram positivas, com as respectivas médias de 0,63 e 1,18 m/s. Finalmente, nas imagens de ecocardiografia as medições realizadas pelos clínicos foram negativas ou positivas, com uma média dos valores absolutos de 1,48 m/s.

De modo análogo, os sinais (positivos ou negativos) das VTIs dependeram do tipo de exame realizado; contudo, não houve uma padronização do número de ciclos cardíacos para a medição desta grandeza. As amostras variaram no intervalo de $-150 \mathrm{~cm}$ a $91 \mathrm{~cm}$.

O Gráfico 5.3 apresenta análises comparativas pelo método de Bland e Altman (1986) e pela regressão linear da velocidade de pico sistólico para o total de 102 amostras. A grandeza "A" corresponde às medições realizadas através dos sistemas de ultrassonografia e a grandeza "B" aos resultados obtidos pela metodologia proposta. O bias (ou viés) calculado como a diferença média: $\overline{A-B}$ e o desvio-padrão sd são mostrados na Tabela 5.4 que inclui o coeficiente de correlação de Pearson $r_{A B}$ (COSTA NETO, 1977) e a equação da reta de regressão. 


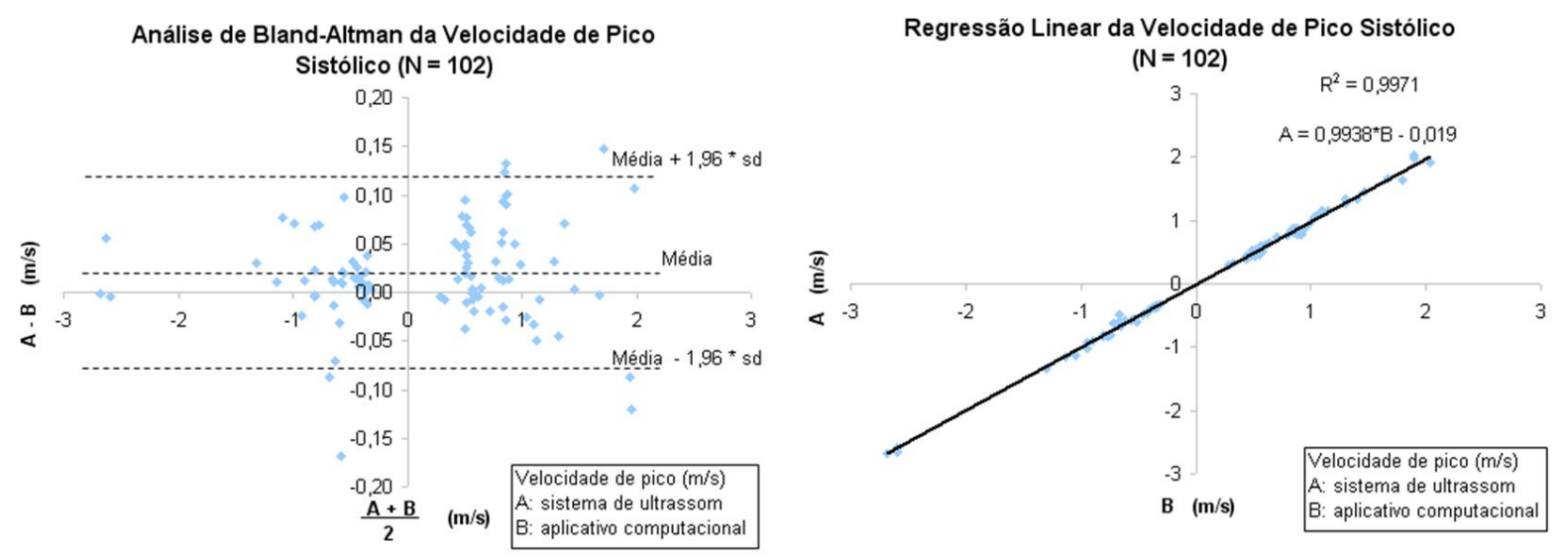

Gráfico 5.3 - Análises de Bland-Altman (esquerda) e Regressão Linear (direita) da velocidade de pico sistólico medida pelo sistema de ultrassonografia e pela metodologia proposta.

Tabela 5.4 - Resumo dos cálculos estatísticos da velocidade de pico sistólico.

\begin{tabular}{cccc}
\hline \multicolumn{4}{c}{ Velocidade de Pico Sistólico $(\mathrm{N}=102)$} \\
\hline $\begin{array}{c}\text { Bias } \\
(\mathbf{m} / \mathbf{s})\end{array}$ & $\begin{array}{c}\mathbf{s d} \\
(\mathbf{m} / \mathbf{s})\end{array}$ & $\begin{array}{c}\mathbf{r}_{\mathrm{AB}} \\
(\mathrm{p}<0,01)\end{array}$ & $\begin{array}{c}\text { Equação de } \\
\text { regressão linear }\end{array}$ \\
\hline 0,02 & 0,05 & 0,9985 & $\mathrm{~A}=0,9938^{*} \mathrm{~B}-0,0190$ \\
\hline
\end{tabular}

Tanto o bias quanto o desvio-padrão estimados foram muito baixos, como desejado, indicando que a metodologia proposta pode ser validada. No trabalho de Tschirren, Lauer e Sonka (2001) que propôs outra metodologia com objetivo semelhante, a magnitude do bias e o desvio-padrão da velocidade de pico sistólico foram maiores: $0,40 \mathrm{~m} / \mathrm{s}$ e $1,48 \mathrm{~m} / \mathrm{s}$, respectivamente. Há que se considerar, porém, que, naquele trabalho, os dados eram provenientes de um estudo de dilatação da artéria braquial, geralmente da ordem de grandeza 10 vezes superior às das amostras do presente estudo.

A expressão da reta de regressão, o coeficiente de correlação próximo a 1 e a disposição dos dados no Gráfico 5.3 corroboram a confiabilidade desta metodologia.

Como na análise da velocidade de pico, o método de Bland-Altman e a regressão linear aplicados à VTI resultaram no Gráfico 5.4 para o total de 75 amostras. Os valores calculados do bias, desvio-padrão, coeficiente de correlação e equação da reta de regressão linear estão dispostos na Tabela 5.5. Tschirren, Lauer e Sonka (2001) obtiveram um bias e um desvio-padrão maiores para a VTI: $7 \mathrm{~cm}$ e $122 \mathrm{~cm}$, respectivamente. 

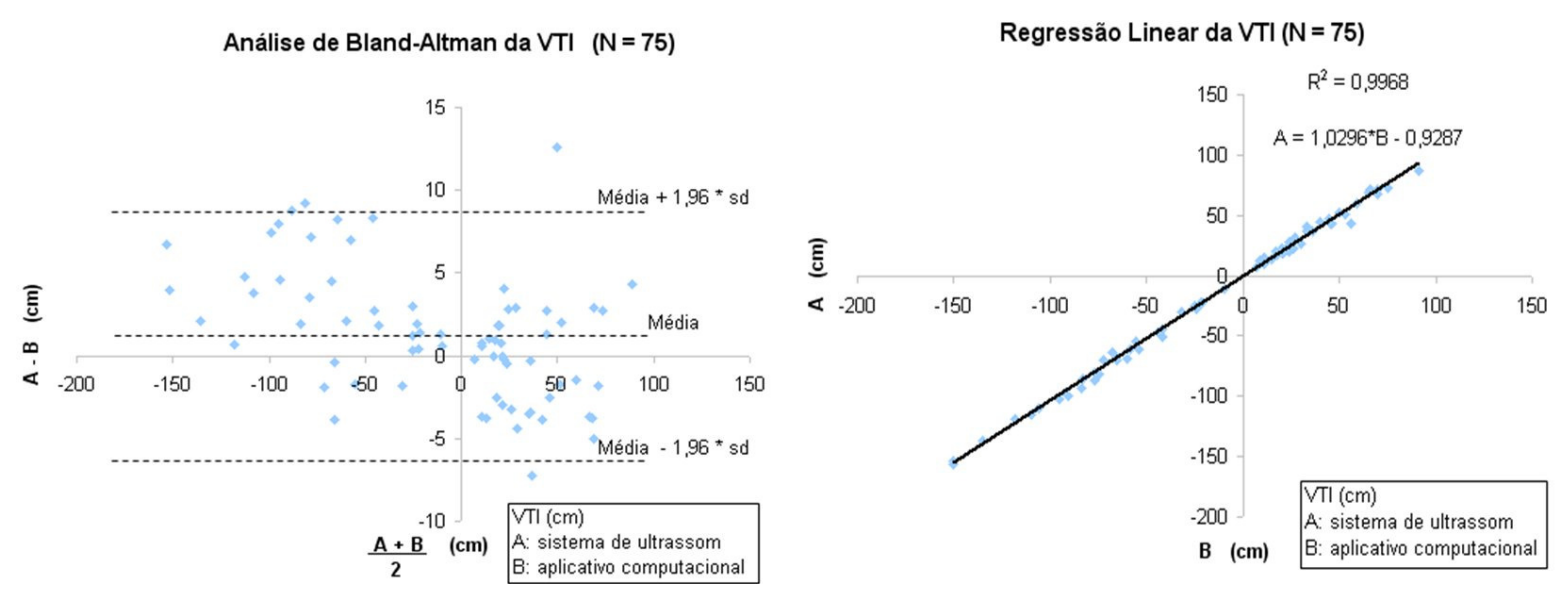

Gráfico 5.4 - Análises de Bland-Altman (esquerda) e Regressão Linear (direita) da VTI medida pelo sistema de ultrassonografia e pela metodologia proposta.

Tabela 5.5 - Resumo dos cálculos estatísticos da VTI.

\begin{tabular}{cccc}
\hline & \multicolumn{3}{c}{$\mathrm{VTI}(\mathrm{N}=75)$} \\
\hline $\begin{array}{c}\text { Bias } \\
(\mathbf{c m})\end{array}$ & $\begin{array}{c}\mathbf{s d} \\
(\mathbf{c m})\end{array}$ & $\begin{array}{c}\mathbf{r}_{\mathrm{AB}} \\
(\mathrm{p}<0,01)\end{array}$ & $\begin{array}{c}\text { Equação de } \\
\text { regressão linear }\end{array}$ \\
\hline 1,25 & 3,86 & 0,9984 & $\mathrm{~A}=1,030^{*} \mathrm{~B}-0,9287$ \\
\hline
\end{tabular}

Cabe observar que os resultados da VTI foram alcançados com um limiar de conversão da imagem de tons de cinza para binária (vide subitem "binarização" na seção 4.6) igual a 60. A alteração do limiar padrão de 40 utilizado na extração da velocidade de pico sistólico foi motivada pelos resultados mais próximos em relação às medidas através do sistema de ultrassonografia. Por exemplo, com o limiar de 40, na análise comparativa entre os dois métodos o bias e o desvio-padrão da VTI foram maiores: $1,70 \mathrm{~cm}$ e $6,78 \mathrm{~cm}$, respectivamente. Apesar destes dados, não se pode afirmar que o limiar de 60 é mais apropriado que o de 40, pois o procedimento manual do operador do equipamento de ultrassonografia também está sujeito a erros e aproximações.

Pela observação visual das envoltórias traçadas sobre os gráficos de velocidade nota-se que, pela metodologia proposta (Figura 4.7), a envoltória é mais rica em detalhes que na obtida pelo sistema de ultrassonografia (Figura 3.6), pois neste último o operador não percebe ou, simplesmente, desconsidera pequenas variações de brilho da imagem, em parte porque, para uma aproximação mais refinada, exige-se uma manipulação mais cuidadosa do trackball para desenhar o contorno. Assim, este procedimento, que é altamente dependente do operador, caracteriza-se pela subjetividade e difícil reprodutibilidade. 
O aplicativo computacional desenvolvido neste trabalho possibilita que, através de uma caixa de diálogo, o usuário altere o limiar de binarização do gráfico de velocidade. Este ajuste atua diretamente na detecção da envoltória, pois o seu incremento (ou decremento) faz com que todo o contorno seja deslocado para o interior (ou exterior) do espectro correspondente ao gráfico de velocidade, adequando-se ao critério do usuário. Os resultados visuais associados aos estatísticos foram determinantes na adoção do limiar de 40 para a conversão binária como o valor padrão da caixa de diálogo. 


\section{CONCLUSÃO}

\subsection{Conclusões e contribuições}

Após o ajuste dos parâmetros de cada filtro, com o equilíbrio entre a necessária atenuação do ruído e a preservação das interfaces de interesse, especialmente a média-adventícia da parede distal, o filtro de difusão anisotrópica, na sua proposição original, apresentou resultados visuais um pouco mais favoráveis que o gaussiano e o SRAD para a etapa de inicialização dos contornos. No entanto, os resultados da avaliação quantitativa através dos coeficientes de correlação foram similares para o DL, indicando que pequenas diferenças alcançadas pelos filtros podem ter sido compensadas pelos contornos ativos.

A avaliação quantitativa indicou também que a combinação do filtro SRAD e o algoritmo de Kass, Witkin e Terzopoulos destacou-se, entre as demais, pelo melhor resultado para o DL utilizando o phantom matemático.

Em contrapartida, os ótimos resultados encontrados para o DL, tanto com 0 phantom quanto com imagens reais, não foram alcançados para a EIM. A metodologia requer um tratamento específico para contornar o problema da reduzida dimensão da camada conjunta íntima-média que levou a variações indesejadas dos cálculos. Mesmo assim, pela análise quantitativa com o phantom matemático, obteve-se uma combinação ótima para o cálculo da EIM com o filtro de difusão anisotrópica e o algoritmo de Williams e Shah.

Utilizando uma diversidade de imagens Doppler das artérias carótida comum e braquial e de exames ecocardiográficos provenientes de quatro modelos distintos de sistemas comerciais de ultrassonografia, a metodologia implementada para os cálculos de velocidade e VTI foi validada pela análise de Bland-Altman e pelos coeficientes de correlação. A análise visual também confirmou que a detecção da envoltória do espectro do gráfico de velocidade é bastante satisfatória.

Como produto deste trabalho, um aplicativo executável em computadores pessoais pode ser disponibilizado e facilmente utilizado pelos clínicos que tenham 
interesse em estudar possíveis relações entre a velocidade ou fluxo sanguíneo e doenças cardiovasculares, entre outras aplicações.

A combinação da interface gráfica amigável para o usuário e a característica semiautomática desta ferramenta computacional elimina a delineação manual da envoltória e, consequentemente, proporciona as seguintes vantagens: redução do tempo operacional, redução da subjetividade correspondente à simplificação ou não percepção do operador para acompanhar as variações de brilho da imagem e aumento do grau de reprodutibilidade dos resultados.

Além do aplicativo supra, os códigos dos filtros e algoritmos desenvolvidos na linguagem de programação $\mathrm{C}_{++}$, com auxílio do ITK, estarão disponíveis para uso no InCor.

Finalmente, outra contribuição foi a edição e a aplicação de um phantom matemático para representar uma imagem de ultrassonografia $2 \mathrm{D}$ da artéria carótida. Tal imagem, corrompida com um ruído multiplicativo para simular o speckle, foi útil para a determinação dos parâmetros dos filtros e dos contornos ativos dentro de um ambiente controlado. Ao se alternar entre este ambiente e a situação com imagens reais, o ajuste fino destes parâmetros foi facilitado. A comparação visual entre os resultados a partir das imagens sintética (Figuras $5.1 \mathrm{e}$ 5.2) e real (Figuras 5.3 e 5.4) mostra que o phantom, dentro das suas limitações, está representando satisfatoriamente a imagem real para esta aplicação.

\subsection{Trabalhos futuros}

Apesar dos resultados das diversas combinações de filtros e algoritmos de contornos ativos não terem apresentado diferenças significativas, fica aberta a possibilidade de incorporar ao código de programação novas técnicas de filtragem, como a difusão anisotrópica robusta proposta por Black et al. (1998) e algoritmos de contornos ativos, como os snakes não-paramétricos propostos por Ozertem e Erdogmus (2007).

Outro campo para posterior desenvolvimento é a exploração de uma lacuna decorrente de uma limitação do ITK: esta ferramenta computacional não dispõe de 
uma interface gráfica que certamente facilitaria a interação com o usuário, de modo que todo o processamento foi realizado através de linhas de comando.

Uma proposta interessante que possibilita o aproveitamento dos módulos baseados no ITK, visto que também utiliza a linguagem de programação $\mathrm{C}_{++}$, é o Medical Image Processing and Visualization (MeVisLab) (2009). Assim como o ITK, - MeVisLab na versão SDK é gratuito e conta com a colaboração de usuários em todo o mundo no seu desenvolvimento. $O$ amplo conjunto de classes do ITK pode ser combinado com a plataforma visual e de interação intuitiva com o usuário do MeVisLab para o processamento das imagens médicas.

No entanto, o estudo do MeVisLab e a instalação deste e de outros pacotes de software necessários para a integração com o ITK ocuparam um tempo considerável na etapa inicial. Na sequência, a complexidade para a programação dentro do ambiente do MeVisLab fez com que a sua incorporação neste trabalho fosse postergada. 


\section{REFERÊNCIAS}

AL-BAYATI, A. K. S.; ALJUDI, A. A. R. Novel design of a simple and accurate white gaussian noise generator, International Journal of Electronics, v. 70, n. 2, p. 321-326, 1991.

AMATO, M. et al. Carotid intima-media thickness by B-mode ultrasound as surrogate of coronary atherosclerosis: correlation with quantitative coronary angiography and coronary intravascular ultrasound findings, European Heart Journal, v. 28, n. 17, p. 2094-2101, 2007.

AMINI, A. A.; WEYMOUTH, T. E.; JAIN, R. C. Using dynamic programming for solving variational problems in vision, IEEE Transactions on Pattern Analysis and Machine Intelligence, v. 12, n. 9, p. 855-867, 1990.

ATL. Apogee 800Plus ultrasound system reference manual. Rev. A 9/96, 1996, (4703-0019-03).

BAMBER, J. C.; TRISTAM, M.; WEBB, S. (Ed.). The physics of medical imaging: diagnostic ultrasound (ch. 7). London: IOP Publishing, 1993. 633 p.

BLACK, M. J. et al. Robust anisotropic diffusion, IEEE Transactions on Image Processing, v. 7, n. 3, p. 421-432, 1998.

BLAND, J. M.; ALTMAN, D. G. Statistical methods for assessing agreement between two methods of clinical measurement, The Lancet, v. 327, n. 8476, p. 307-310, 1986.

BOTS, M. L. et al.. Common carotid intima-media thickness and risk of stroke and myocardial infarction, the Rotterdam study, Circulation, v. 96, p. 1432-1437, 1997.

BOTS, M. L. et al. Carotid intima-media thickness and coronary atherosclerosis: weak or strong relations?, European Heart Journal, v. 28, n. 4, p. 398-406, 2007.

CARVALHO, R. T. de et al. Exercício resistido na avaliação da disfunção endotelial na insuficiência cardíaca, Arquivos Brasileiros de Cardiologia, São Paulo, v. 86, n. 6, p. 459-465, 2006. 
COHEN, I.; COHEN, L. D.; AYACHE, N. Using deformable surfaces to segment 3D images and infer differential structures, CVGIP: Image Understanding, v. 56, n. 2, p. 242-263, 1992.

CORRETTI, M. C. et al. Guidelines for the ultrasound assessment of endothelial-dependent flow-mediated vasodilation of the brachial artery: A report of the International Brachial Artery Reactivity Task Force, Journal of the American College of Cardiology, v. 39, n. 2, p. 254-265, 2002.

COSTA NETO, P. L. de O. Estatística. São Paulo: Edgard Blücher, 1977. 264 p.

FISH, P. Physics and instrumentation of diagnostic medical ultrasound. Chichester, England: John Wiley \& Sons Ltd, 1990. 250 p.

FROST, V. S. et al. A model for radar images and its application to adaptive digital filtering of multiplicative noise, IEEE Transactions on Pattern Analysis and Machine Intelligence, v. PAMI-4, n. 2, 1982.

GERHARD-HERMAN, M. et al. Guidelines for noninvasive vascular laboratory testing: a report from the American Society of Echocardiography and the Society for Vascular Medicine and Biology, Vascular Medicine, v. 11, n. 3, p. 183200, 2006.

GONZALEZ, R. C.; WOODS, R. E. Digital image processing. $2^{\text {nd }}$ ed. Upper Saddle River, N. J.: Prentice Hall, 2002. 793 p.

GUTIERREZ, M. A. et al. Automatic measurement of carotid diameter and wall thickness in ultrasound images. In: Computers in Cardiology 22-25 Sep 2002, p. 359-362. Disponível em:

$<\mathrm{http}$ ://ieeexplore.ieee.org/stamp/stamp.jsp?tp=\&arnumber=1166783\&isnumber=263 05?tag=1 http://www. >. Acesso em: 11 ago. 2009.

HOSKINS, P. R. Measurement of arterial blood-flow by Doppler ultrasound, Clinical Physics and Physiological Measurement, v. 11, n. 1, p. 1-26, 1990.

IBÁÑEZ, L.; SCHROEDER, W. The ITK software guide - the insight segmentation and registration toolkit. Kitware Inc, 2005. $787 \mathrm{p}$.

KASS, M.; WITKIN, A.; TERZOPOULOS, D. Snake: active contour models, International Journal of Computer Vision, v. 1, p. 321-331, 1988. 
KOENDERINK, J. J. The structure of images, Biological Cybernetics, v. 50, n. 5, p. 363-370, 1984.

LAGE, S. G. et al. Angiotensin II contributes to arterial compliance in congestive heart failure, American Journal of Physiology - Heart and Circulatory Physiology, v. 283, n. 4, p. H1424-H1429, 2002.

LATHI, B. P. Modern digital and analog communication systems. $2^{\text {nd }}$ ed. Orlando, Florida: Holt, Rinehart and Winston, Inc. 1989. 720 p.

LEE, J. S. Digital image enhancement and noise filtering by use of local statistics, IEEE Transactions on Pattern Analysis and Machine Intelligence, v. PAMI-2, n. 2, 1980.

LIANG, J.; McINERNEY, T.; TERZOPOULOS, D. United snakes, Medical Image Analysis, v. 10, p. 215-233, 2006.

LOBREGT, S.; VIERGEVER, M. A. A discrete dynamic contour model, IEEE Transactions on Medical Imaging, v. 14, n. 1, p. 12-24, 1995.

LORENZ, M. W. et al.. Prediction of clinical cardiovascular events with carotid intima-media thickness: a systematic review and meta-analysis, Circulation, v. 115, p. 459-467, 2007.

LYNCH, T. G.; HOBSON, R. W. (Ed.); WILSON, S. E. (Ed.); VEITH, F. J. (Ed.). Vascular surgery: principles and practice: noninvasive cerebrovascular diagnostic techniques (ch. 8). $3^{\text {rd }}$ ed., revised and expanded. Marcel Dekker, Inc., 2004. 1600 p.

McINERNEY, T.; TERZOPOULOS, D. Deformable models in medical image analysis: a survey, Medical Image Analysis, v. 1, n. 2, p. 91-108, 1996.

MEVISLAB. Medical Image Processing and Visualization. Disponível em : <http://www.mevislab.de/>. Acesso em: 06 ago. 2009.

NICHOLS, W.; O'ROURKE, M. McDonald's blood flow in arteries: theoretic, experimental and clinical principles: Doppler ultrasound for arterial blood flow measurement (ch. 7). $3^{\text {rd }}$ ed. Malvern, Philadelphia, USA: Lea \& Febiger, 1990. 456 p. 
O'LEARY, D. H. et al. Carotid-artery intima and media thickness as a risk factor for myocardial infarction and stroke in older adults, The New England Journal of Medicine, v. 340, n. 1, p. 14-22, 1999.

OZERTEM, U.; ERDOGMUS, D. Nonparametric snakes, IEEE Transactions on Image Processing, v. 16, n. 9, p. 2361-2368, 2007.

PERONA, P.; MALIK, J. Scale-space and edge detection using anisotropic diffusion, IEEE Transactions on Pattern Analysis and Machine Intelligence, v. 12, n. 7, p. 629-639, 1990.

PIGNOLI, P. et al. Intimal plus medial thickness of the arterial wall: a direct measurement with ultrasound imaging, Circulation, v. 74, n. 6, p. 1399-1406, 1986.

PILON, P. E. Método para a detecção automática de diâmetro de artérias em imagens de ultra-som. 2002. Dissertação (Mestrado) - Escola Politécnica, Universidade de São Paulo. São Paulo, 2002. 73 p.

ROHEN, J. W.; YOKOCHI, C.; LÜTJEN-DRECOLL, E. Anatomia humana: atlas fotográfico de anatomia sistêmica e regional. Tradução de Nader Wafae. 6ª . ed. Barueri, SP: Manole, 2007. 532 p.

ROUTH, H. F. Doppler ultrasound: the ability to measure and image blood flow, IEEE Engineering in Medicine and Biology Magazine, v. 15, n. 6, p. 31-40, 1996.

SALONEN, J. T.; SALONEN, R. Ultrasound B-mode imaging in observational studies of atherosclerotic progression, Circulation, v. 87 supplement II, p. II-56$65,1993$.

SCHWARTZ, M.; SHAW, L. Signal processing: discrete spectral analysis, detection, and estimation. New York: McGraw-Hill, 1975. 396 p.

SHUNG, K. K.; SMITH, M. B.; TSUI, B. M. W. Principles of medical imaging. Academic Press, University of Michigan, 1992. 289 p.

SIEMENS MEDICAL SOLUTIONS USA, INC. ACUSON Cypress ${ }^{\text {TM }}$ System $^{\text {SION }}$ Operator's Manual. Rev. A, 2002, Document No. 08267349. 
TSCHIRREN, J.; LAUER, R. M.; SONKA, M. Automated analysis of Doppler ultrasound velocity flow diagrams, IEEE Transactions on Medical Imaging, v. 20, n. 12 , p. 1422-1425, 2001.

UNIVERSIDADE DE SÃO PAULO. Escola Politécnica. Divisão de Biblioteca. Diretrizes para apresentação de dissertações e teses. 3.ed. São Paulo, 2006. $103 \mathrm{p}$.

WENDELHAG, I. et al. A new automated computerized analyzing system simplifies readings and reduces the variability in ultrasound measurement of intima-media thickness, Stroke, v. 28, p. 2195-2200, 1997.

WIKSTRAND, J. Methodological considerations of ultrasound measurement of carotid artery intima-media thickness and lumen diameter, Clinical Physiology and Functional Imaging, v. 27, n. 6, p. 341-345, 2007.

WILLIAMS, D. J.; SHAH, M. A fast algorithm for active contours and curvature estimation, CVGIP Image Understading, v. 55, n. 1, p. 14-26, 1992.

XU, C; PRINCE, J. L. Snakes, shapes, and gradient vector flow, IEEE Transactions on Image Processing, v. 7, n. 3, p. 359-369, 1998.

XU, C.; PHAM, D. L.; PRINCE, J. L.; SONKA, M. (Ed.); FITZPATRICK, J. M. (Ed.). Handbook of medical imaging: medical image processing and analysis (v. 2): image segmentation using deformable models (ch. 3). Washington: SPIE Press, 2000. 1218 p.

YAO, J. S. T.; HOBSON, R. W. (Ed.); WILSON, S. E. (Ed.); VEITH, F. J. (Ed.). Vascular surgery: principles and practice: noninvasive studies of peripheral vascular disease (ch. 7). $3^{\text {rd }}$ ed., revised and expanded. Marcel Dekker, Inc., 2004. $1600 \mathrm{p}$.

YU, Y.; ACTON, S. T. Speckle reducing anisotropic diffusion, IEEE Transactions on Image Processing, v. 11, n. 11, p.1260-1270, 2002.

ZAHALKA, A.; FENSTER, A. An automated segmentation method for threedimensional carotid ultrasound images, Physics in Medicine and Biology, v. 46, p.1321-1342, 2001. 


\section{APÊNDICE - TRABALHOS PUBLICADOS}

HIGA, M.; PILON, P. E.; LAGE, S. G.; GUTIERREZ, M. A. A computational tool for quantitative assessment of peripheral arteries in ultrasound images. In:

Computers in Cardiology 13-16 Sep 2009, Park City, UT. Oral presentation, 2009. No prelo.

HIGA, M.; REBELO, M. S.; SANTOS, C. S.; GUTIERREZ, M. A. Comparison of Three Different Derivative Approaches Aiming at Estimation of Image Movement. In: SIBGRAPI 7-10 Oct 2007, Belo Horizonte, MG. Technical Poster Session of the 20th Brazilian Symposium on Computer Graphics and Image Processing, 2007. 


\title{
A Computational Tool for Quantitative Assessment of Peripheral Arteries in Ultrasound Images
}

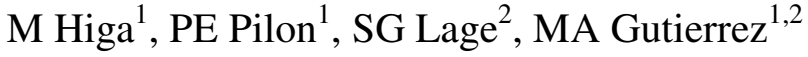 \\ ${ }^{1}$ Polytechnic School, University of São Paulo, São Paulo, Brazil \\ ${ }^{2}$ Heart Institute (InCor) - Medical School, University of São Paulo, São Paulo, Brazil
}

\begin{abstract}
Blood velocity vs. time graphic images, that are based on ultrasound Doppler technique, can be used to reveal relationships between data within them and the presence of cardiovascular diseases, among other applications. In clinical protocols, this kind of study involves, typically, hundreds of patients and a manual and tedious segmentation of the blood velocity curve from the images. In this paper we present a computational tool designed to extract quantitative data from these graphics. The algorithm detects the baseline and the spectrum envelope to calculate peak velocity and velocity-time integral (VTI). A comparative analysis between commercial ultrasound systems and the present methodology included measurements of carotid and brachial arteries and echocardiographic exams. The results showed small bias and high correlation for both: systolic peak velocity (bias $=0.02 \mathrm{~m} / \mathrm{s} ; r>0.998 ; p$ $<0.001 ; n=102$ ) and VTI (bias $=1.25 \mathrm{~cm} ; r>$ 0.998; $p<0.001 ; n=75$ ).
\end{abstract}

\section{Introduction}

Ultrasound signals have been extensively used in clinical sites, by exploiting Doppler effect to measure vascular blood velocity and flow, among other applications [1,2]. Typically, a spectrum of frequencies related to the different velocities of the blood cells is presented as a curve of velocity vs. time (Figure 1). This information can reveal important relationships between the frequency spectral pattern along the cardiac cycle and the presence of cardiovascular diseases [3,4], among other examples [5,6,7].

Since commercial ultrasound systems are primarily dedicated to get instantaneous data for individual patients, they have, in general, low flexibility to perform large-scale researches. Thus, to make easier this kind of study in clinical protocols involving hundreds of patients, a user friendly computational tool was developed to extract quantitative data from spectral display of Doppler images.

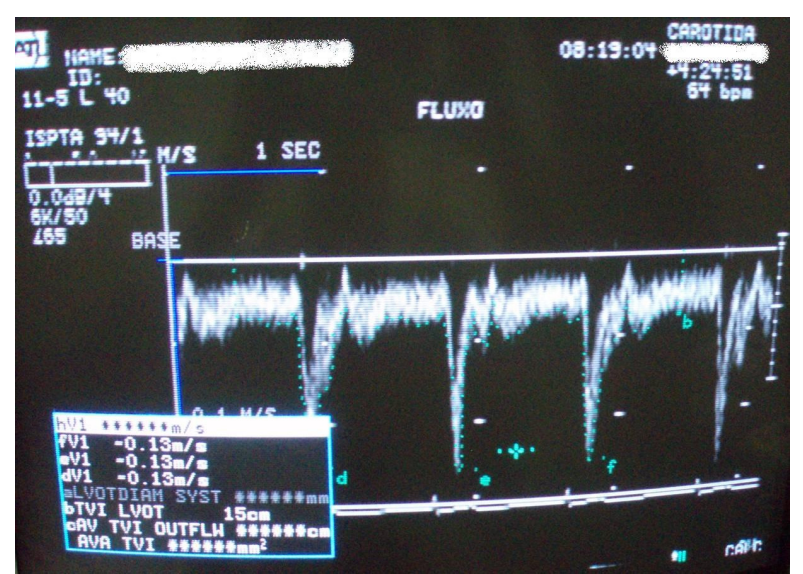

Figure 1. Typical screen of an ultrasound system showing a graphic of vessel's blood velocity vs. time, including amplitude and integral measurements.

The aim of this paper is to describe and evaluate the semi-automatic methodology to detect the spectrum envelope and to measure blood velocity, flow and velocity-time integral (VTI).

\section{Methods}

The spectral images displayed in the form of blood velocity vs. time graphics were acquired from four different ultrasound system models: a) Apogee 800 Plus (ATL, Bothell, WA, USA) equipped with a 115L40 linear transducer (5-11 MHz); b) Cypress ${ }^{\mathrm{TM}}$ (Acuson, Mountain View, CA, USA) - 7L3 (5.22 $\mathrm{MHz}$ ); c) HDI 5000 (Philips/ATL, Bothell, WA, USA) - P4-2 (2-4 MHz) or P5-3 (3-5 MHz); d) Sonos 5500 (HP/Philips, Bothell, WA, USA) - S3 (1-3 MHz) or S4 (2-4 MHz).

To extract blood velocity and flow a new module was added to a previously developed computational tool $[8,9]$, which, given B-mode ultrasound images as input data, was specialized for arterial wall thickness and lumen diameter measurements. An overview of the methodology used in this new module is presented below. 
After two steps defined by the user: calibration and selection of the region of interest (ROI), a Gaussian filter $(\sigma=1$ pixel, precision $\geq 90 \%$ ) is applied to the grayscale input image to attenuate high frequency noise.

The detection process of the time axis (' $X$ ') considers that it is exactly in the horizontal direction and their pixel intensities have small variation. Thus, equations (1), (2) and (3) calculates the ordinate ' $y$ ' expected for the axis ' $\mathrm{X}$ ', which will be the reference $(0 \mathrm{~m} / \mathrm{s})$ to the velocity calculation.

$$
\begin{aligned}
& g(i, j)=\left\{\begin{array}{cc}
\frac{1}{|I(i, j)-I(i+1, j)|+1}, \quad I(i, j)>z \\
0 \quad, \quad I(i, j) \leq z
\end{array}\right. \\
& f(j)=\sum_{i=0}^{m-2} g(i, j), \quad j \in\left[y_{\text {min }}, y_{\text {max }}\right] \\
& y=\left\{j \in\left[y_{\text {min }}, y_{\text {max }}\right] \quad \mid \quad f(y)=\max f(j)\right\}
\end{aligned}
$$

where:

$I(i, j)$ is the image intensity (grayscale level) at $i$ and $j$ coordinates; $\mathrm{m}$ is the image width (in pixels); $\mathrm{y}_{\min }$ and $\mathrm{y}_{\max }$ are, respectively, the ordinates of the superior and inferior lines that delimit the rectangular ROI defined by the user; and $\mathrm{z}=40$ is an empirical pre-defined threshold to reject the graphic background which, in general, has darker colors.

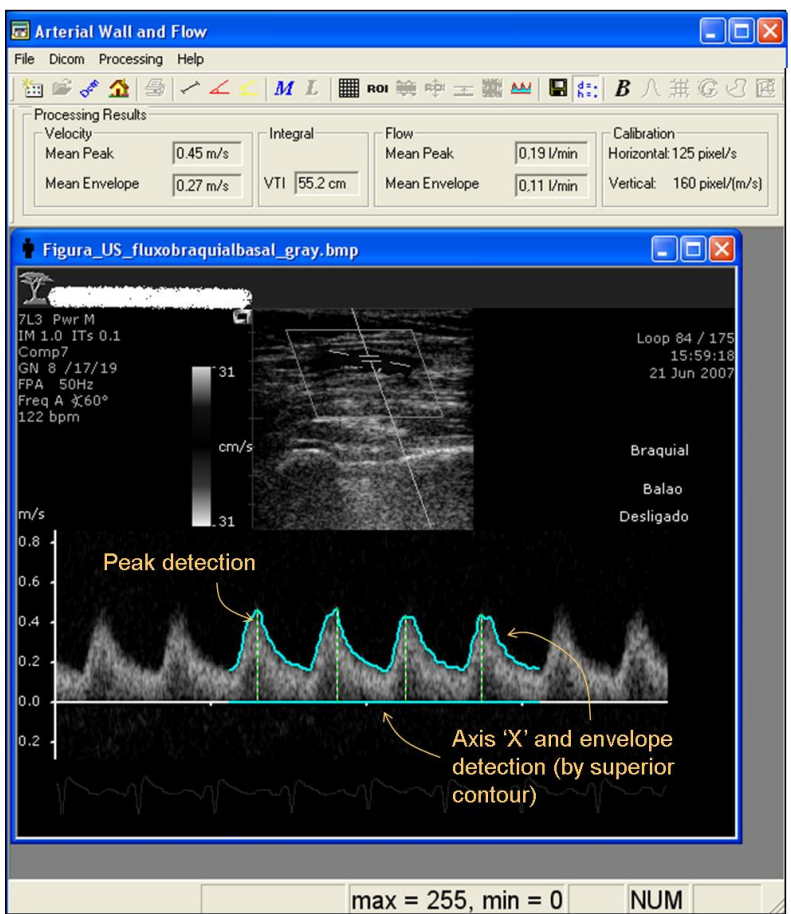

Figure 2. Detection of the axis ' $\mathrm{X}$ ', envelope (by superior or inferior contour) and peaks.
The image is, then, converted to binary values depending on a threshold level (default: 40) that can be adjusted by the user according to his criterion. A Median filter (size: $3 \times 3$ pixels) is applied to the binary image for edge smoothing and spurious suppression.

The envelope detection step is initialized with horizontal lines at the top and at the bottom of the ROI. Each point of these lines is moved down or up to the border of the binary curve. At last, the algorithm holds either the superior or the inferior contour (Figure 2 ), assuming that, in general, the desired one has higher amplitude variation.

Finally, after peak detections, the algorithm computes the mean peak velocity, the mean envelope velocity and the VTI. They are displayed in a bar measurements of the tool (Figure 2) and can be exported to a text file.

In addition, if B-Mode images are available, an arterial wall interface detection module determines the vessel diameter and the blood flow can be estimated.

A comparative analysis between ultrasound systems operated by specialists and the present methodology included systolic peak velocities (102 samples) and VTIs (75 samples) of common carotid and brachial arteries under basal condition, brachial arteries in the reactive hyperemic response and echocardiographic exams.

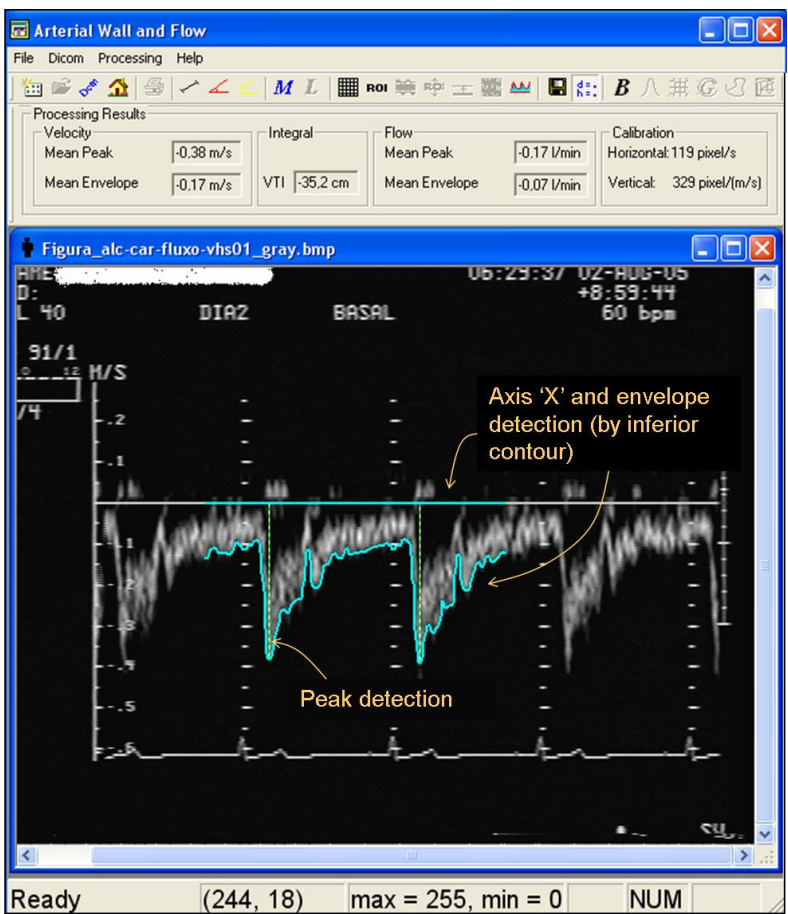

NUM 


\section{Results}

According to the adopted procedure, the peak velocities measured from the carotid artery were negative (average: $-0.59 \mathrm{~m} / \mathrm{s}$ ), while from the brachial artery under basal condition as well as in the reactive hyperemic response, the peak velocities were positive (averages: $0.63 \mathrm{~m} / \mathrm{s}$ and $1.18 \mathrm{~m} / \mathrm{s}$, respectively). In the echocardiographic images the measurements were either positive or negative and the average of the absolute values was $1.48 \mathrm{~m} / \mathrm{s}$.

Similarly, positive or negative VTIs were dependent on the exam type. However, the number of cardiac cycles used to get these measurements was not standardized, leading to a range of the samples, from 150 to $91 \mathrm{~cm}$.

Figure 3 shows Bland-Altman's [10] and Linear Regression graphics for the systolic peak velocity analysis, where ' $A$ ' refers to the measurements done with a commercial ultrasound system and ' $\mathrm{B}$ ' refers to the proposed methodology.

Bias, standard-deviation, correlation coefficient, and linear equation results are presented in Table 1. Like peak velocity, Figure 4 and Table 2 were obtained for VTI's analysis.
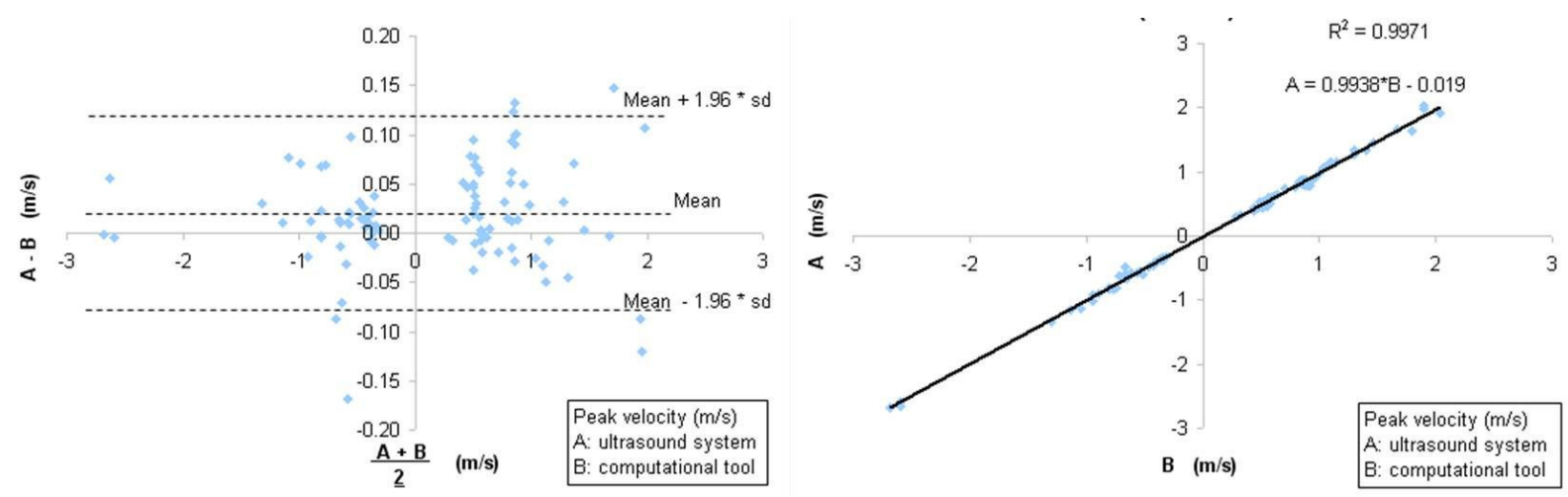

Figure 3. Bland-Altman's (left) and Linear Regression (right) analysis of the systolic peak velocity (102 samples) measured by the ultrasound system and by the proposed methodology.

Table 1. Summary of systolic peak velocity statistics.

\begin{tabular}{cccc}
\hline & \multicolumn{3}{c}{ Systolic Peak Velocity $(\mathrm{N}=102)$} \\
\hline $\begin{array}{c}\text { Bias } \\
(\mathrm{m} / \mathrm{s})\end{array}$ & $\begin{array}{c}\mathrm{sd} \\
(\mathrm{m} / \mathrm{s})\end{array}$ & $\begin{array}{c}\mathrm{r}_{\mathrm{AB}} \\
(\mathrm{p}<0.001)\end{array}$ & $\begin{array}{c}\text { Linear Regression } \\
\text { Equation }\end{array}$ \\
\hline 0.02 & 0.05 & 0.9985 & $\mathrm{~A}=0.9938 * \mathrm{~B}-0.0190$ \\
\hline
\end{tabular}
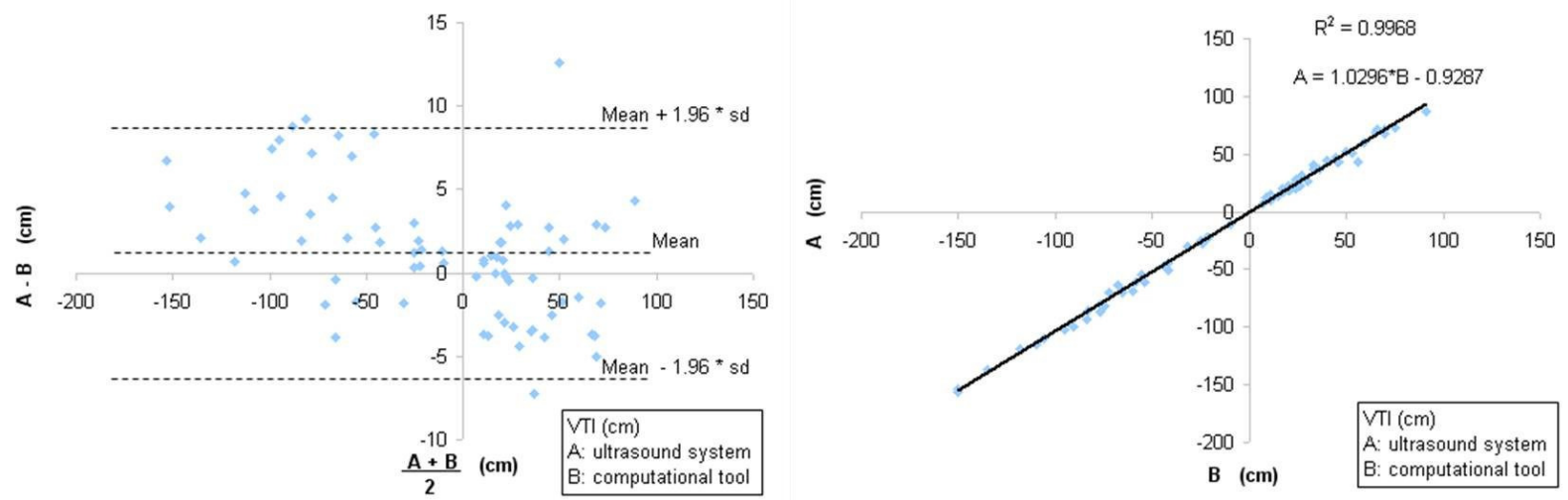

Figure 4. Bland-Altman's (left) and Linear Regression (right) analysis of the VTI (75 samples) measured by the ultrasound system and by the proposed methodology.

Table 2. Summary of VTI statistics.

\begin{tabular}{cccc}
\hline & \multicolumn{2}{c}{ VTI $(\mathrm{N}=75)$} \\
\hline Bias & $\mathrm{sd}$ & $\mathrm{r}_{\mathrm{AB}}$ & $\begin{array}{c}\text { Linear Regression } \\
\text { Equation }\end{array}$ \\
\hline $\mathrm{cm})$ & $(\mathrm{cm})$ & $(\mathrm{p}<0.001)$ & $\mathrm{A}=1.030 * \mathrm{~B}-0.9287$ \\
\hline 1.25 & 3.86 & 0.9984 & \\
\hline
\end{tabular}




\section{Discussion and conclusions}

The small bias and high correlation for both, peak velocity and VTI, indicate the reliability of this methodology and these findings are better than those presented by Tschirren et al. [11] (bias: $0.40 \mathrm{~m} / \mathrm{s}$ for peak velocity and $7 \mathrm{~cm}$ for VTI), though their results refers to a dilatation study of the brachial artery, where data values were about ten times higher than the present study.

It is important to note that for VTI statistics shown in Table 2, the threshold used to get the binary image was 60 , instead of the default 40 used to extract the systolic peak velocity. This change was motivated by the higher bias $(1.70 \mathrm{~cm})$ and standard deviation $(6.78 \mathrm{~cm})$ obtained with the default value for VTI.

Despite these numerical results, it is not possible to conclude that the threshold of 60 is more appropriate than 40 , since the human operation to get measurements using the ultrasound equipment may also be subject to systematic errors and deviations. For instance, visual results showing the envelopes drawn on the blood velocity graphics point that, by using the proposed methodology (Figure 2), the envelope line is more refined than that obtained by manual operation of an ultrasound system (Figure 1), because in the latter, the user does not notice or, simply, disregards small image brightness variations, which means that this procedure is highly dependent on the user's subjective evaluation and it is hardly reproducible.

By processing diversity of common carotid, brachial and echocardiographic Doppler image samples, collected from four different commercial ultrasound systems, the methodology implemented in this tool to measure velocity and VTI was validated by the Bland-Altman's analysis and by the correlation coefficient. Visual analysis also confirmed that the spectrum envelope detection is very satisfactory.

The user friendly graphical interface combined to the semi-automatic characteristic of this tool intends to help the clinicians for their studies based on Doppler ultrasound images, with the following advantages: to save operational time, to lower subjective results, and to support measurement reproducibility.

\section{Acknowledgements}

To CAPES (Coordenação de Aperfeiçoamento de Pessoal de Nível Superior) and FUSP (Fundação de Apoio à Universidade de São Paulo) for funding this research.

To Heart Institute (InCor) HC FMUSP, especially to R\&D/Division of Informatics and Clinical Investigation Laboratory/Intensive Care Unit staffs for their technical and operational contributions.

\section{References}

[1] Nichols WW, O'Rourke MF. McDonald's blood flow in arteries: theoretic, experimental and clinical principles: Doppler ultrasound for arterial blood flow measurement (ch. 7). $3^{\text {rd }}$ ed. Malvern, Philadelphia, USA: Lea \& Febiger, 1990, 456 p.

[2] Gerhard-Herman $M$ et al. Guidelines for noninvasive vascular laboratory testing: a report from the American Society of Echocardiography and the Society for Vascular Medicine and Biology Vascular Medicine, v. 11, n. 3, p. 183-200, Nov 2006.

[3] Hoskins PR. Measurement of arterial blood flow by Doppler ultrasound. Clinical Physics and Physiological Measurement, v. 11, n. 1, p. 1-26, Feb 1990.

[4] Yao JST, Hobson RW (Ed.) et al. Vascular surgery: principles and practice: noninvasive studies of peripheral vascular disease (ch. 7). $3^{\text {rd }}$. ed. Marcel Dekker, Inc., 2004, 1600 p.

[5] Corretti MC et al. Guidelines for the ultrasound assessment of endothelial-dependent flow-mediated vasodilation of the brachial artery: a report of the International Brachial Artery Reactivity Task Force. Journal of the American College of Cardiology, v. 39, n. 2, p. 257-265, Jan 2002.

[6] Carvalho RT et al. Resistive exercise in the evaluation of endothelial dysfunction in heart failure. Arquivos Brasileiros de Cardiologia, São Paulo, v. 86. n. 6, p. 459-465, Jun 2006.

[7] Lage SG et al. Angiotensin II contributes to arterial compliance in congestive heart failure. American Journal of Physiology - Heart and Circulatory Physiology, v. 283, n. 4, p. H1424-1429, Oct 2002.

[8] Pilon PE. Método para a detecção automática de diâmetro de artérias em imagens de ultra-som. 2002. Master Thesis, Universidade de São Paulo, São Paulo, 2002.73 p.

[9] Gutierrez MA et al. Automatic measurement of carotid diameter and wall thickness in ultrasound images. In: Computers in Cardiology 22-25 Sep 2002, p. 359-362.

[10] Bland JM, Altman DG. Statistical methods for assessing agreement between two methods of clinical measurement. The Lancet, v. 327, n. 8476, p. 307-310, Feb 1986.

[11] Tschirren J, Lauer RM, Sonka M. Automated analysis of Doppler ultrasound velocity flow diagrams, IEEE Transactions on Medical Imaging, v. 20, n. 12, p. 14221425, 2001.

Address for correspondence

Name: Marco Antonio Gutierrez

Full postal address: Instituto do Coração (InCor) - Av. Dr. Enéas de Carvalho Aguiar, 44 - São Paulo, SP - Brazil. CEP: 05403-000

E-mail address: marco.gutierrez@incor.usp.br 


\section{Comparison of Three Different Derivative Approaches Aiming at Estimation of Image Movement}

\author{
Mauricio Higa \\ Polytechnic School - University of São Paulo \\ Carlos da Silva Santos \\ Institute of Mathematics and Statistics - \\ University of São Paulo
}

\author{
Marina de Sá Rebelo \\ Heart Institute (InCor) - HCFMUSP \\ Marco Antonio Gutierrez \\ Heart Institute (InCor) - HCFMUSP \\ Polytechnic School - University of São Paulo
}

\begin{abstract}
The use of optical flow techniques to extract the velocity from the cardiac movement has to take into account the computational inaccuracy raised from the derivative operator over discrete data. This study presents a comparison of three different derivative approaches (two based on linear and other based on non-linear filtering) to find out the best solution. Results of the experiments are compared using a structural distortion based image quality metric.
\end{abstract}

\section{Introduction}

The diagnosis quality of cardiac diseases has a potential to be improved by extracting quantitative information from 3D image sequences of the heart.

Given the cardiac movements, a possible approach to estimate their velocity components for each voxel is the optical flow technique [1], and here extended for a 3D space. However, a critical problem to obtain this estimation lies in the fact that this process depends on derivative approximations from discrete data.

This work performs a comparison of three different approaches for calculation of image derivatives in the presence of different noise levels, applied to a simplified and well-controlled mathematical model. The aim is to determine which approach estimates the derivatives more accurately in the presence of noise.

\section{Methodology}

The first method, named "Traditional Derivative", follows the steps usually performed to calculate partial derivatives of noisy data: the noisy image is convolved with a Gaussian filter, followed by the application of a partial derivative operator [2].

The second method, named "Gaussian Derivative", is based on linear scale-space theory applied to discrete data: partial derivatives of a rescaled image can be obtained by the convolution of the original image with the corresponding derivatives of the Gaussian function [3].

Both methods tend to create very smooth flow fields and can reduce the precision of the velocity estimation. In the third method, the anisotropic diffusion filter proposed by Perona and Malik [4] was applied prior to the derivative operation. The main objective of using this non-linear smoothing filter is to preserve edges, so possible abrupt flow discontinuities may be preserved during the estimation process.

All filters and differential operators were implemented using the libraries of the open-source software system Insight Toolkit (ITK) [5].

\section{Experiments}

The experiments were performed using an image of a cube, which consisted of $10 \times 10 \times 10$ voxels in a volume with spatial resolution of $64 \times 64 \times 64$ voxels. This cube moved along all directions $(\mathrm{X}, \mathrm{Y}$, and $\mathrm{Z}$ ) resulting in a sequence of 16 frames. The intensities of the image were 138 in the cube and 10 in the background. The original volume was corrupted by either Poisson or Gaussian noise with three different intensities: high, medium, or low. Poisson noise level is defined as the square root of the voxel count. In the present experiment, the noise levels were: 3 for the background and 12 for the cube. The Gaussian noise level was measured by the contrast-to-noise ratio (CNR) [2]. The CNR for the three levels of Gaussian noise were: 26 (low), 14 (medium), and 7 (high). 
Let $\mathrm{A}$ be the ideal derivative image obtained from the application of the partial derivative operator on $\mathrm{X}, \mathrm{Y}, \mathrm{Z}$, or $\mathrm{T}$ direction to the original noiseless volume. The three derivative approaches were applied in each direction to the noisy volumes resulting in a set of images (image B) that were compared to A. These comparisons were evaluated through a structural distortion based image quality measurement proposed by Wang et al [6]:

$Q=\frac{s_{A B}}{s_{A} \cdot s_{B}} \cdot \frac{2 \cdot \overline{\mathrm{A}} \cdot \overline{\mathrm{B}}}{(\overline{\mathrm{A}})^{2}+(\overline{\mathrm{B}})^{2}} \cdot \frac{2 \cdot s_{A} \cdot s_{B}}{s_{A}^{2}+s_{B}^{2}}$

where: $\overline{\mathrm{I}}$ represents the average of all voxels of the image I, $s_{I}^{2}$ is the variance of I, and $s_{A B}$ is the covariance between $\mathrm{A}$ and $\mathrm{B}$.

This equation models any distortion as a combination of three different factors: loss of correlation, mean and variance distortion between images $\mathrm{A}$ and $\mathrm{B}$. The range of $\mathrm{Q}$ is $[-1,1]$ and the best value 1 is achieved when $A_{i}=B_{i}$ for every voxel i [6].

Figure 1 shows two chart samples obtained in the experiments for the proposed quality index. The curves for all other charts, including other partial derivatives and noise intensities, present similar behaviors.

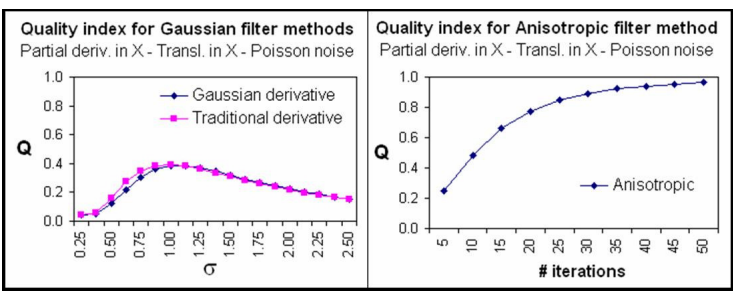

(a)

(b)

Figure 1: Quality index vs. (a) $\sigma$ for two linear approaches or (b) number of iterations for nonlinear approach referred to partial derivative in $X$, translation in the $X$ direction, and in the presence of Poisson noise.

There are no noticeable differences between the application of Traditional and Gaussian Derivative methods. $Q$ is maximized for a determined value of $\sigma$ that depends on the noise level. When dealing with real images of the same spatial resolution with unknown noise level, the results suggest that a value for $\sigma$ around 1.4 can be tried out to optimize the quality of the partial derivative estimation. However, considering the overall experiments using Gaussian methods, the best result for $\mathrm{Q}$ is limited to, approximately, 50\% of the ideal noiseless case.

Better results are reached with non-linear anisotropic method. Q tends asymptotically to 1 as the number of iterations increases, which means optimal quality or minimal distortion. For all experiments two filter parameters were previously set: the time step to $1 / 32$ and the conductance to 9 . According to Figure 1, less than 10 iterations are enough to get better quality (over $40 \%$ ) than using Gaussian methods. Fixing the same quality level for the worst tested case, observed with Gaussian high noise, the required number of iterations does not exceed 35 .

\section{Conclusion}

In this work three methods to calculate image derivatives were compared by applying them to sets of noisy images of a simple mathematical model. The choice of this model was due to its simplicity that allows interpretation and analysis of the results. Despite of its simplicity, the simulated images have the same spatial resolution of PET or SPECT images, and the cube volume has the same magnitude order of the human heart left ventricle.

For the experiments reported, the best performance among the three approaches was achieved with the anisotropic method.

In the sequence of this work, which intends to calculate the velocity by using the optical flow technique, new experiments shall allow a direct comparison between real and the estimated velocity data. The aim is not only to commit the most suitable methodology, but also to set the ideal range of parameters according to the image resolution and structures size. Getting the best possible precision of the derivative parameters will lead to find out more reliable velocity field for clinical application.

\section{References}

[1] B.K.P. Horn and B.G. Schunck, "Determining Optical Flow”, Artificial Intelligence, 17, pp. 185-203, 1981.

[2] R.M. Rangayyan, Biomedical Image Analysis, Boca Raton, Florida: @CRC Press, 2005.

[3] L.M.J. Florack, B.M. ter Haar Romeny, J.J. Koenderink, and M.A. Viergever, "Linear Scale-space", Journal of Math. Imaging and Vision, vol. 4(4), pp. 325351, 1994.

[4] P. Perona and J. Malik, "Scale-space and Edge Detection Using Anisotropic Diffusion", IEEE Transactions on Pattern Analysis and Mach. Intellig., vol. 12(7), pp. 629-639, 1990.

[5] L. Ibáñez and W.J. Schroeder, ITK Software Guide The Insight Segmentation and Registration Toolkit, Kitware, Inc., ISBN 1-930934-15-7, 2005.

[6] Z. Wang, A.C. Bovik, and L. Lu, "Why Is Image Quality Assessment So Difficult?", IEEE Intern. Conf. on Acoustics, Speech, and Signal Processing, vol. 4, pp. 3313-3316, 2002. 